ANDRÉ RANGEL SOUZA

\title{
OBTENÇÃO E CARACTERIZAÇÃO DE COMPOSTOS DE POLI(ETÉR-SILOXANO) E TITANATO DE BÁRIO
}


ANDRÉ RANGEL SOUZA

\section{OBTENÇÃO E CARACTERIZAÇÃO DE COMPOSTOS DE POLI(ETÉR-SILOXANO) E TITANATO DE BÁRIO}

Dissertação apresentada à Escola

Politécnica da Universidade de São Paulo para obtenção do titulo de Mestre em Engenharia.

SÃO PAULO 
ANDRÉ RANGEL SOUZA

\section{OBTENÇÃO E CARACTERIZAÇÃO DE COMPOSTOS DE POLI(ETÉR-SILOXANO) E TITANATO DE BÁRIO}

Dissertação apresentada à Escola

Politécnica da Universidade de São Paulo para obtenção do titulo de Mestre em Engenharia.

Área de Concentração:

Engenharia Metalúrgica e de Materiais

Orientadora: Prof ${ }^{a}$. Dr ${ }^{a}$. Wang Shu Hui

SÃo PAULO 
Este exemplar foi revisado e alterado em relação à versão original, sob responsabilidade única do autor e com a anuência de seu orientador.

São Paulo, 25 de maio de 2010.

Assinatura do autor

Assinatura do orientador

FICHA CATALOGRÁFICA

Souza, André Rangel

Obtenção e caracterização de compostos de poli(éter-siloxano) e titanato de bário / A.R. Souza. -- ed.rev. -- São Paulo, 2010. $73 \mathrm{p}$.

Dissertação (Mestrado) - Escola Politécnica da Universidade de São Paulo. Departamento de Engenharia Metalúrgica e de Materiais.

1. Materiais 2. Materiais compósitos 3. Materiais compósitos Poliméricos I. Universidade de São Paulo. Escola Politécnica. Departamento de Engenharia Metalúrgica e de Materiais II. t. 


\section{DEDICATÓRIA}

Dedico este trabalho aos meus pais

Bernardino e Izabel, ao meu irmão Mateus

e a minha noiva Barbara. 


\section{AGRADECIMENTOS}

Aos meus pais e irmão, por serem os responsáveis pela minha formação pessoal e profissional, pelo constante esforço, educação e apoio que me proporcionaram ao longo destes anos.

À professora Dra. Wang Shu Hui, pela confiança e a oportunidade de desenvolver este trabalho. Pela orientação e constante disposição em colaborar. Devo-Ihe muito pelo imprescindível apoio à minha formação.

Ao Prof. Dr. Jivaldo do Rosário Matos e ao funcionário Renato do Laboratório de Análises Térmicas do Instituto de Química da USP, pelas análises DSC e TGA. Pessoas extremamente atenciosas e prestativas.

Ao Prof. Dr. Victor Sonnenberg do Laboratório de Sistemas Integráveis (LSI) da Escola Politécnica da USP pela atenção e prestativas nas etapas de medidas elétricas.

Luiz Henrique Piffer do núcleo de Documentação do Centro de Computação Eletrônica da Universidade de São Paulo pelo auxilio com o software AutoCAD.

À minha namorada Barbara pela paciência e compressão. Por ter me acompanhado nesse período de insistentes pesquisas e estudo.

Aos amigos Fabio, Flávia, Telma, Tunísia e Walker com quem trabalhei no Departamento de Engenharia Metalúrgica e de Materiais da Escola Politécnica da USP que tanto me ensinaram e ajudaram neste mestrado.

Aos funcionários do departamento de engenharia metalúrgica e de materiais da Escola Politécnica da USP pelo apoio didático. A todas as pessoas que de forma direta ou indiretamente contribuíram para a realização deste trabalho. 


\section{RESUMO}

O desenvolvimento da sociedade humana somente atingiu o estágio atual devido à utilização de materiais compósitos de diferentes misturas, que vem desempenhando um papel fundamental no desenvolvimento da sociedade moderna. Com a finalidade de explorar o crescente interesse nas pesquisas de novos materiais, este trabalho apresenta um estudo sobre as propriedades do compósito elastomérico a base de poli(éter-siloxano) e sólido particulado cerâmico de titanato de bário $\left(\mathrm{BaTiO}_{3}\right)$.

Amostras com quantidades adequadas dos componentes, matriz polimérica não curada e particulada de titanato de bário, foram curadas em diferentes concentrações (puro, 10, 20, 30, 40 e $50 \%$ ) por meio de mistura em massa em uma câmara glove box em ambiente de nitrogênio, até obtenção de mistura homogênea.

O copolímero puro e uma série de compósitos com diferentes concentrações foram submetidos a ensaios de inchamento, análises térmicas gravimétricas, calorimetria diferencial exploratória, caracterização morfológica por microscopia eletrônica de varredura, ensaios mecânicos de tração e medidas elétricas. Por meio dessa série de técnicas de caracterização foram observadas propriedades bem distintas entre o polímero puro e os compósitos, caracterizado pelo aumento das ligações cruzadas.

Neste trabalho foi também construído um capacitor de placas paralelas para teste de capacitância elétrica dos materiais preparados, visando o estudo do comportamento elétrico dos materiais em estudo.

Palavras-chave: Materiais, Materiais Compósitos, Materiais Compósitos Poliméricos. 


\begin{abstract}
The present development of the human society should be credited to the use of the composite and blend materials. In this dissertation composites of an elastomer, poly(ether-siloxane), along with barium titanate are prepared and their properties are studied.

Nanoparticles of barium tiatanate were incorporated in the elastomer in the range 0-50 wt\% through bulk mixing under nitrogen atmosphere in a glovebox, using a porcelain mortar and pestle. The mixtures thus prepared were placed in molds and allowed to cure in order to prepare specimens for properties' analyses.

The composites were submitted to swelling tests, thermal gravimetric analysis (TGA), differential scanning calorimetry (DSC), mechanical strength tension test, electrical measurements and electron scanning microscopy (SEM). It was possible to make a correlation between the observed properties and the morphology and composition of the composites.

Additionally, a parallel plates capacitor for injection and test of small samples was built and used to evaluate the electrical capacitance of the composites prepared in this work.
\end{abstract}

Keywords: materials, composite, polymer composite 


\section{LISTA DE ILUSTRAÇÕES}

Figura 1 - (a) Estrutura polimérica linear e (b) ramificada.............................................

Figura 2 - Pontes de siloxano e pontes C-C. ..........................................................

Figura 3 - Estruturas moleculares do copolímero poli(éter-siloxano)............................... 8

Figura 4- Célula unitária do titanato de bário $\left(\mathrm{BaTiO}_{3}\right), \mathrm{a}=0,398 \mathrm{~nm} ; \mathrm{c}=0,403 \mathrm{~nm} .10$

Figura 5 - (a) Capacitor de placas paralelas com núcleo de vácuo, (b) organização dos dipolos do dielétrico não polarizado, (c) polarização do dielétrico de capacitor..13 Figura 6 - (a) Representação de cargas de átomo sem aplicação de potencial elétrico, (b) com aplicação de campo elétrico externo, (c) esquema representativo de

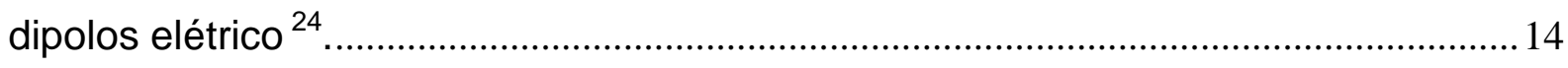

Figura 7 - Câmara glove box usada para preparo de compósito. .................................23

Figura 8 - Aparato de medida de densidade de acordo com a ASTM D3800 ............25

Figura 9 - Aspecto da montagem do aparato para medir densidade............................26

Figura 10 - Recipientes usados nos ensaios de inchamento .........................................28

Figura 11 - Equipamento Shimadzu TGA 51 ............................................................

Figura 12 - Sistema para medida de DSC com amostra (direita) e amostra de

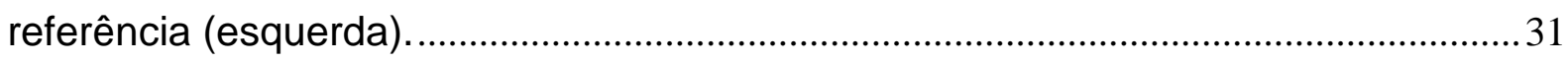

Figura 13 - Célula desenvolvida para caracterização elétrica............................................34

Figura 14 - Desenho da estrutura mecânica do capacitor para caracterização

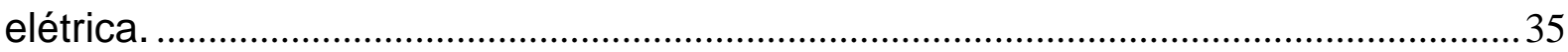

Figura 15 - Corpos de prova de ensaios de tração..........................................................36

Figura 16 - Densidade de amostras não inchadas. ......................................................... 37

Figura 17 - Inchamento em diferentes solventes após 72 horas * $\left(\delta / \mathrm{MPa}^{1} / 2\right) \ldots \ldots \ldots \ldots . . . .40$

Figura 18 - Inchamento volumétrico em diferentes solventes após 72 horas * $\left(\delta / \mathrm{MPa}^{1} / 2\right)$.

Figura 19 - Microscopia eletrônica de varredura da amostra de titanato de bário, aumento 20000 vezes.

Figura 20 - Microscopia eletrônica de varredura da amostra de titanato de bário.......44

Figura 21 - Microscopia eletrônica de varredura da amostra P100 ...............................4

Figura 22 - Microscopia eletrônica de varredura da amostra C10 ...............................45 
Figura 23 - Microscopia eletrônica de varredura da amostra C20. 45

Figura 24 - Microscopia eletrônica de varredura da amostra C30. 46

Figura 25 - Microscopia eletrônica de varredura da amostra C40. 46

Figura 26 - Microscopia eletrônica de varredura da amostra C50.

Figura 27 - Microscopia eletrônica de varredura da amostra C50, aumento 1500 vezes. 48

Figura 28 - EDX da amostra de titanato de bário. 49

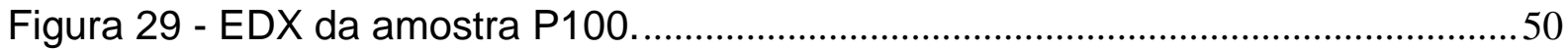

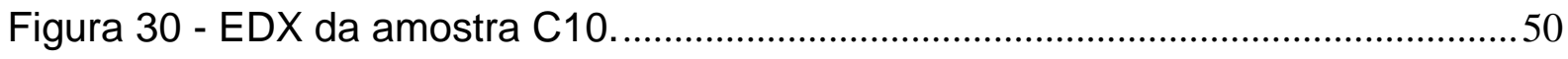

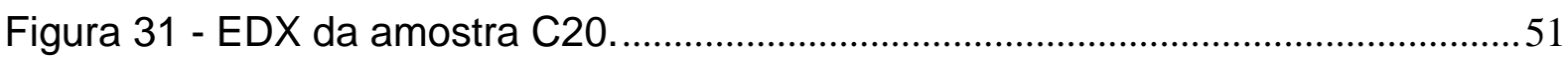

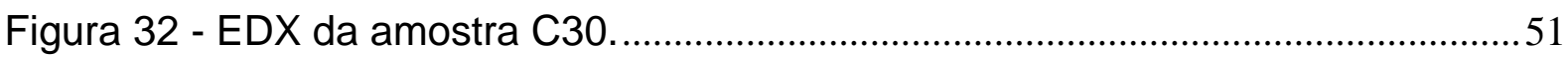

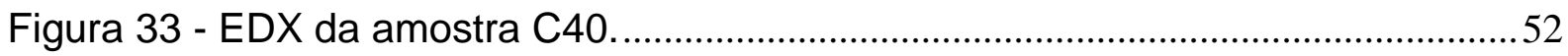

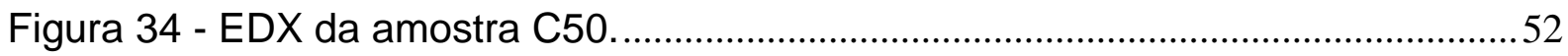

Figura 35 - Curvas de análise termogravimétrica de amostra P100 ...........................55

Figura 36 - Curvas de análise termogravimétrica de amostra P100 e compósitos. ...56

Figura 37 - Derivada da curva de análise termogravimétrica (DrTg) ..........................57

Figura 38 - Curvas DSC amostra P100 e de compósitos ( $\downarrow$ Endo)................................59

Figura 39 - Curvas DSC da amostra P100 e de compósitos ( $\downarrow$ Endo). ........................60

Figura 40 - Medida elétrica de capacitância versus tensão..........................................61

Figura 41 - Medida de Constante Dielétrica versus Tensão..........................................62

Figura 42 - Medidas de resistividade do polímero e seus compósitos........................62

Figura 43 - Curva de ensaio mecânico de tração. .........................................................64 


\section{LISTA DE TABELAS}

Tabela 1 - Mercado mundial e nacional de borracha natural e sintética em 2005 e $2006^{8}$.

Tabela 2 - Constantes e rigidez dielétrica para alguns materiais ${ }^{26} \ldots \ldots \ldots \ldots \ldots \ldots \ldots . . . . .12$

Tabela 3 - Propriedades do sólido particulado. ................................................ 24

Tabela 4 - Propriedades das amostras utilizadas no trabalho............................... 24

Tabela 5 - Propriedade de solventes utilizados............................................. 27

Tabela 6 - Medidas de densidades teórica e observada..................................... 38

Tabela 7 - Medida de densidade $\left[\mathrm{g} / \mathrm{cm}^{3}\right]$ de amostras após 72 horas em diferentes

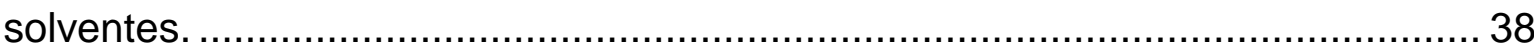

Tabela 8 - Medida de densidade $\left[\mathrm{g} / \mathrm{cm}^{3}\right]$ de amostras após 720 horas em diferentes solventes.

Tabela 9 - Resultados calculados pela Equação de Flory-Rehner após 72 horas de

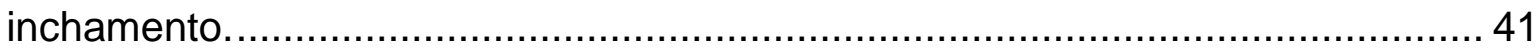

Tabela 10 - Resultados calculados pela Equação de Flory-Rehner após 720 horas

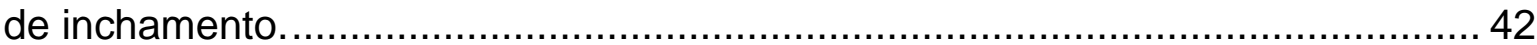

Tabela 11 - Análise quantitativa e qualitativa do polímero e compósitos sem recobrimento de ouro.

Tabela 12 - Análise quantitativa e qualitativa do polímero e compósitos com recobrimento de ouro. 53

Tabela 13 - Perda de massa para temperatura de 150, 350, 550 e $750{ }^{\circ} \mathrm{C}$ 57

Tabela 14 - Análise das curvas de calorimetria diferencial exploratória. 60

Tabela 15 - Propriedades do ensaio de tração. 65 


\section{LISTA DE ABREVIATURAS, SIGLAS}

$\mathrm{BaTiO}_{3}:$ Titanato de Bário

A : área $\left(\mathrm{m}^{2}\right)$

Atm : Atmosfera ((101325 Pa)

C : Capacitância (F)

C : velocidade de propagação da onda eletromagnética $\left(3.10^{10} \mathrm{~cm} / \mathrm{seg}\right.$ no vácuo)

DSC : Calorimetria Diferencial Exploratória

E : Módulo de elasticidade

$E D X$ : Energia dispersiva de raio $X$

EO: Óxido de Etileno

F: Farads

G : Energia de Gibbs

h : Constante de Planck $\left(6,62 \cdot 10^{-34} \mathrm{~J} . \mathrm{s}\right)$

$\mathrm{k}$ : Constante de Boltzmann $\left(1,38.10^{-23} \mathrm{~J} / \mathrm{K}\right)$

$\mathrm{K}_{1}$ : Constante dielétrica

KHz : Kilohertz, Quilohertz (10 ciclos por segundo)

I : Distância (m)

$\bar{M}$ c : Inverso da Densidade de Ligações Cruzadas (1/v)

MEV : Microscopia Eletrônica de Varredura

$\mathrm{N}:$ Newton $\left(\mathrm{kg} \cdot \mathrm{m} / \mathrm{s}^{2}\right)$

$\mathrm{Nn}$ : Número de moléculas do componente

PDMS : Poli(dimetilsiloxano)

PO : Óxido de Propineno

$\mathrm{q}$ : Carga elementar armazenada $\left(1,60 \cdot 10^{-19} \mathrm{C}\right)$.

Qt : Calor Transferido

R : Constante Universal dos Gases (0,082 atm.I/mol.K)

sccm : Centímetros cúbicos-padrão por minuto

$\mathrm{T}:$ Temperatura $\left({ }^{\circ} \mathrm{C}\right)$

Tg : Temperatura de Transição Vítrea

$T G A$ : Análise Termogravimétrica 
Tm : Temperatura de fusão.

$\mathrm{U}:$ Energia do sistema

$\mathrm{V}$ : Voltagem $(\mathrm{J} / \mathrm{C})$.

Vm : Volume Molar

Vr: Volume Reduzido

W : Trabalho do Sistema

$\delta$ : Parâmetro de Solubilidade

$\Delta \mathrm{U}$ : Diferença de energia entre dois níveis.

$\Delta \mathrm{G}$ : Energia Parcial Molar

$\Delta \mathrm{H}$ : Entalpia Parcial Molar

$\Delta S$ : Entropia Parcial Molar

$\lambda$ : Comprimento de Onda

$\varepsilon_{0}$ : Permissividade dielétrica no vácuo $\left(8,85.10^{-12} \mathrm{~F} / \mathrm{m}\right)$

omax : Resistência a Tração

$v$ : Densidade de Ligações Cruzadas

$\chi$ : Parâmetro de Interação

Z : número atômico 


\section{SUMÁRIO}

1. INTRODUÇÃO

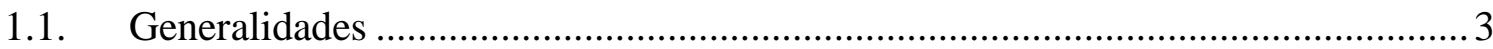

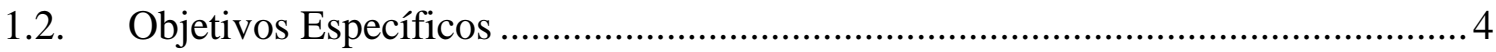

1.3. Organização do Trabalho.............................................................................. 4

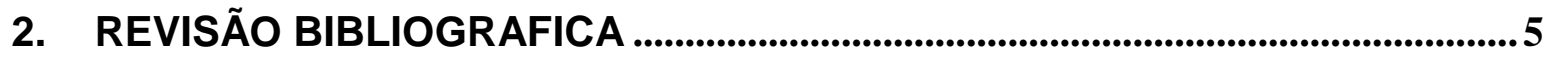

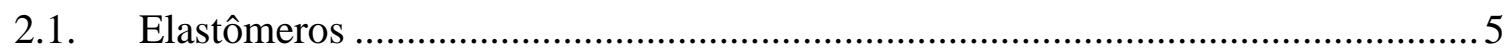

2.1.1. Reticulação polimérica ............................................................................ 6

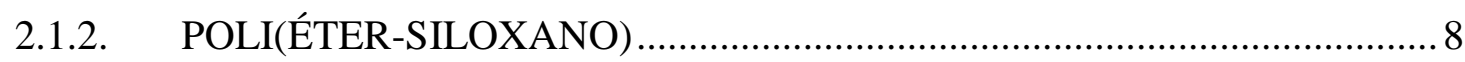

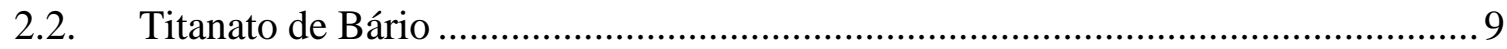

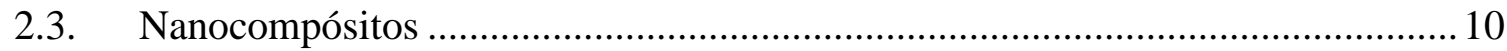

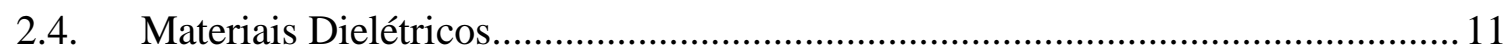

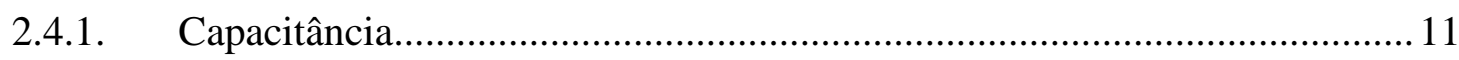

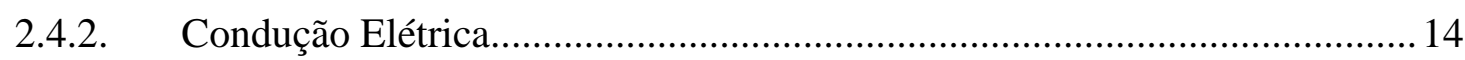

2.5. Comportamento Termodinâmico de Soluções de Polímeros. .................................. 16

2.5.1. Inchamento de polímero em presença de solvente .......................................... 16

2.5.2. Modelo de Hildebrand e Scott ................................................................. 17

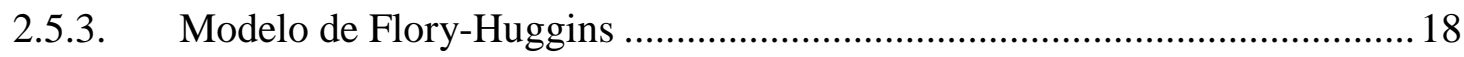

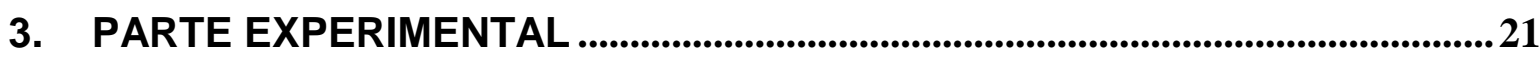

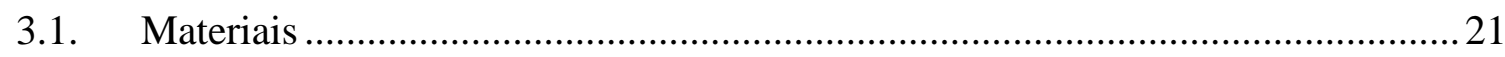

3.1.1. Elastômeros e seus compósitos.................................................................... 21

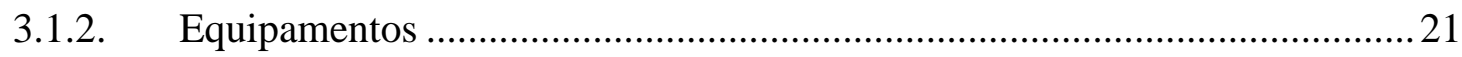

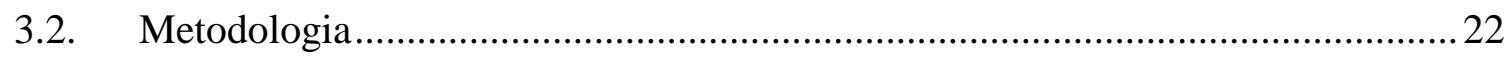

3.2.1. Preparação dos Compósitos ........................................................................ 23

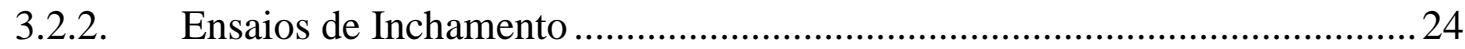

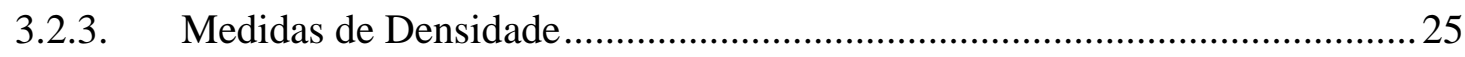

3.3. Procedimentos de Análise e Caracterização...........................................................2

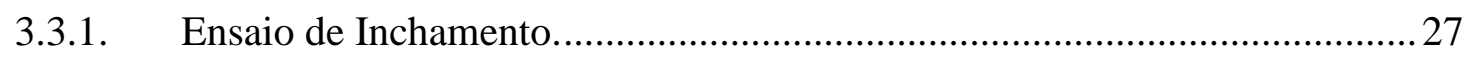

3.3.2. Análise Termogravimétrica (TGA) ………………................................ 29

3.3.3. Análise Térmica Diferencial (DSC) ............................................................ 30

3.3.4. Microscopia Eletrônica de Varredura (MEV) ................................................ 32 


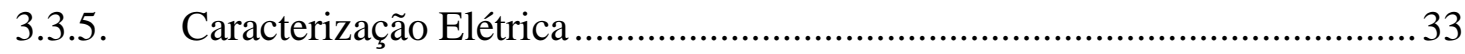

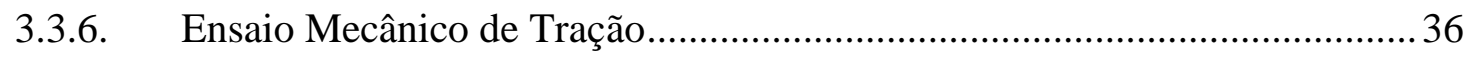

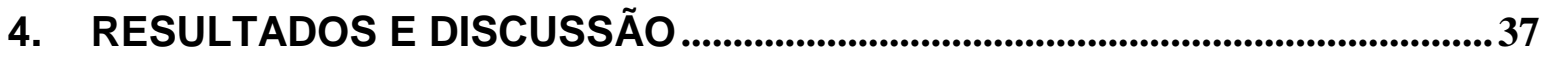

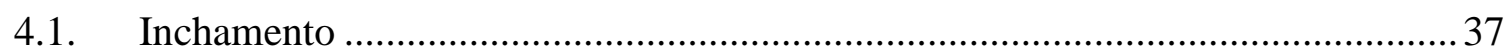

4.2. Microscopia Eletrônica de Varredura.............................................................. 42

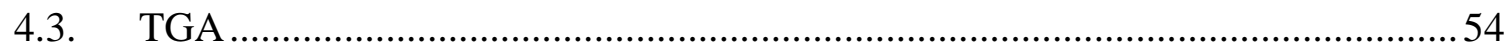

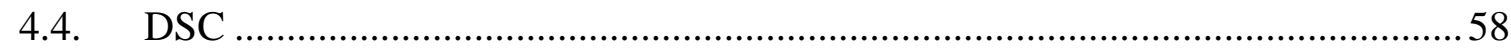

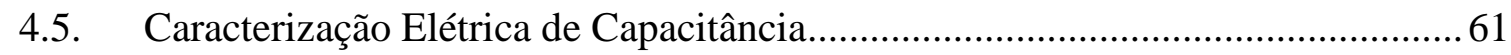

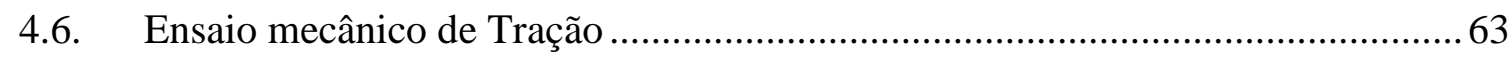

5. CONCLUSÕES ................................................................................................................66

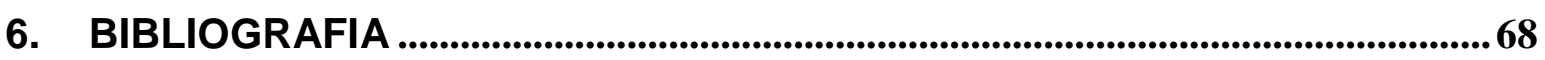




\section{INTRODUÇÃO}

\subsection{Generalidades}

O uso de misturas de diferentes materiais pela sociedade é certamente uma atividade milenar ${ }^{1}$. Essas misturas resultaram em materiais com propriedades diferenciadas e são conhecidas como compósitos, que contribuíram para o desenvolvimento da sociedade antiga. Com o passar dos anos, esses materiais foram continuamente sendo desenvolvidos, aprimorados e utilizados pelo homem, que percebia os benefícios proporcionados pela conjugação de materiais.

Com a finalidade de melhorar as propriedades dos polímeros, materiais inorgânicos ou carga mineral com dimensões nanométricas foram dispersas em matrizes poliméricas formando os nanocompósitos ${ }^{1}$. Desde $1857^{2}$, experimentos com os materiais nanocompósitos têm atraído o interesse de muitos pesquisadores, devido à possibilidade de combinar as diferentes propriedades, em especial os materiais poliméricos com nanocarga adicionada, que resulta em materiais com uma vasta aplicação na engenharia ${ }^{1,3}$. Na década de 80 ocorreu um grande avanço no desenvolvimento de compostos poliméricos com cargas minerais ${ }^{3}$.

Uma importante categoria de materiais de engenharia são as borrachas ou elastômeros, que tem extraordinárias propriedades físicas ${ }^{1,3}$, e é formada de uma rede molecular tridimensional reticulada, que permite manter ou incrementar o comportamento elástico, diminuir o escoamento plástico, aumentar o módulo de elasticidade, dureza, resiliência, e resistência à fadiga e à abrasão $0^{4,5}$.

A adição de particulado sólido nanométrico na rede polimérica tem sido uma importante ferramenta no controle das propriedades dos materiais, combinando de forma extraordinária as características dos componentes da mistura. Mas, o processo de reticulação da matriz polimérica ainda é uma lacuna no controle dessas propriedades. 


\subsection{Objetivos Específicos}

A necessidade de se realizar estudos sobre compósitos com matriz elastomérica esta embasada no fato desta classe de materiais apresentarem propriedades ímpares, desempenhando um papel muito importante na indústria de elastômeros e adesivos selante.

Desta forma, os objetivos desse trabalho são:

- Obtenção de nanocompósitos de poli(éter-siloxano) com adição do sólido particulado nanométrico de titanato de bário $\left(\mathrm{BaTiO}_{3}\right)$.

- Avaliar as propriedades de reticulação do compósito, usando o princípio de interação polímeros-solvente e a teoria de Flory-Rehner.

- Caracterizar os compósitos e o polímero em estado puro, usando análises térmicas de TGA (Análise Termogravimétrica), e DSC (Calorimetria Diferencial Exploratória), análise morfológica por MEV (Microscopia Eletrônica de Varredura), medidas elétricas e ensaios mecânicos de tração.

\subsection{Organização do Trabalho}

Esta dissertação de mestrado está dividida em 6 partes. Após esta introdução, no capítulo 2 é abordada uma revisão bibliográfica, onde são apresentados conceitos de solubilidade de materiais poliméricos e de termodinâmica de soluções poliméricas, além das motivações para o emprego de materiais orgânicos elastoméricos. Inicialmente são apresentadas as perspectivas econômicas da indústria brasileira e mundial em relação aos produtos que potencialmente podem englobar as tecnologias de polímeros. No capitulo 3 é apresentada a parte experimental contendo a relação dos materiais, métodos e as respectivas descrições de equipamentos e técnicas utilizadas. Em seguida, no capítulo 4 são apresentados os resultados obtidos por meio de tabelas, gráficos e posteriores discussões. No capítulo 5 são apresentadas as conclusões do trabalho. O sexto e último capítulo traz as referências bibliográficas utilizadas no trabalho. 


\section{REVISÃO BIBLIOGRAFICA}

Na revisão bibliográfica serão abordados a importância social dos polímeros e os fundamentos da ciência dos polímeros relativos às borrachas. São apresentados os aspectos econômicos da indústria brasileira e mundial de elastômeros, conceitos de nanocompósitos, comportamento termodinâmico de solução polimérica e caracterização elétrica de capacitância.

\subsection{Elastômeros}

Os elastômeros são materiais poliméricos, que se distinguem pela capacidade de se deformarem quando submetidos a um esforço externo que aumenta seu tamanho em pelo menos duas vezes e retornam rapidamente à forma e às dimensões originais quando retirada a tensão mecânica ${ }^{6}$. Apesar de conhecidos e utilizados para fins lúdicos ou ornamentais há muito tempo por povos indígenas das Américas, os elastômeros só começaram a ter utilização industrial no início do século $X I X^{5}$.

No Brasil, o consumo de borrachas foi de aproximadamente 900 mil toneladas em 2008, correspondendo a 3,5 \% do mercado mundial. O mercado de elastômeros recentemente tem passado por grandes transformações e turbulências, por meio da forte concorrência das importações, dos impactos da crise financeira global (2008) e do recuo da indústria automobilística, os preços dos elastômeros brasileiros tem reduzido consideravelmente, gerando grandes perdas nos setores automotivos, nas empresas produtoras de materiais e artefatos ${ }^{7}$.

Atualmente (2008), consomem-se cerca de 25 milhões de toneladas (t) de borracha por ano no mundo, sendo 12,3 milhões de toneladas de borracha natural e 12,7 milhões de toneladas de borracha sintética. As cargas e os aditivos consumidos pela indústria de elastômeros representam ainda vendas de produtos químicos da ordem de US\$ 14 bilhões a 16 bilhões no mundo ${ }^{7}$. Na Tabela 1 são apresentados alguns dados de produção e consumo de elastômeros. 
Tabela 1 - Mercado mundial e nacional de borracha natural e sintética em 2005 e $2006^{7}$.

\begin{tabular}{|c|c|c|c|c|c|}
\hline & & \multicolumn{2}{|c|}{2005} & \multicolumn{2}{|c|}{$2006^{*}$} \\
\hline & & Mundo & Brasil & Mundo & Brasil \\
\hline \multirow{4}{*}{$\begin{array}{l}\text { Borracha } \\
\text { Natural }\end{array}$} & Produçăo * & 8.920 & 105 & 9.360 & 110 \\
\hline & $\begin{array}{c}\text { Participação do Brasil } \\
\text { pa Produçao Mundial } \\
\text { (\%) }\end{array}$ & & 1,2 & & 1,2 \\
\hline & Consumo * & 9.000 & 295 & 8.920 & 310 \\
\hline & $\begin{array}{c}\text { Participaçäo do Brasil } \\
\text { ho Consumo Mundial } \\
\text { (\%) }\end{array}$ & & 3,3 & & 3,5 \\
\hline \multirow{4}{*}{$\begin{array}{l}\text { Borracha } \\
\text { Sintética }\end{array}$} & Produçăo & 12.060 & 385 & 12580 & 445 \\
\hline & $\begin{array}{c}\text { articipaçăo do Brasil } \\
\text { pa Produçåo Mundial } \\
\text { (\%) }\end{array}$ & & 3,2 & & 3,5 \\
\hline & Consumo & 11.900 & 395 & 12470 & 400 \\
\hline & $\begin{array}{c}\text { Participaçào do Brasil } \\
\text { po Consumo Mundial } \\
\text { (\%) }\end{array}$ & & 3,3 & & 3,2 \\
\hline
\end{tabular}

As indústrias de transporte e automotiva são responsáveis pelo consumo de $2 / 3$ do total de borracha sintética e natural, dos quais $90 \%$ são destinados aos pneumáticos e o restante a peças diversas dos veículos: mangueiras, molduras de portas e janelas, tapetes, buchas e dispositivos antivibratórios ${ }^{8}$.

\subsubsection{Reticulação polimérica}

Dependendo da natureza química dos monômeros e da técnica empregada para a polimerização, os polímeros podem exibir diferentes tipos de estruturas e, consequentemente, diferentes propriedades físicas, o que no final irá determinar a sua aplicabilidade. Os mais comuns são os de estrutura linear e ramificada como mostrado esquematicamente na Figura 1. 


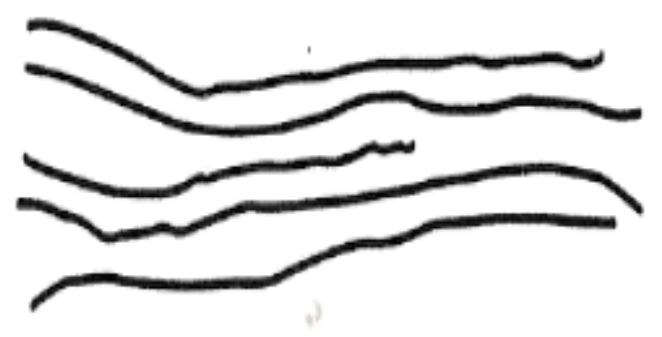

a

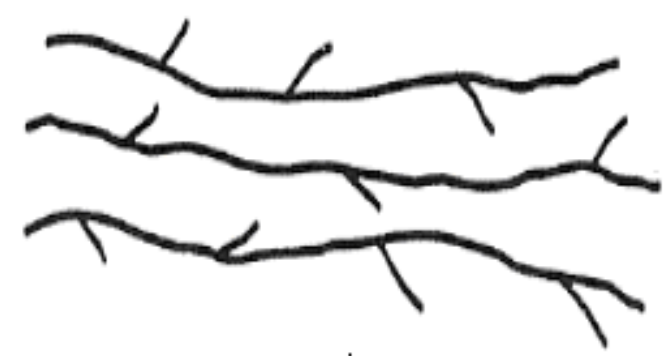

b

Figura 1 - (a) Estrutura polimérica linear e (b) ramificada.

Os elastômeros podem possuir diversas estruturas produzidas através de vários processos de síntese, que lhe conferem características próprias de densidade, massa molecular, distribuição de massa molecular, entre outras. Uma importante modalidade de reticulação observada são os polímeros com cadeias de silício, as pontes de siloxano (Si-O-Si) conferem uma menor rigidez fornecendo maior flexibilidade ao material comparadas às ligações de hidrocarbonetos (ligações C-C) $)^{9,10}$ como mostrado esquematicamente na Figura 2.
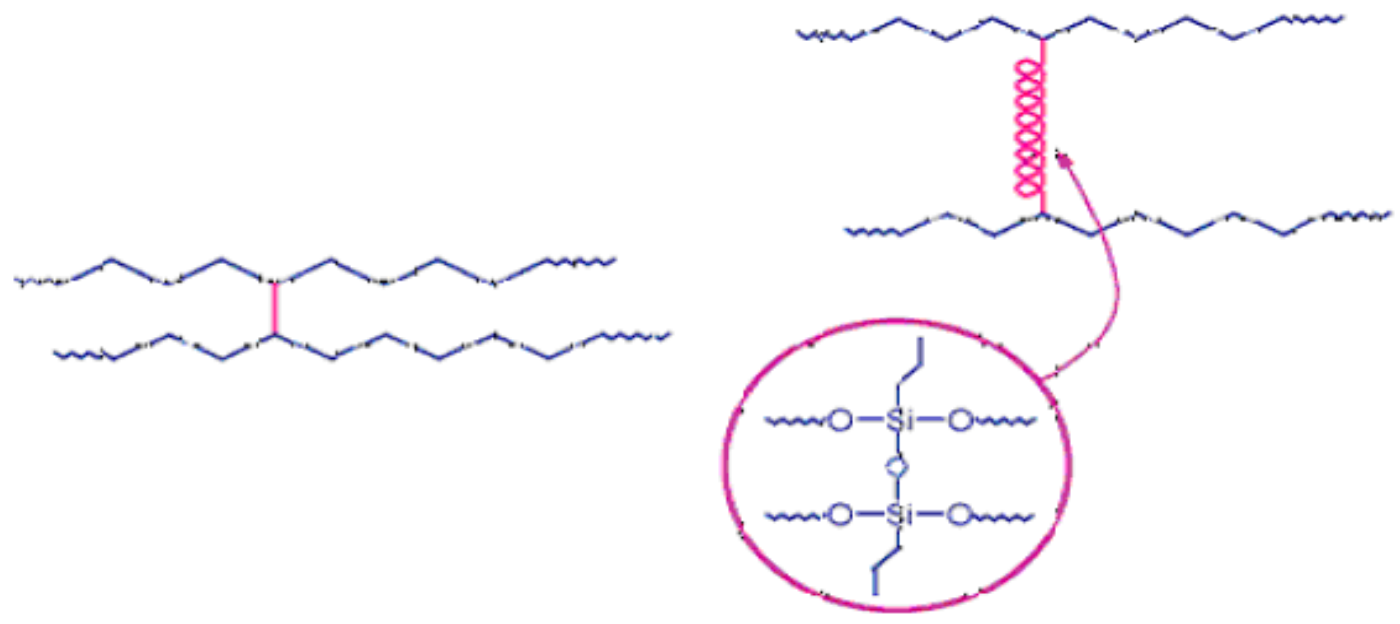

Figura 2 - Pontes de siloxano e pontes C-C.

A quantidade de ligações cruzadas, o tamanho e o tipo delas também determinam em grande parte as propriedades como densidade, rigidez, resistência, flexibilidade, elongação e fluência. Sua densidade é determinada pela presença e regularidade das ramificações, a distribuição da massa molecular e a quantidade de ramificações determinam muitas de suas propriedades químicas e mecânicas. Essa 
grande variedade de processos de transformação permite uma gama de aplicações do material nos mais diferentes setores industriais ${ }^{11}$.

\subsubsection{POLI(ÉTER-SILOXANO)}

O poli(éter-siloxano) é um copolímero constituído de poli(dimetil-siloxano) (PDMS) e poliéteres. Dependendo da fração de poli(óxido de etileno-co-óxido de propileno) (poli(EO-co-PO)), a solubilidade do poli(éter-siloxano) pode ser ajustada para obter um produto com valores de parâmetro de solubilidade $\left[\delta=\left(\mathrm{J} / \mathrm{m}^{3}\right)^{1 / 2}\right]$ distintas ${ }^{12}$.

Na Figura 3 são mostradas as estruturas mais freqüentes resultantes da copolimerização do PDMS e do poliéter. Onde R e R' podem ser centenas de diferentes grupos terminais, entre eles, os vinílicos, fenílicos, alquilênicos e mesmo oligômeros, p.ex., polietér.
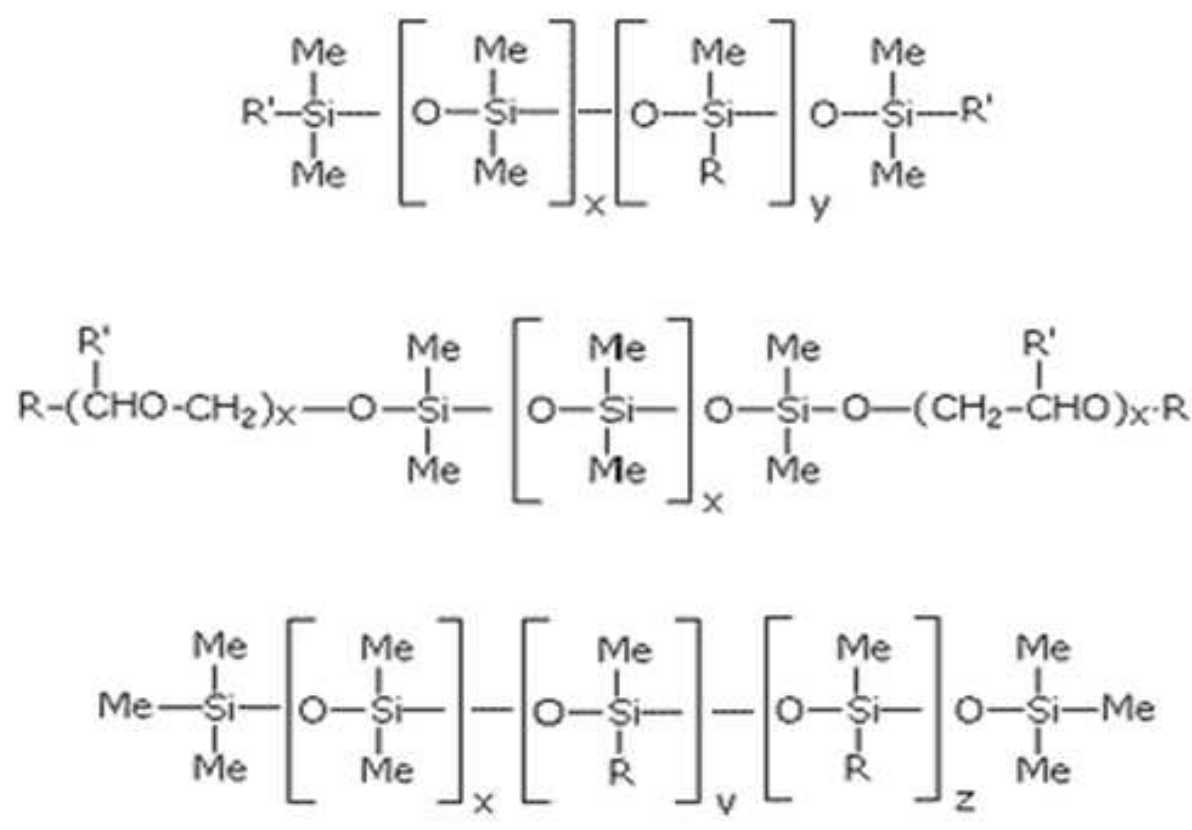

Figura 3 - Estruturas moleculares do copolímero de poli(éter-siloxano).

O copolímero poli(éter-siloxano) tem algumas propriedades notáveis. Trata-se de um adesivo selante que combina as propriedades do silicone e do poliéter, 
baseado em polímero híbrido, quimicamente neutro e com excelentes propriedades elásticas. Além disso, apresenta um acelerado processo de cura, boas propriedades mecânicas a resiliência e uma poderosa aderência em outros materiais, e é isento de isocianatos, solventes voláteis, halogênios e ácidos ${ }^{13}$. Portanto, tornando-o um dos produtos mais versáteis, que podem ainda apresentar modificações dos grupos silanos e de densidade de ligações cruzadas presentes na rede polimérica ${ }^{10-12}$.

\subsection{Titanato de Bário}

O titanato de bário $\left(\mathrm{BaTiO}_{3}\right)$ foi inicialmente preparado para aplicações nas indústrias de materiais cerâmicos, mas suas propriedades peculiares foram descobertas em 1943 por meio de estudos simultâneos e independentes de Wainer e Salomon nos Estados Unidos ${ }^{14}$, Coursey e Brand no Reino Unido ${ }^{15}$ e Wul e Goldman na Rússia ${ }^{16}$. As propriedades de ferroeletricidade e piezoeletricidade do titanato de bário foram relatadas em 1947 por S. Robert ${ }^{17}$ e Von Hippel ${ }^{18}$. Devido às suas elevadas propriedades de constante dielétrica o titanato de bário se tornou um dos materiais ferroelétricos mais estudados, tendo como principais aplicações o emprego na fabricação de capacitores, transdutores, dispositivos eletro-óptico ${ }^{19}$.

Na Figura 4 é apresentada uma estrutura de célula unitária tetragonal do $\mathrm{BaTiO}_{3}$, em que a célula é constituída por um átomo de titânio (formador de rede) no centro do octaedro formado por seis átomos de oxigênio localizados nas faces do cubo, com átomos de bário (modificador de rede) situados no vértice. 


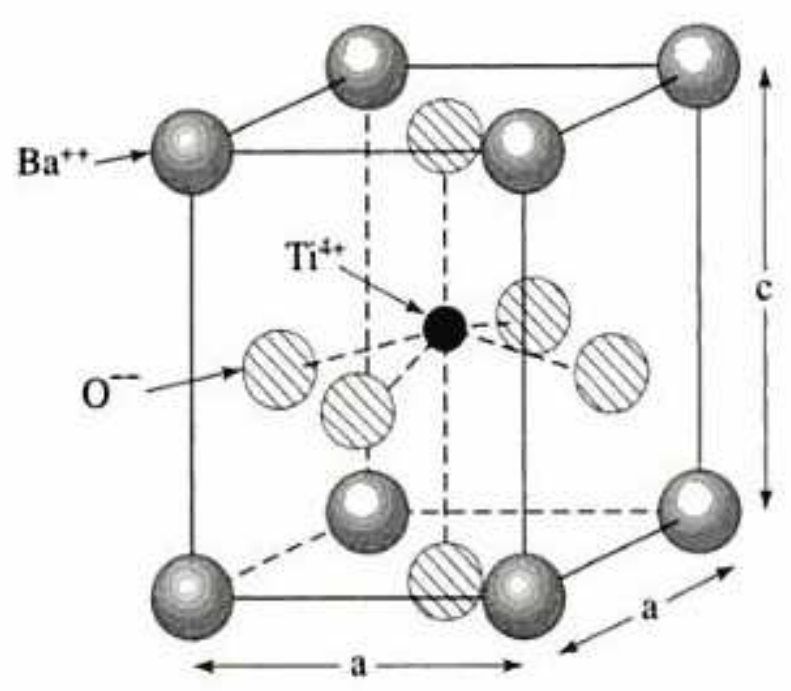

Figura 4- Célula unitária tetragonal do titanato de bário $\left(\mathrm{BaTiO}_{3}\right), \mathrm{a}=0,398 \mathrm{~nm} ; \mathrm{c}=$ $0,403 n m$.

\subsection{Nanocompósitos}

Por definição, os materiais compósitos são formados por dois ou mais materiais distintos que apresentam em sua estrutura uma fase conhecida como matriz e outra fase chamada de dispersa. A adição de nanoparticulado inorgânico à matriz tem como resultado o nanocompósito polímero ${ }^{20}$. De modo geral, as fases dispersas são materiais sólidos particulados ou fibrosos (cargas) que tenham ao menos uma de suas dimensões físicas, da ordem de algumas dezenas de nanômetros, que adicionados à matriz polimérica tem como objetivos a redução de custos, melhorias nas propriedades mecânicas e no processamento ${ }^{21}$.

As cargas são divididas em duas categorias principais: as cargas de enchimento e as chamadas cargas funcionais. Apesar de qualquer carga apresentar propriedade funcional, a distinção acima se deve ao objetivo de sua incorporação à matriz polimérica. Cargas de enchimento são usadas exclusivamente para redução de custos, enquanto que cargas funcionais têm a finalidade de modificar positivamente as propriedades, entre elas, a dureza, a temperatura de amolecimento, a resistência a impacto e a rigidez dielétrica ${ }^{22}$. 
Outro aspecto relevante na alteração das propriedades dos nanocompósitos diz respeito aos chamados efeitos de superfície. Os átomos da superfície têm um papel diferenciado em relação a aqueles presentes no interior do material, uma vez que podem participar de todas as interações físicas e químicas do meio no qual ele está inserido, como a troca de calor e processos de oxidação ${ }^{19-21}$.

No entanto, a nanociência busca entender a razão para essa sutil mudança de comportamento dos materiais, além de buscar o aproveitamento desta nova propriedade que surge, para desenvolver produtos e dispositivos para diferentes tipos de aplicações tecnológicas ${ }^{23}$.

\subsection{Materiais Dielétricos}

Os materiais dielétricos são eletricamente isolantes e exibem ou podem ser levados a exibir uma estrutura de dipolo elétrico; isto é, existe uma separação de cargas eletricamente carregadas positivas e negativas num nível molecular ou atômico, resultado de interações de dipolo com o campo elétrico. Os materiais dielétricos são geralmente utilizados na construção de dielétrico de capacitores ${ }^{24}$.

\subsubsection{Capacitância}

Quando uma tensão elétrica (V) é aplicada em duas placas paralelas, uma placa se torna positivamente carregada e a outra negativamente carregada, com o correspondente campo elétrico induzido dirigido a partir da placa positiva para a placa negativa ${ }^{25}$. A quantidade de carga $(q)$ armazenada em ambos os lados da placa é definido como capacitância (C) e pode ser calculada usando a Equação 2.1, onde $V$ é a tensão elétrica aplicada através do capacitor. A unidade de capacitância é o Coulomb por volt, ou Farad (F). 


$$
C=\frac{q}{V}
$$

Considerando um capacitor de placas paralelas com vácuo na região entre as placas $^{24}$, a medida de capacitância pode ser calculada a partir da Equação 2.2, onde A representa a área das placas, lé a distância entre elas, $K_{1}$ é a constante dielétrica e $\varepsilon_{0}$ é a permissividade dielétrica no vácuo uma constante universal que tem o valor numérico de $8,85.10^{-12} \mathrm{~F} / \mathrm{m}$.

$$
\mathrm{C}=\mathrm{K}_{1} \cdot \varepsilon_{0} \cdot\left[\frac{\mathrm{A}}{\mathrm{I}}\right]
$$

Se um material dielétrico é inserido entre as placas, o valor final da capacitância sofre mudança devido à polarização do dielétrico que resulta na produção de carga induzida pela aplicação de campo elétrico no volume do dielétrico. Diferentes valores de capacitância são adquiridos com diferentes tipos de materiais dielétricos usados, pois cada isolante, na presença de um mesmo campo elétrico, adquire mais ou menos cargas na superfície ${ }^{22-26}$. A Tabela 2 apresenta alguns valores típicos de constante e rigidez dielétrica de materiais.

Tabela 2 - Constantes e rigidez dielétrica para alguns materiais ${ }^{25}$.

\begin{tabular}{|c|c|c|c|}
\hline & \multicolumn{2}{|c|}{$\begin{array}{c}\text { Constante } \\
\text { Dielétrica }\left(\mathrm{K}_{1}\right)\end{array}$} & $\begin{array}{c}\text { Rigidez } \\
\text { Dielétrica } \\
(\mathrm{kV} / \mathrm{m})\end{array}$ \\
\hline & $\begin{array}{c}60 \\
\mathrm{~Hz}\end{array}$ & $1 \mathrm{MHz}$ & \\
\hline $\begin{array}{c}\text { Cerâmica } \\
\text { Titânio }\end{array}$ & - & $15-10^{3}$ & $50-300$ \\
\hline Mica & - & 7 & $1000-2000$ \\
\hline Porcelana & - & 6 & $40-400$ \\
\hline Nylon 6,6 & 4 & 3,6 & 400 \\
\hline Polietileno & 2,3 & 2,3 & $450-500$ \\
\hline
\end{tabular}


Quando é aplicado um campo elétrico no material inserido no capacitor, as moléculas no interior do dielétrico são polarizadas pelo campo elétrico externo, gerando um alinhamento dos dipolos elétricos das moléculas. Na Figura 5a, está representado um capacitor polarizado de placas paralelas, com núcleo de ar, na Figura 5b é mostrada a organização dos dipolos do dielétrico sem polarização e na Figura 5c a configuração dos dipolos induzidos do dielétrico do capacitor ${ }^{22-25}$.
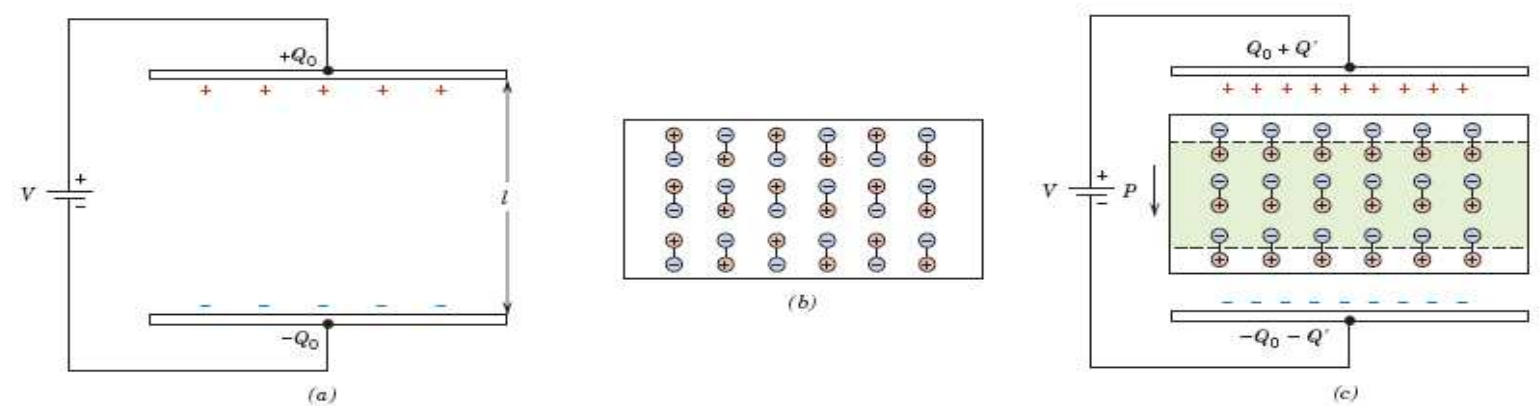

Figura 5 - (a) Capacitor de placas paralelas com núcleo de vácuo, (b) organização dos dipolos do dielétrico não polarizado, (c) polarização do dielétrico de capacitor.

Na Figura 6a, um átomo é representado por um núcleo carregado positivamente orbitado por uma nuvem eletrônica em equilíbrio. Após aplicação de campo elétrico externo, a nuvem eletrônica altera sua configuração, gerando um momento dipolar elétrico entre as cargas representado na Figura 6b. Essa polarização acarreta a formação de cargas elétricas induzidas nas superfícies do dielétrico com sinais contrários aos das cargas nas placas do capacitor, o que diminui o campo resultante dentro do dielétrico, e aumenta também sua capacitância, representada na Figura 6c. 


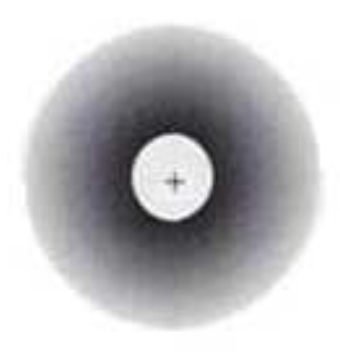

(a)

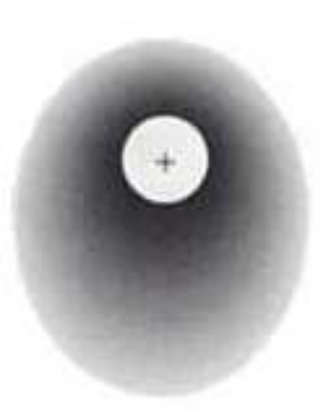

(b)

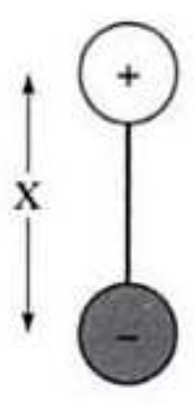

(c)

Figura 6 - (a) Representação de cargas de átomo sem aplicação de potencial elétrico, (b) com aplicação de campo elétrico externo, (c) esquema representativo de dipolos elétrico ${ }^{24}$.

Os valores de constante dielétrica $\left(\mathrm{K}_{1}\right)$ dos materiais pode ser representada por meio da Equação $2.3^{26}$, onde $C$ é a capacitância medida após a introdução do dielétrico entre as placas e $\mathrm{C}_{0}$ é a capacitância geométrica no vácuo.

$$
\mathrm{K}_{1}=\frac{\mathrm{C}}{\mathrm{C}_{0}}
$$

A constante dielétrica $\left(K_{1}\right)$ é uma propriedade do material da mais alta importância para o projeto de um capacitor. Observa-se, portanto, que a capacitância é determinada pelos fatores geométricos e pelo tipo de dielétrico que separa as duas placas paralelas. Quando a área das placas aumenta, o valor de capacitância aumenta, adicionalmente, quando a distância entre as placa é reduzida, a capacitância aumenta.

\subsubsection{Condução Elétrica}

Em contraste aos metais e semicondutores os materiais dielétricos apresentam alta resistência ao fluxo de corrente elétrica. Observa-se que a unidade 
do sistema internacional da resistividade é o ohm-metro $(\Omega \mathrm{m})$ e pode ser calculada por meio da equação 2.4 .

$$
\rho=\frac{R \cdot A}{I}
$$

Onde $\rho$ é a resistividade elétrica, $R$ é a resistência elétrica $(\Omega)$, L é o comprimento do material medido $(\mathrm{m})$ e $A$ é a área do capacitor $\left(\mathrm{m}^{2}\right)$. A Tabela 3 apresenta a resistividade elétrica de alguns materiais de engenharia.

Tabela 3 - Resistividade de alguns materiais ${ }^{27}$.

\begin{tabular}{|c|c|}
\hline Material & $\begin{array}{c}\text { Resistividade } \\
(\Omega . c m)\end{array}$ \\
\hline \multicolumn{2}{|c|}{ Condutores } \\
\hline Prata & $1,7.10^{-6}$ \\
\hline Cobre & $1,8.10^{-6}$ \\
\hline Ferro & $13.10^{-6}$ \\
\hline \multicolumn{2}{|c|}{ Semicondutores } \\
\hline SiC & 10 \\
\hline Silício & 40 \\
\hline Germânio & $2.10^{-5}$ \\
\hline \multicolumn{2}{|c|}{ Isolantes } \\
\hline MgO & $>10^{14}$ \\
\hline Borracha & $10^{14}$ \\
\hline Vulcanizada & $10^{14}$ \\
\hline Nylon & \\
\hline
\end{tabular}

Por meio da Tabela 3 é possível observar que um grande número de materiais cerâmicos e poliméricos apresenta boas propriedades dielétricas e são utilizados como componentes dielétricos em capacitores. Muitos desses materiais 
fornecem também alto grau de estabilidade dimensional, resistência mecânica e rigidez elétrica ${ }^{28-29}$.

\subsection{Comportamento Termodinâmico de Soluções de Polímeros.}

\subsubsection{Inchamento de polímero em presença de solvente}

Uma das equações mais importantes que caracteriza o comportamento dos componentes de uma solução relaciona-se com a alteração da energia livre de Gibbs - Helmholtz ${ }^{30}$. Essa variação energética ocorre com a adição de um número infinitamente pequeno de moléculas de uma das fases componentes, considerando constantes a temperatura, a pressão e a concentração do outro componente. A energia de equilíbrio no sistema pode ser representada pela equação 2.5 , onde $G$ representa a energia livre de Gibbs, $\mathrm{H}$ a entalpia, $\mathrm{T}$ a temperatura e $\mathrm{S}$ a entropia.

$$
G=H-T S
$$

As mudanças de energia livre são validas também para as funções parciais, onde $\Delta \mathrm{H}$ é conhecida por entalpia parcial molar, $\Delta \mathrm{S}$ é a entropia parcial molar e $\Delta \mathrm{G}$ é a variação da energia livre de Gibbs parcial molar, que são representadas na expressão 2.6:

$$
\mathrm{H}_{1}=\frac{\Delta \mathrm{H}}{\Delta \mathrm{n}_{1}} ; \mathrm{S}_{1}=\frac{\Delta \mathrm{S}}{\Delta \mathrm{n}_{1}} ; \mathrm{G}_{1}=\frac{\Delta \mathrm{G}}{\Delta \mathrm{n}_{1}}
$$

A função parcial molar é um modelo molar termodinâmico extensivo que implica na variação de entalpia, entropia, volume e temperatura. O modelo adotado envolve inevitavelmente uma mudança no arranjo espacial das cadeias com a finalidade de minimizar as energias, resultando em um aumento do volume da amostra $^{30,31}$, também conhecido como inchamento ${ }^{32}$. 


\subsubsection{Modelo de Hildebrand e Scott}

Os primeiros fundamentos sobre o parâmetro de solubilidade foram desenvolvidos no inicio da década de 30 e foram formalizados por Hildebrand, em $1932^{33}$ e Hansen em $1967^{34}$. Essa teoria é derivada de uma aproximação da pressão interna de um fluido e da densidade de energia coesiva, baseado em trabalhos realizados por Gordon e Giauque, em $1948^{35}$ e por Vassallo e Harden, em $1962^{36}$.

Numa solução polímero-solvente, o valor de variação de entropia da mistura geralmente é desprezível devido aos tamanhos das moléculas de polímero serem extremamente maiores que as moléculas dos solventes. Assim sendo, a solubilidade do polímero é determinada pela entalpia da mistura, a qual precisa apresentar o menor valor possível ou valores negativos, através da correta escolha do solvente. A primeira lei da termodinâmica ${ }^{37}$ para um sistema que passa por uma mudança de estado é dada por:

$$
\mathrm{U} 1-\mathrm{U} 2=\mathrm{Qt}-\mathrm{W}
$$

Onde U1 e U2 são os valores inicial e final de energia total do sistema, Qt é o calor transferido para o sistema durante a mudança de estado e $W$ é trabalho feito pelo sistema durante a sua mudança.

O significado físico da energia U representa a somatória de energias do sistema, esta variável pode se apresentar de várias formas, incluindo, energia cinética ou potencial que estão associadas ao movimento e posicionamento das moléculas. O parâmetro de solubilidade de Hildebrand fornece, portanto, um valor numérico estimado do grau de interação entre os materiais e pode indicar a solubilidade, particularmente para materiais não polares, como é o caso de muitos polímeros. O parâmetro de solubilidade pode ser calculado por meio da raiz quadrada da densidade de energia coesiva, dada pela Equação 2.8

$$
\delta=\sqrt{\frac{\Delta \mathrm{H} \mathrm{RT}}{\mathrm{Vm}}}
$$


Onde $\delta$ é o parâmetro de solubilidade, $\Delta \mathrm{H}$ é a entalpia parcial molar, $\mathrm{R}$ a constante universal dos gases, T a temperatura e Vm é o volume molar.

Os polímeros no seu estado sólido apresentam cadeias entrelaçadas, em solução, essas cadeias se expandem e ganham liberdade para movimentos translacionais regidos pelas diferentes conformações que possam assumir, confirmando a teoria de movimento browniano molecular de pequenos segmentos, onde cada espaço pode ser preenchido por uma molécula de solvente ou por uma unidade da cadeia polimérica, que resulta no aumento de entropia que ocorre durante o processo de dissolução ${ }^{32,33}$.

O conhecimento do parâmetro de solubilidade de um polímero tem importância tanto pelo aspecto científico quanto tecnológico, tornando-se uma ferramenta importante para a caracterização das propriedades de soluções ${ }^{38}$. Inúmeras aplicações de soluções de polímeros são encontradas nas indústrias farmacêutica, alimentícia, cosmética, de tintas e vernizes, de processamento de petróleo e de mineração ${ }^{39}$. O parâmetro de solubilidade, tem como unidade CGS $\left(\mathrm{cal} / \mathrm{cm}^{3}\right)^{1 / 2}$ dada por $\left(\mathrm{J} . \mathrm{m}^{3}\right)^{1 / 2}$, que tradicionalmente é obtido através de sua entalpia de vaporização ou observado por meio da atenuação das diferenças entre pressão interna e densidade de energia coesiva da mistura ${ }^{40}$.

\subsubsection{Modelo de Flory-Huggins}

O modelo matemático de Flory-Huggins ${ }^{40-41}$ é a teoria mais utilizada para prever o comportamento de fases em misturas binárias, não somente de soluções/polímeros, mas também de polímero/polímero, onde a variação da energia livre das misturas é uma condição necessária para a estabilidade de fases presentes e da minimização das energias do sistema ${ }^{42}$. Nesta teoria estão envolvidos termos como temperatura, volume de expansão, número de segmentos de cadeia(s) e parâmetro de interação. O parâmetro de interação $\chi$ está relacionado com o calor de mistura desenvolvido e pode ser calculado usando a equação 2.9, onde: $\delta 1$ e $\delta 2$ correspondem os parâmetros de solubilidade do solvente e do polimero, respectivamente 1 e 2 : 


$$
\mathrm{X} 1=\frac{\mathrm{V}\left(\delta(\delta 2)^{2}\right.}{\mathrm{RT}}
$$

A forma mais utilizada para determinar o parâmetro de interação é através do ensaio de inchamento (também conhecido como intumescimento) de um polímero reticulado. As interações polímero-solvente são variáveis termodinâmicas de especial interesse na caracterização de sistemas poliméricos, tendo em vista que o seu conhecimento permite a determinação da densidade de ligações cruzadas $(v)$ em redes poliméricas simples ou interpenetrantes ${ }^{43}$. $O$ método universalmente adotado para esta determinação baseia-se na teoria de Flory-Rehner ${ }^{44}$ e usa dados de inchamento em solventes. A relação de Flory-Rehner origina-se da combinação da teoria de Flory-Huggins para misturas polímero-solvente com a teoria da mecânica estatística para a variação da energia livre provocada pelo inchamento. A Equação 2.10 resultante relaciona 0 inchamento com a densidade de ligações cruzadas ${ }^{45}$.

$$
\mathrm{V}=\frac{\left[\ln (1 \quad \mathrm{Vr})+\mathrm{Vr}+\mathrm{X} \cdot \mathrm{Vr}^{2}\right]}{\left[\rho \rho_{.1} \cdot\left(\mathrm{Vr}^{1 / 3} \frac{\mathrm{Vr}}{2}\right)\right]}
$$

Nesta Equação, $v$ é a densidade de ligações cruzadas que corresponde ao número de cadeias efetivo por unidade de volume e é igual a $1 / \overline{\mathrm{M}} \mathrm{c}, \quad \rho$ é a densidade do solvente, Vr é o volume reduzido (volume da amostra seca/volume da amostra inchada), $\chi$ é o parâmetro de interação polímero-solvente e $V_{1} \circ$ volume molar do solvente puro.

$$
\mathrm{Vr}=\frac{\mathrm{v} 1}{\mathrm{v} 2}
$$


Uma relação gráfica entre o grau de intumescimento e o parâmetro de interação do solvente permite também obter o parâmetro de solubilidade do polímero. Além da natureza da interação polímero-solvente outros fatores alteram o processo de inchamento, variáveis inerentes à estrutura do polímero contribuem significativamente na mobilidade das partículas, entre elas podemos citar a alta cristalinidade e altas massas moleculares, que têm efeito negativo, o que torna mais difícil a escolha de um solvente apropriado ${ }^{45-47}$. 


\section{PARTE EXPERIMENTAL}

\subsection{Materiais}

Os reagentes e solventes químicos usados neste trabalho foram utilizados da forma como recebidos, quando não mencionado, nenhum tratamento específico foi utilizado para purificação.

- Acetona - Procedência: Synth; grau de pureza 99,5\%

- Clorofórmio - Procedência: Casa Americana; grau de pureza, P.A.

- Dimetilformamida - Procedência: Casa Americana; grau de pureza 99\%

- Hexano - Procedência: Synth; grau de pureza 98,5\%

- Pesilox - Poli(éter-siloxano) - Procedência: Adespec adesivos especiais;

- Titanato de bário nano (fase cristalina cúbica), 30-50 nm tamanho do sólido particulado - Procedência: Sigma Aldrich; grau de pureza P.A

- Tolueno - Procedência: Casa Americana; grau de pureza 99\%

- Xileno - Procedência: Synth; grau de pureza 98,5\%

\subsubsection{Elastômeros e seus compósitos}

Para a preparação do compósito de elastômero com titanato de bário foi utilizado o adesivo selante amplamente difundido no mercado de elastômeros, o poli(éter-siloxano) e como carga o titanato de bário nanométrico com 30-50 nm de diâmetro (sólido particulado pulverulento)

\subsubsection{Equipamentos}

Além dos materiais de laboratório comuns necessários para a realização da pesquisa, tais como vidraria, materiais de consumo e etc, utilizaram-se também os seguintes equipamentos: 
- Câmara "Glove-box": A mistura em massa do nanocompósito ocorreu em ambiente inerte $\left(\mathrm{N}_{2}\right.$ seco).

- Microscópio eletrônico de varredura (MEV) - Phillips modelo XL-30 equipamento pertencente ao Departamento de Engenharia Metalúrgica e de Materiais da Escola Politécnica da USP;

- Sonda para espectroscopia de energia dispersiva de raio $x(E D X)$ EDAX modelo gênesis 4000 - equipamento acoplado ao microscópio eletrônico de varredura;

- Maquina de deposição por sputtering - sputter do fabricante BALZERS, modelo SCD 050 - equipamento pertencente ao Departamento de Engenharia Metalúrgica e de Materiais, da Escola Politécnica da USP;

- Calorímetro diferencial exploratório - DSC50 da Shimadzu, Kyoto, Japão - equipamento pertencente ao Laboratório de Análises Térmicas do Instituto de Química da Universidade de São Paulo;

- Analisador Termogravimétrico - TGA 51 da Shimadzu, Kyoto, Japão equipamento pertencente ao Laboratório de Análises Térmicas do Instituto de Química da Universidade de São Paulo;

- Medidor de caracterização elétrica - modelo HP 4280 A da Hewlett Packard - equipamento pertencente ao Laboratório de Sistemas Integráveis do Departamento de Engenharia de Sistemas Eletrônicos, Escola Politécnica da USP.

- Balança analítica Ohaus, modelo AR 2140.

\subsection{Metodologia}

Como já mencionado anteriormente, a parte experimental deste trabalho engloba três etapas:

- Preparo de compósitos e corpos de prova.

- Caracterização dos compósitos.

- Tratamento dos dados obtidos. 


\subsubsection{Preparação dos Compósitos}

As quantidades adequadas dos componentes, precursor polimérico e a fase particulada de titanato de bário, foram pesados em diferentes concentrações (puro, $10,20,30,40$ e $50 \%$ ) de massa. A mistura ocorreu em câmara glove box em ambiente de nitrogênio conforme apresentado na Figura 7, a mistura ocorreu por meio de processamento manual em massa até obtenção de mistura homogênea.

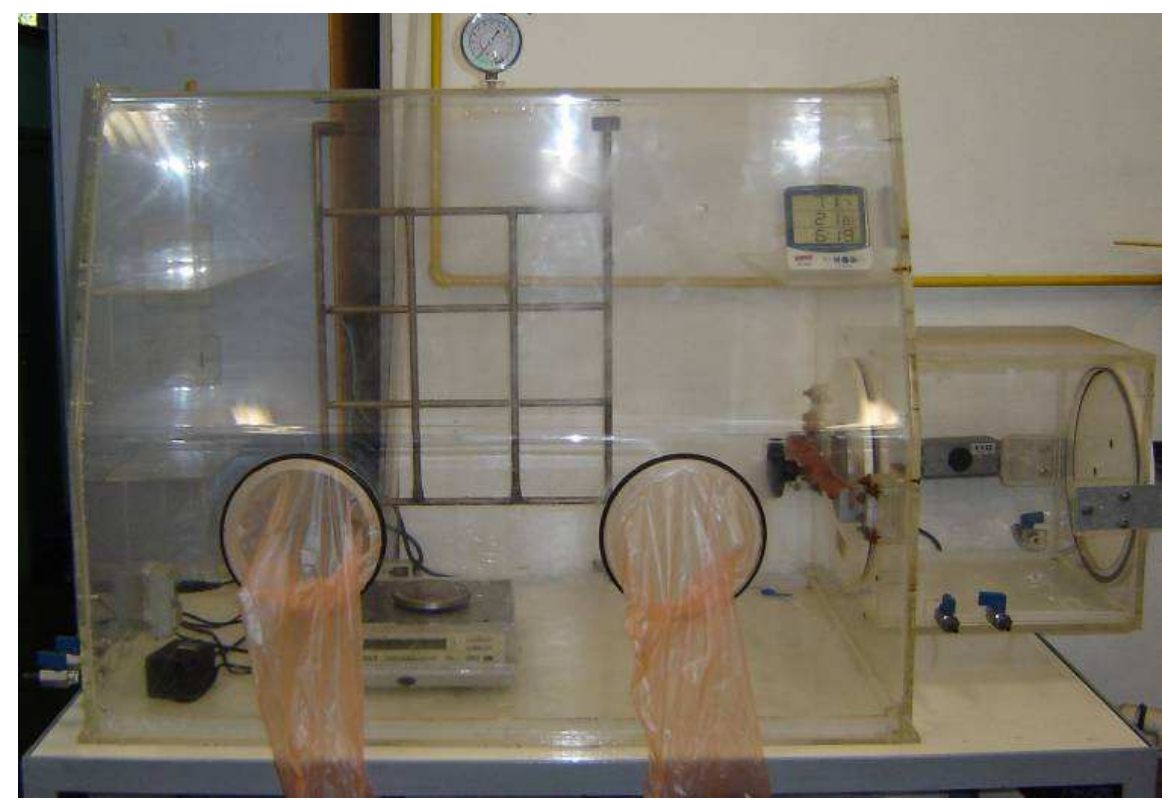

Figura 7 - Câmara glove box usada para preparo de compósito.

A mistura resultante não reticulada foi utilizada na fabricação dos corpos de prova para as etapas de caracterização. Os corpos de prova foram curados num sistema aberto de ar atmosférico com pressão ambiente constante de $1 \mathrm{~atm}$ (atmosfera) e temperatura ambiente de $25^{\circ} \mathrm{C}$ por 72 horas para completar a reação de reticulação das cadeias. Na Tabela 4 são apresentas algumas propriedades do material sólido particulado de titanato de bário e na Tabela 5 as propriedades resultantes dos compósitos obtidos no processo descrito acima. 
Tabela 4 - Propriedades do sólido particulado.

\begin{tabular}{|c|c|c|c|}
\hline \multicolumn{4}{|c|}{ Propriedades do titanato de bário } \\
\hline $\begin{array}{c}\text { Densidade } \\
\left(\mathrm{g} / \mathrm{cm}^{3}\right)\end{array}$ & $\begin{array}{c}\text { Pureza } \\
(\%)\end{array}$ & $\begin{array}{c}\text { Tamanho do } \\
\text { particulado }(\mathrm{nm})\end{array}$ & $\begin{array}{c}\text { Constante } \\
\text { Dielétrica }\end{array}$ \\
\hline 6,08 & 99 & $30-50$ & 150 \\
\hline
\end{tabular}

Tabela 5 - Propriedades das amostras utilizadas no trabalho.

\begin{tabular}{|c|c|c|c|}
\hline Material & $\begin{array}{l}\text { Nome da } \\
\text { Amostra }\end{array}$ & $\begin{array}{c}\text { Densidade } \\
\left(\mathrm{g} / \mathrm{cm}^{3}\right)\end{array}$ & $\begin{array}{c}\text { Parâmetro de solubilidade } \\
\text { Calculado ((ס/MPa1/2) }\end{array}$ \\
\hline Poli(éter-siloxano) & P100 & 1,026 & \multirow{6}{*}{18,599} \\
\hline $\begin{array}{c}\text { Poli(éter-siloxano) e } \\
\mathrm{BaTiO}_{3} \text { com } 10 \% \text { em massa. }\end{array}$ & C10 & 1,1122 & \\
\hline $\begin{array}{c}\text { Poli(éter-siloxano) e } \\
\mathrm{BaTiO}_{3} \text { com } 20 \% \text { em massa. }\end{array}$ & C20 & 1,2249 & \\
\hline $\begin{array}{c}\text { Poli(éter-siloxano) e } \\
\mathrm{BaTiO}_{3} \text { com } 30 \% \text { em massa. }\end{array}$ & C30 & 1,2749 & \\
\hline $\begin{array}{c}\text { Poli(éter-siloxano) e } \\
\mathrm{BaTiO}_{3} \text { com } 40 \% \text { em massa. }\end{array}$ & C40 & 1,4157 & \\
\hline $\begin{array}{c}\text { Poli(éter-siloxano) e } \\
\mathrm{BaTiO}_{3} \text { com } 50 \% \text { em massa. }\end{array}$ & C50 & 1,7011 & \\
\hline
\end{tabular}

\subsubsection{Ensaios de Inchamento}

Nesse trabalho foi utilizado o método de inchamento no equilíbrio. Após a cura do polímero foram cortados 6 corpos de prova de formato retangular com dimensões de $20 \times 20 \times 3 \pm 0,01 \mathrm{~mm}$. Foram processados corpos de prova com pequenas dimensões com a finalidade de facilitar o processo difusional do solvente para dentro do polímero, aumentando a eficiência do processo e empregando uma 
quantidade menor de solvente. Os ensaios de inchamento foram feitos de acordo com a ASTM D 3616.

\subsubsection{Medidas de Densidade}

O efeito da mudança na densidade está associado a alterações da estrutura química e sua organização molecular, onde as regiões cristalinas são mais compactas, enquanto as regiões amorfas são menos densas. Com a finalidade de estudar a estrutura atômica foram feitas medidas de densidade utilizando o método de Arquimedes, também conhecido como método hidrostático.

Os ensaios de densidade foram feitos de acordo com a ASTM D3800, o arranjo utilizado é apresentado de acordo com o esquema da Figura 8.

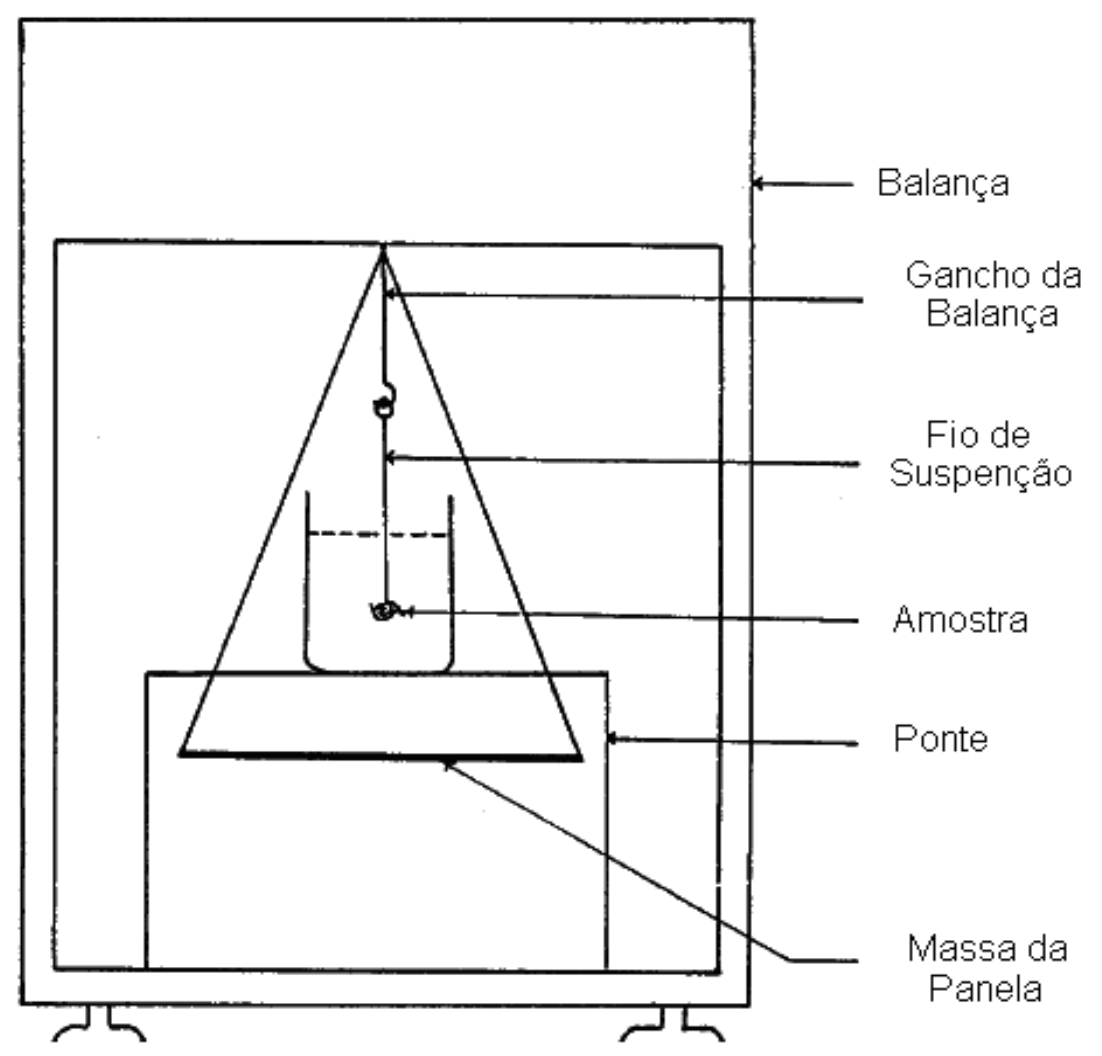

Figura 8 - Aparato de medida de densidade de acordo com a ASTM D3800 ${ }^{46}$. 
Com a finalidade de determinar as densidades as amostras foram pesadas sem imersão em balança analítica, em seguida, as mesmas foram novamente pesadas com imersas em hexano $\left(\rho=0,6590 \mathrm{~g} / \mathrm{cm}^{3}\right)$ com o auxilio de um suporte para fixação do corpo de prova, o arranjo representado pela norma ASTM D3800 é apresentado na Figura 9.

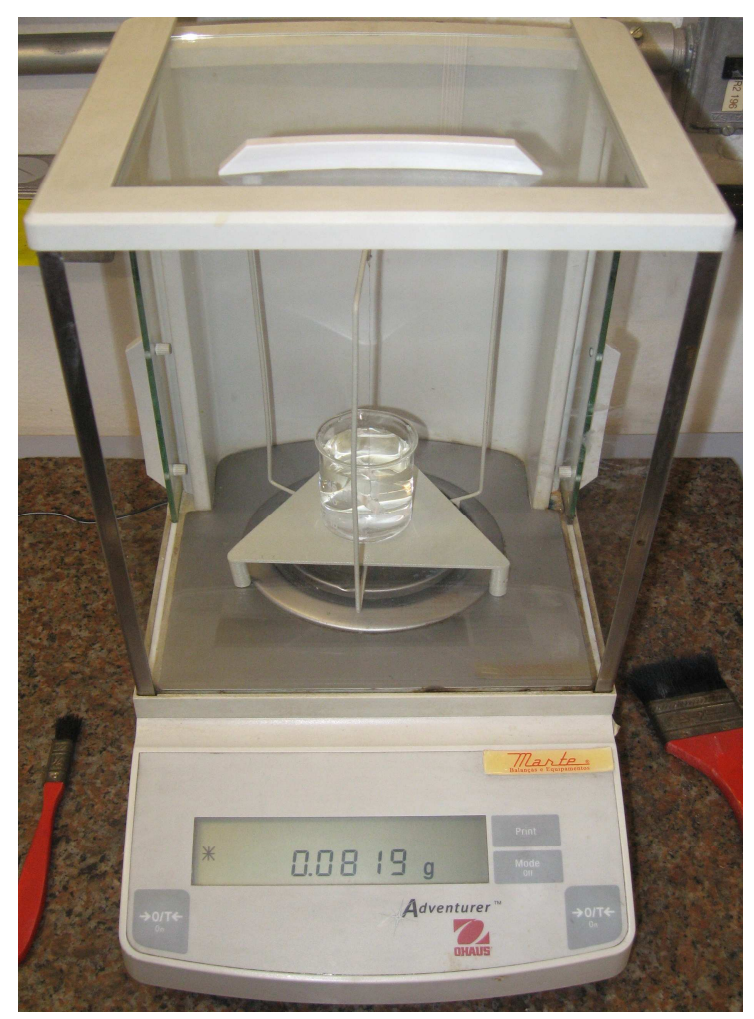

Figura 9 - Aspecto da montagem do aparato para medir densidade.

A densidade ( $\rho$ ) foi calculada por meio da Equação 3.1, onde Mps é a massa do polímero seco e Mpi a massa do polímero imerso.

$$
\rho=\frac{\left(\mathrm{Mps}^{*} 0,6590\right)}{(\mathrm{Mps} \mathrm{Mpi})}
$$


3.3. Procedimentos de Análise e Caracterização.

\subsubsection{Ensaio de Inchamento.}

No primeiro momento foi medida a massa inicial e densidade (obtidas por método hidrostático) dos corpos de prova, posteriormente, imersos nos solventes selecionados: xileno $\left[\delta=18,102\left(\mathrm{~J} \cdot \mathrm{m}^{3}\right)^{1 / 2}\right]$, hexano $\left[\delta=14,809\left(\mathrm{~J} \cdot \mathrm{m}^{3}\right)^{1 / 2}\right]$, acetona $\left[\delta=19,984\left(\mathrm{~J} \cdot \mathrm{m}^{3}\right)^{1 / 2}\right]$, dimetilformamida $\left[\delta=24,832\left(\mathrm{~J} \cdot \mathrm{m}^{3}\right)^{1 / 2}\right]$, tolueno $[\delta=18,225$ $\left.\left(\mathrm{J} . \mathrm{m}^{3}\right)^{1 / 2}\right]$ e clorofórmio $\left[\delta=18,839\left(\mathrm{~J} \cdot \mathrm{m}^{3}\right)^{1 / 2}\right]$. Foram selecionados solventes com uma vasta faixa de parâmetro de solubilidade, para assegurar que ocorra uma boa variação no grau de inchamento do polímero em função do parâmetro de solubilidade do solvente utilizado. A Tabela 6 apresenta com maiores detalhes algumas propriedades dos solventes utilizados no trabalho ${ }^{47}$.

Tabela 6 - Propriedade de solventes utilizados.

\begin{tabular}{|c|c|c|c|c|c|}
\hline Solvente & $\begin{array}{c}\text { Parâmetro de } \\
\text { Sol.((ס/MPa } 1 / 2)\end{array}$ & $\begin{array}{c}\text { Pureza } \\
(\%)\end{array}$ & $\begin{array}{c}\text { Massa } \\
\text { Molar } \\
(\mathrm{g} / \mathrm{mol})\end{array}$ & $\begin{array}{c}\text { Densidade } \\
\left(\mathrm{g} / \mathrm{cm}^{3}\right)\end{array}$ & $\begin{array}{c}\text { Molar } \\
\left(\mathrm{cm}^{3} / \mathrm{mol}\right)\end{array}$ \\
\hline Xileno & 18,102 & 98,5 & 106,16 & 0,8700 & 122,02 \\
\hline Hexano & 14,809 & 98,5 & 86,17 & 0,6590 & 130,78 \\
\hline Acetona & 19,984 & 99,5 & 58,08 & 0,7910 & 73,42 \\
\hline Dimetilformamida & 24,832 & 99 & 73,13 & 0,9440 & 77,46 \\
\hline Tolueno & 18,225 & 99 & 92,13 & 0,8670 & 106,26 \\
\hline Clorofórmio & 18,839 & 98,5 & 120,38 & 1,4920 & 80,68 \\
\hline
\end{tabular}

O inchamento foi feito à temperatura ambiente, com uso de recipientes fechados (erlenmeyer), conforme descrito nas normas ASTM D 1460-86 ${ }^{48}$ e ASTM D $6814{ }^{49}$, como mostrado na Figura 10. 


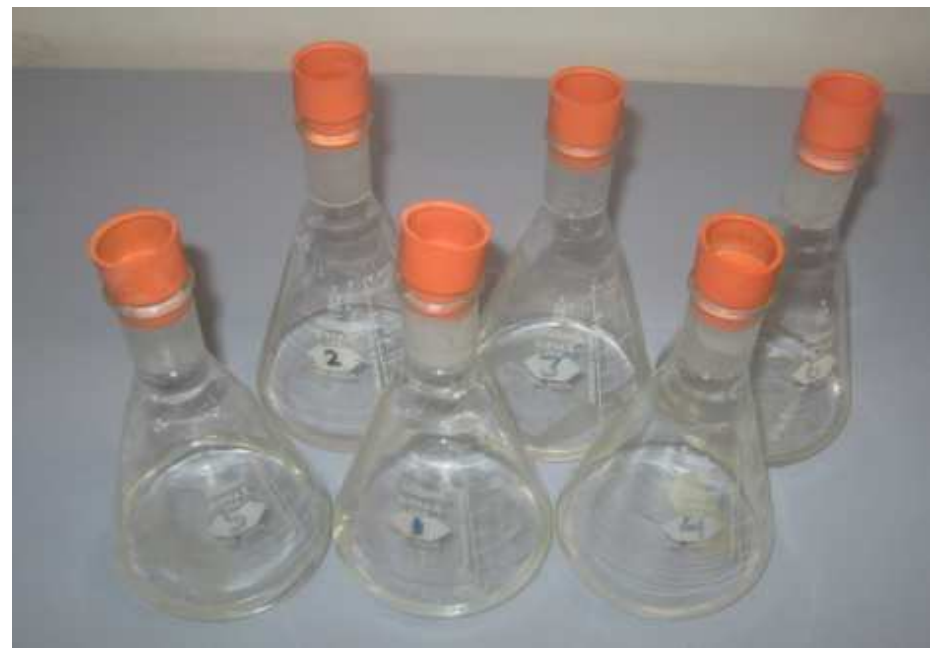

Figura 10 - Recipientes usados nos ensaios de inchamento.

Todos os polímeros utilizados nesse ensaio de inchamento foram reticulados através da reação química de cura por um período de 72 horas e posteriormente imersos em solventes até o equilíbrio por um período de 72 e 720 horas.

Com a finalidade de obter resultados de maior precisão, foram utilizados polímeros com diferentes concentrações de carga, medida que garante diferentes concentrações de ligações cruzadas dos polímeros. A Equação 3.2 foi utilizada para medir o percentual de inchamento do polímero e de seus compósitos ${ }^{50}$.

$$
\mathrm{S} \%=\frac{\mathrm{mx} \mathrm{mo}}{\mathrm{mo}} .100
$$

Sendo S\% o inchamento no equilíbrio; $m x$ a massa do corpo de prova após o inchamento e mo a massa inicial antes do inchamento. Para o cálculo do percentual de inchamento volumétrico foi utilizado à Equação 3.3:

$$
\mathrm{Q}=\frac{\mathrm{mx} m o}{\mathrm{mo} \cdot \rho \mathrm{\rho}}
$$

Onde $\rho$ s é dado como a densidade do solvente.

O grau de inchamento máximo $\left(Q_{\max }\right)$ no equilíbrio o parâmetro de solubilidade do polimero $\left(\delta_{1}\right)$ será igual ou próximo ao parâmetro de solubilidade do 
solvente $\left(\delta_{2}\right)$ que pode ser expresso pelo grau de inchamento máximo, por meio da equação 3.4 .

$$
\delta_{2}=\delta_{1} \pm\left[\frac{1}{V_{1}} \cdot \ln \left(\frac{Q_{\text {máx }}}{Q}\right)\right]^{\frac{1}{2}}
$$

Por meio do inchamento em diferentes solventes é possivel determinar qual o solvente no qual o inchamento é máximo. A parametrização do coeficiente de inchamento versus parâmetro de solubilidade é obtida a curva que determina 0 inchamento máximo do polímero para determinado solvente.

\subsubsection{Análise Termogravimétrica (TGA)}

A análise termogravimétrica (TGA) é a técnica na qual ocorre o registro da massa do material em função da temperatura enquanto a substância é submetida a uma programação de temperaturas, em uma atmosfera controlada. O registro é a curva termogravimétrica ou curva de decomposição térmica, que permite tirar conclusões sobre a estabilidade térmica da amostra, processos de decomposição térmica, determinando as temperaturas em que ocorrem e a quantidade dos resíduos do processo de decomposição. É uma técnica basicamente de natureza quantitativa.

As análises termogravimétricas foram feitas em um ambiente de ar comprimido com fluxo de $50,0 \mathrm{sccm}$ (centímetros cúbicos padrão por minuto) de vazão, com ambiente seco devido uso de filtro em linha de ar, com taxa inicial de aquecimento de $10^{\circ} \mathrm{C} / \mathrm{min}$ e temperatura inicial de $50^{\circ} \mathrm{C}$ e final de $850^{\circ} \mathrm{C}$. $\mathrm{O}$ software TA 60 foi utilizado para calcular as temperaturas de estabilidade térmica do polímero e dos compósitos, determinando os principais parâmetros de estudo: temperaturas em que o material iniciará a degradação e consequente perda de massa, resíduos da análise térmica e determinar a temperatura máxima possível 
para o ensaio de DSC. O equipamento utilizado nos ensaios de TGA pode ser observado na Figura 11.

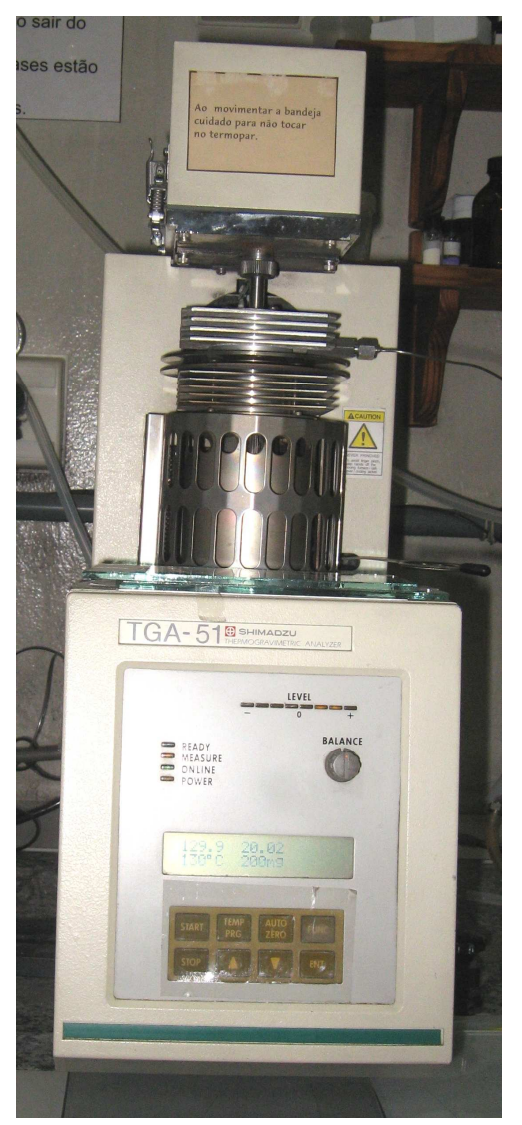

Figura 11 - Equipamento Shimadzu TGA 51.

\subsubsection{Análise Térmica Diferencial (DSC)}

A análise por calorimetria diferencial exploratória (differential scanning calorimetry) é uma técnica que mede a quantidade de energia absorvida ou emitida de uma amostra em função da temperatura ou do tempo. Quando ocorre uma transição térmica na amostra, o equipamento DSC quantifica a energia da transição e a temperatura em que ela ocorre.

Essas análises foram realizadas em atmosfera de ar comprimido com fluxo de $50 \mathrm{sccm} / \mathrm{min}$ e taxa de aquecimento de $10^{\circ} \mathrm{C} / \mathrm{min}$. Amostras com aproximadamente 18 - $25 \mathrm{mg}$ foram pesadas e hermeticamente fechadas em cadinhos de alumínio e, 
posteriormente, pesadas para confirmação da massa contida no cadinho de amostra, de acordo com a norma ASTM D-3418-82 ${ }^{51}$.

A célula foi calibrada antes dos ensaios no eixo de temperatura utilizando padrões de índio (temperatura de fusão $=156,6^{\circ} \mathrm{C}$ ) e zinco (temperatura de fusão = 419,5 C) metálico com pureza de 99,99\%. Também antes do inicio dos experimentos, foi utilizado o ajuste da linha de base. $O$ valor da linha de base não variou mais que $0,5 \mathrm{mV}$, com a finalidade de garantiu precisão ao ensaio. A Figura 12 mostra a plataforma de análise contendo a amostra e o cadinho de referência.

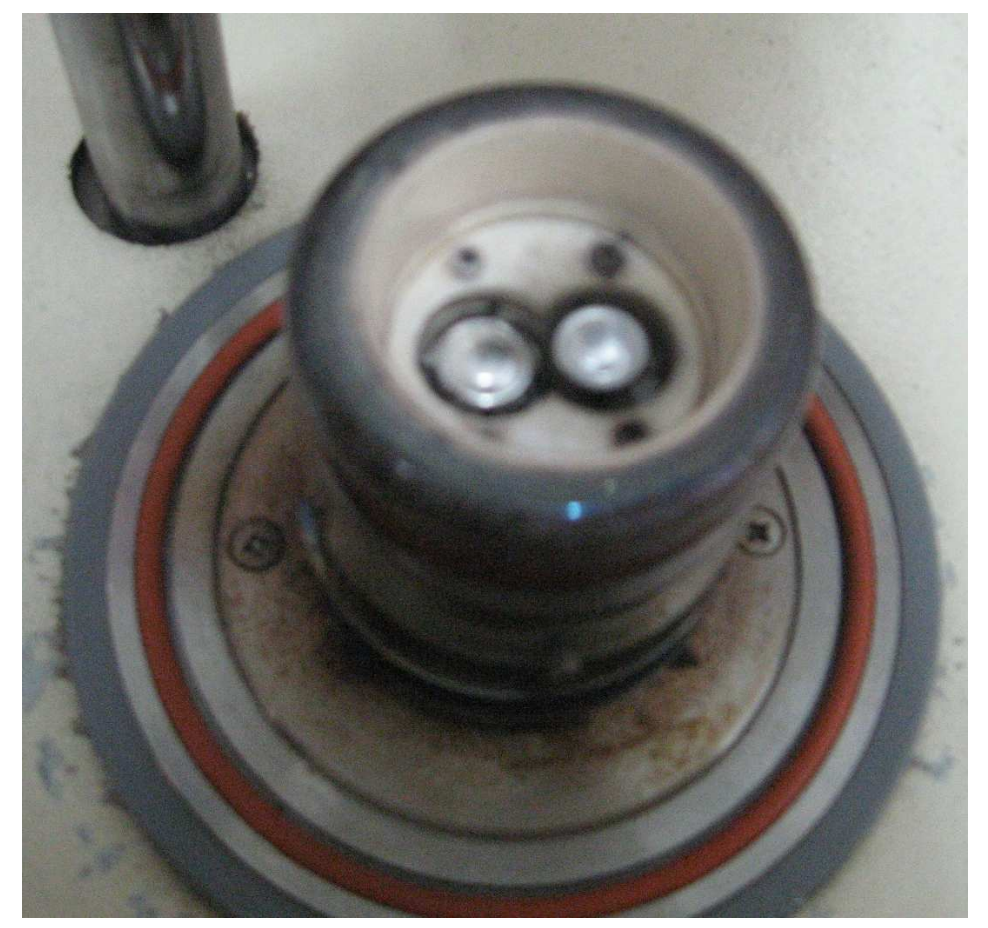

Figura 12 - Sistema para medida de DSC com amostra (direita) e amostra de referência (esquerda).

Nesse ensaio foi inicialmente realizado um estágio de resfriamento partindo da temperatura ambiente até $-100^{\circ} \mathrm{C}$. Esse procedime nto de resfriamento e primeira corrida tem a finalidade de uniformizar as análises, eliminando variações de tratamento térmico que poderia alterar tensões internas devido à densidade de ligações cruzadas e tensões provocadas pela incorporação do sólido particulado. Dessa forma, o valor da temperatura de transição vítrea não foi determinado no primeiro estágio de resfriamento, mas no estágio de aquecimento das amostras. 


\subsubsection{Microscopia Eletrônica de Varredura (MEV)}

A técnica de microscopia eletrônica de varredura (MEV) foi utilizada com a finalidade de avaliar o estado de aglomeração, homogeneidade da forma e tamanho do sólido particulado presente no compósito. Nesta técnica, a superfície de uma espécie é varrida por um feixe colimado de elétrons. A interação entre a radiação e a superfície da amostra pode resultar na produção de elétrons secundários, de fótons por catodo luminescente, de raios $x$ ou de retroespalhamento de elétrons. As informações obtidas foram processadas, coletadas e convertidas em um sinal, a partir do qual pode se obter um registro contínuo.

A caracterização morfológica do compósito foi realizada com uso de microscópio eletrônico de varredura da marca PHILIPS, modelo XL 30. Todas as amostras do polímero e compósitos foram fraturadas criogenicamente (de modo a evitar interferência de deformações plásticas nos materiais), usando nitrogênio liquido, e recobertas com ouro por meio do uso de equipamento de sputtering do fabricante BALZERS, modelo SCD 050. As amostras de polímero puro, compósitos e do titanato de bário puro sem prévio tratamento foram fixadas diretamente no porta-amostra com fita condutora de carbono dupla face da empresa Nisshin Em. Co. Ltd., Tokyo, Japan.

Foram realizadas também análises quantitativas e qualitativas por meio de equipamento de EDX (energy dispersive x-ray) ou EDS da empresa EDAX, modelo gênesis 4000, as análises foram modeladas com o uso do software Genesis Apex 2.

Trata-se de um detector instalado na câmara de vácuo do MEV que detecta elementos presentes na amostra, por meio da emissão de raios-X característicos. Os elétrons do feixe incidem com energia suficiente para excitar os elétrons das camadas mais inferiores dos átomos das amostras e ocupam níveis de maiores energia, dessa forma outros elétrons de qualquer níveis energéticos podem ocupar o 
nível originalmente desocupado, sendo essa diferença entre os níveis dadas pela equação 3.5 .

$$
\text { h. } \frac{\mathrm{C}}{\lambda}=\Delta \mathrm{U}
$$

Onde h corresponde a constante de Plank (6.62.10 $\left.{ }^{-34} \mathrm{~J} . \mathrm{s}\right)$, c representa a velocidade de propagação da onda eletromagnética $\left(3.10^{10} \mathrm{~cm} / \mathrm{seg}\right.$ no vácuo), $\lambda$ é o comprimento de onda e $\Delta U$ é a diferença de energia entre os dois níveis de transição. Como os elétrons de um determinado átomo possuem energias distintas, é possível determinar quais os elementos químicos estão presentes naquele ponto de incidência do feixe e assim identificar em instantes que material está sendo observado. As análises não foram realizadas considerando apenas a presença e ausência dos elementos químicos de cada formulação, mas foram varridas para detecção de possíveis impurezas presentes.

\subsubsection{Caracterização Elétrica}

A caracterização elétrica de capacitância foi feita com o auxilio de medidor HP 4280 A, da empresa Hewlett Packard, a temperatura de $25^{\circ} \mathrm{C}$ e com umidade relativa de $50 \%$. As medidas elétricas foram desenvolvidas por meio do uso de capacitor. As amostras foram montadas em um suporte polimérico de policarbonato (PC) com tampas torneadas em alumínio, de formato circular, com dimensões de 18 $\mathrm{mm}$ de raio, as placas paralelas foram espaçadas com distancia de $0,8 \mathrm{~mm}$ por meio de anel de guarda. Foram adicionados quatro rebaixos na célula com a finalidade de permitir a saída de excesso de material, comprimido entre as placas. Para o capacitor de placas paralelas assim montado, foi obtida a constante geométrica da célula. A célula construída é apresentada na Figura 13. 


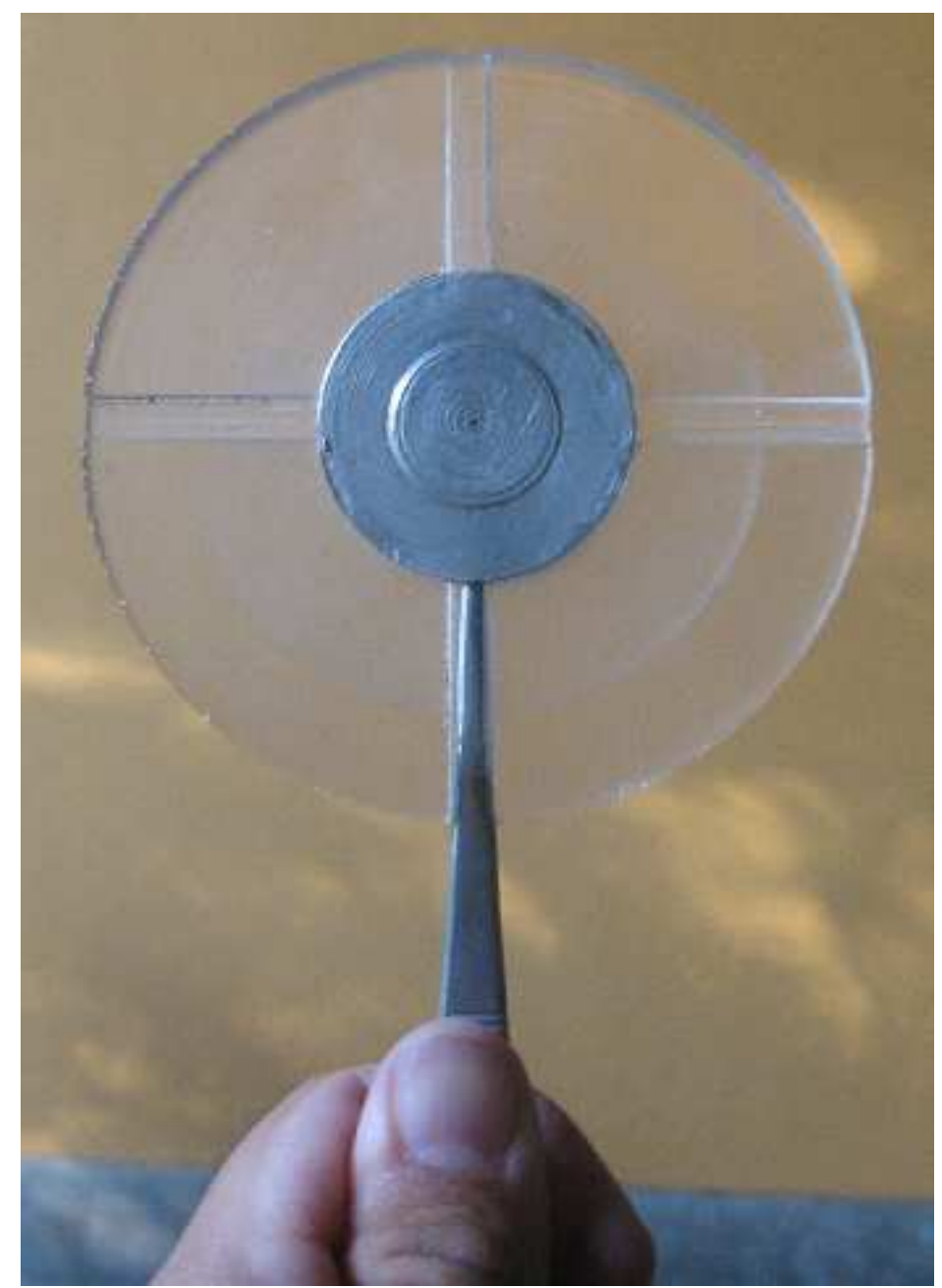

Figura 13 - Célula desenvolvida para caracterização elétrica.

O desenho do projeto mecânico da célula capacitiva pode ser representado esquematicamente conforme a Figura 14, todas as medidas apresentadas estão em unidade milimétrica. 

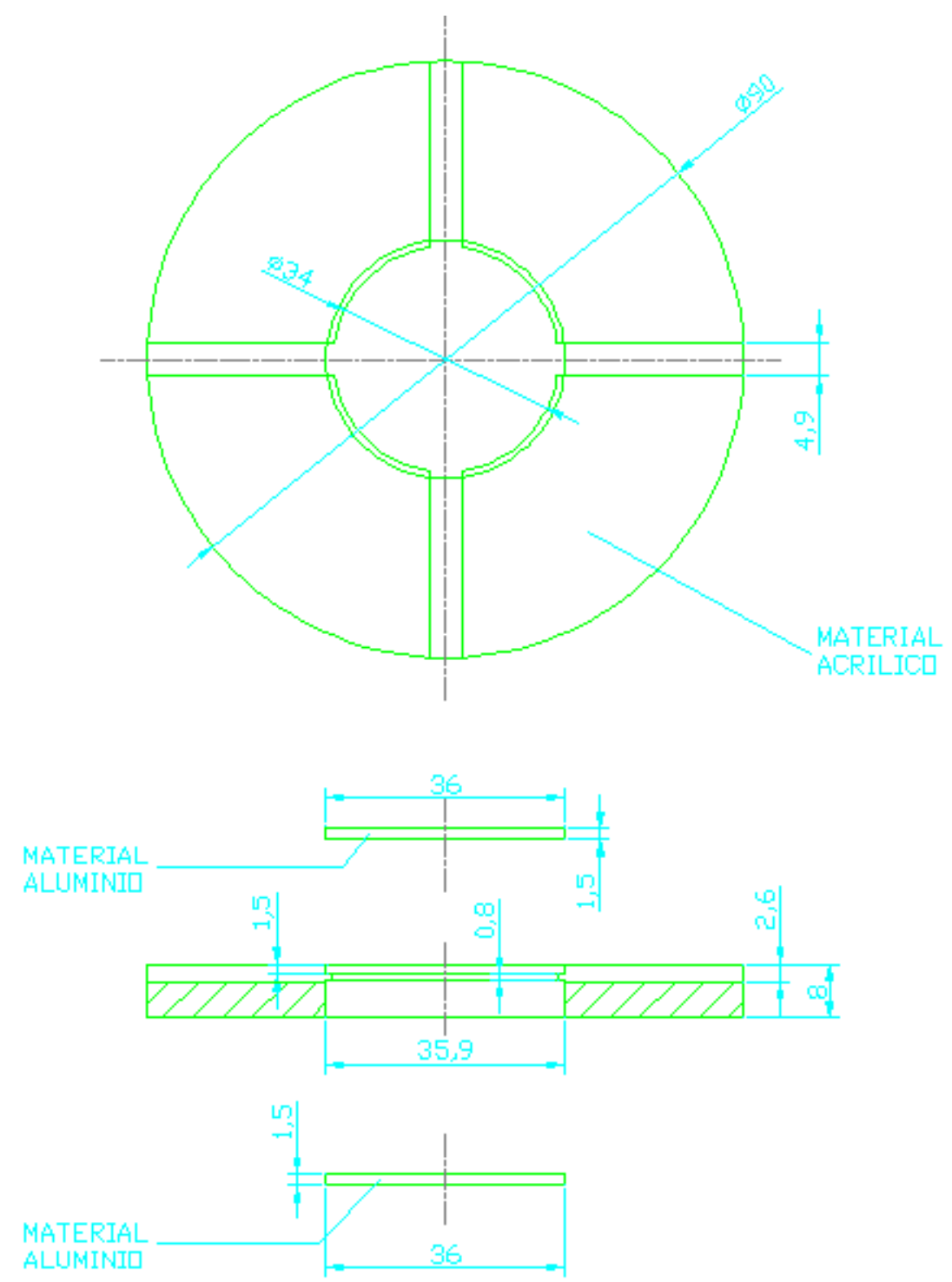

Figura 14 - Desenho da estrutura mecânica do capacitor para caracterização elétrica.

Em seguida, com a amostra curada entre os eletrodos, foram obtidas as curvas capacitância-tensão em alta freqüência (C-Vaf) de $1 \mathrm{MHz}$ do capacitor (c) e obtenção da constante dielétrica $\left(\mathrm{K}_{1}\right)$ do material, usando a Equação 2.2. A resistividade elétrica dos materiais foi medida por meio da Equação 2.4. As medidas C-V foram feitas com uso de iluminação ambiente visto que não foi necessário atenuar efeitos de luz no capacitor.

Como referências para determinação da constante dielétrica foram utilizadas as normas técnicas: ASTM D 150 e ASTM D 924 ${ }^{52}$. Para a determinação da resistividade elétrica foram utilizadas as normas: ASTM D 257 e ASTM D $1169^{53}$. 


\subsubsection{Ensaio Mecânico de Tração}

Os ensaios de tração foram realizados de acordo com a ASTM-D-638 ${ }^{54} \mathrm{em}$ máquina universal marca Kratos, modelo E20; com velocidade de deformação da garra de 1,0 mm/min, célula de carga de 50 Newton (N) sem o uso de extensômetro externo e com distância entre garras de $15 \mathrm{~mm}$. Esse ensaio tem a finalidade de verificar as propriedades de resistência à tração (omax), alongamento na ruptura $(\varepsilon)$ e módulo de elasticidade (E).

Na Figura 15 são apresentados os corpos de prova moldados, o que demonstra a facilidade de manuseio destes materiais em equipamentos convencionais de processamento de polímeros.

Figura 15 - Corpos de prova de ensaios de tração. 


\section{RESULTADOS E DISCUSSÃO}

Neste capítulo, serão discutidos os resultados de todas as análises realizadas com a matéria prima polimérica e os compósitos elastoméricos de titanato de bário obtidos por meio das técnicas descritas no capítulo anterior.

A discussão dos resultados mostrados está inserida no contexto de cada assunto tratado na revisão bibliográfica. Quando necessário, serão relacionados os dados de diversas análises durante a discussão, para melhor compressão dos resultados apresentados.

\subsection{Inchamento}

Inicialmente são apresentados os valores das medidas de densidade antes do inchamento da amostra P100 e dos compósitos. Como se pode observar na Figura 16, ocorreu significativa mudança na densidade dos materiais compósitos, uma tendência de aumento com a inclusão do titanato de bário é observada.

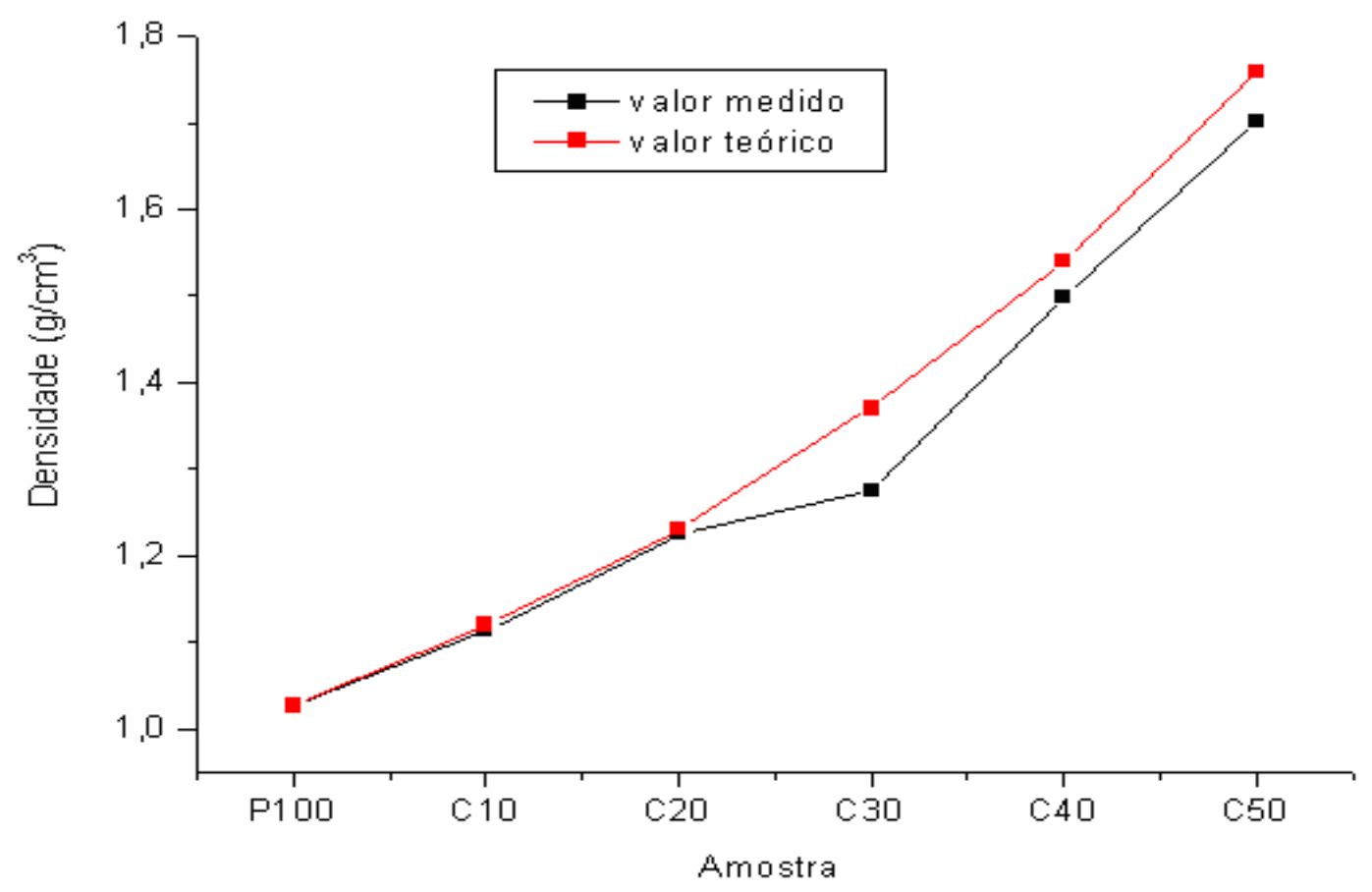

Figura 16 - Densidade de amostras não inchadas. 
Este resultado indica que a introdução do sólido particulado de titanato de bário na estrutura do polímero está afastando as cadeias, apesar do aumentando da densidade medida dos compósitos, os valores observados está abaixo da densidade teórica calculada, como apresentados na Tabela 7. Os valores de densidade teórica foram calculados usando a regra das misturas do polímero com o titanato de bário.

Tabela 7 - Medidas de densidades teórica e observada.

\begin{tabular}{|c|c|c|c|}
\hline Amostra & $\begin{array}{c}\text { Densidade } \\
\text { medida } \\
\left(\mathrm{g} / \mathrm{cm}^{3}\right)\end{array}$ & $\begin{array}{c}\text { Densidade } \\
\text { calculada } \\
(\text { teórica }) \\
\left(\mathrm{g} / \mathrm{cm}^{3}\right)\end{array}$ & $\begin{array}{c}\text { Desvio } \\
\text { Percentual } \\
(\%)\end{array}$ \\
\hline P100 & 1,026 & 1,026 & 0 \\
\hline C10 & 1,1122 & 1,12 & 0,6964 \\
\hline C20 & 1,2249 & 1,23 & 0,4146 \\
\hline C30 & 1,2749 & 1,37 & 6,9416 \\
\hline C40 & 1,4157 & 1,54 & 8,0714 \\
\hline C50 & 1,7011 & 1,76 & 3,3464 \\
\hline
\end{tabular}

Nas Tabelas 8 e 9 são apresentadas as medidas de densidade dos ensaios de inchamento no equilíbrio do polímero e dos compósitos para amostras inchadas por um período de 72 e 720 horas.

Tabela 8 - Medida de densidade $\left[\mathrm{g} / \mathrm{cm}^{3}\right]$ de amostras após 72 horas em diferentes solventes.

\begin{tabular}{|c|c|c|c|c|c|c|}
\hline Amostra & \multicolumn{7}{|c|}{ Solvente } \\
\hline & Xileno & Hexano & Acetona & Dimetilformamida & Tolueno & Clorofórmio \\
\hline P100 & 0,8623 & 0,7869 & 0,8868 & 0,9696 & 0,8385 & 1,1985 \\
\hline C10 & 0,8789 & 0,8267 & 0,8791 & 0,9318 & 0,8909 & 1,3421 \\
\hline C20 & 0,8958 & 0,8628 & 0,9237 & 1,0784 & 0,9153 & 1,1639 \\
\hline C30 & 0,9214 & 0,9042 & 0,9481 & 1,0955 & 0,9617 & 1,2405 \\
\hline C40 & 0,9410 & 0,9995 & 1,0118 & 1,1788 & 0,9419 & 1,318 \\
\hline C50 & 1,0748 & 1,1216 & 1,3257 & 1,2612 & 1,0355 & 1,439 \\
\hline
\end{tabular}


Tabela 9 - Medida de densidade $\left[\mathrm{g} / \mathrm{cm}^{3}\right]$ de amostras após 720 horas em diferentes solventes.

\begin{tabular}{|c|c|c|c|c|c|c|}
\hline Amostra & \multicolumn{6}{|c|}{ solventes } \\
\hline & Xileno & Hexano & Acetona & Dimetilformamida & Tolueno & Clorofórmio \\
\hline P100 & 0,8583 & 0,7484 & 0,8434 & 0,9544 & 0,8541 & 1,2278 \\
\hline C10 & 0,8709 & 0,7749 & 0,8357 & 0,9249 & 0,8859 & 1,1694 \\
\hline C20 & 0,8536 & 0,812 & 0,8713 & 1,0936 & 0,8766 & 1,0983 \\
\hline C30 & 0,8955 & 0,8242 & 0,9548 & 1,0742 & 0,9362 & 1,1572 \\
\hline C40 & 0,9096 & 0,8502 & 0,9012 & 1,3017 & 0,9915 & 0,9478 \\
\hline C50 & 0,9098 & 0,9888 & 0,7991 & 1,3382 & 1,0459 & 1,0896 \\
\hline
\end{tabular}

Por meio das Tabelas 8 e 9 é possível determinar o solvente no qual o inchamento foi máximo $\left(Q_{\max }\right)$, foi possível determinar o fator de inchamento $(\%)$ e o fator volumétrico de inchamento $\left(\mathrm{cm}^{3} / \mathrm{g}\right)$ e, conseqüentemente, o valor experimental do parâmetro de solubilidade do poli(éter-siloxano), por meio da parametrização das curvas de inchamento para diferentes solventes.

Uma análise dos resultados apresentados nas Tabelas 8 e 9 permite comprovar que ocorre a difusão do solvente para o interior da massa polimérica, ocasionando a separação das cadeias do emaranhado polimérico, de uma forma lenta que pode ser visualizada pelo inchamento da amostra, tornando-a inchada e com aspecto gelatinoso. Por meio das Figuras 17 e 18 é possível observar que existe uma diferença de miscibilidade entre a solução polímero-solvente devido à variação no fator percentual e volumétrico de inchamento do polímero e dos compósitos. 


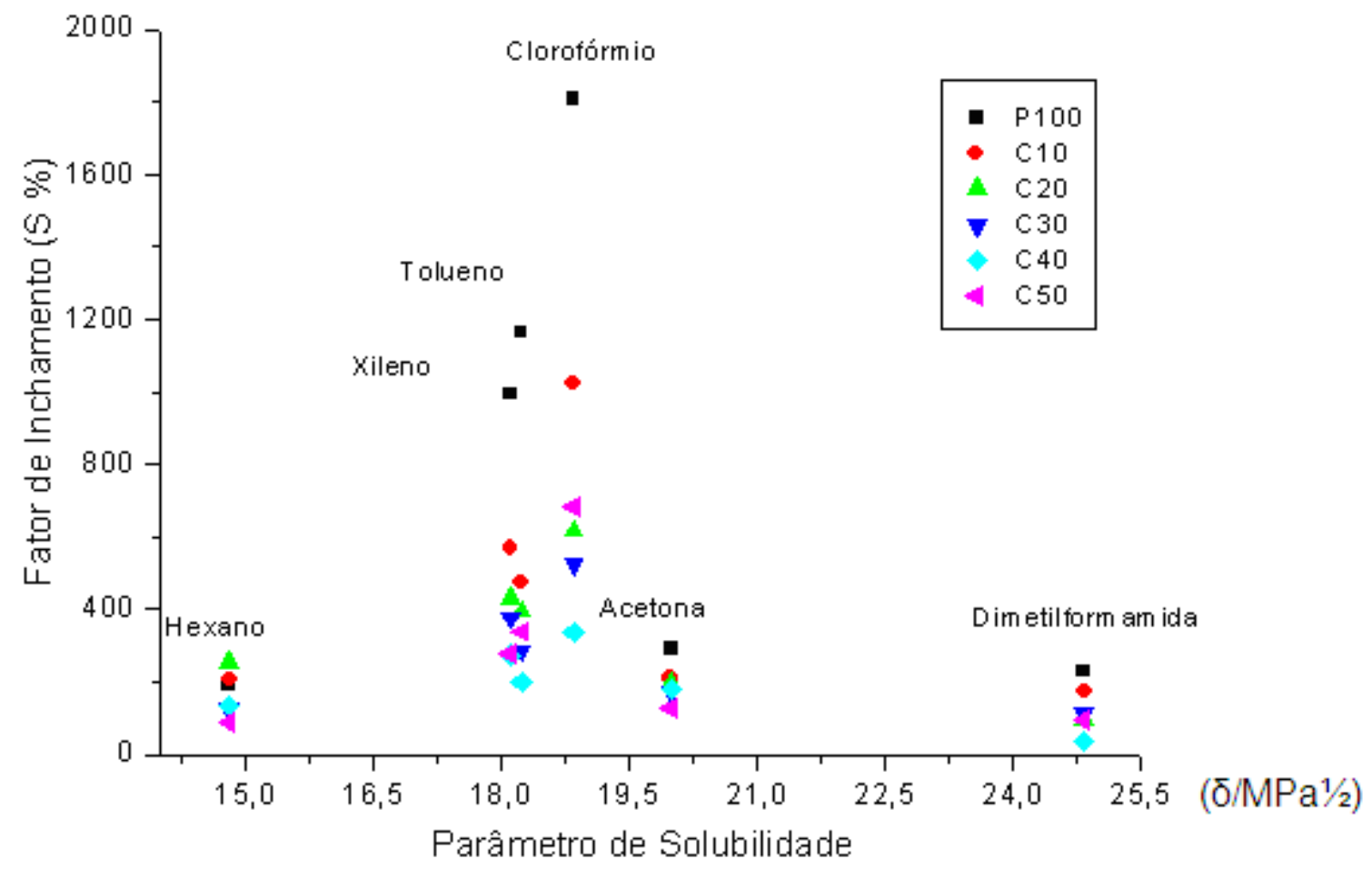

Figura 17 - Inchamento em diferentes solventes após 72 horas.

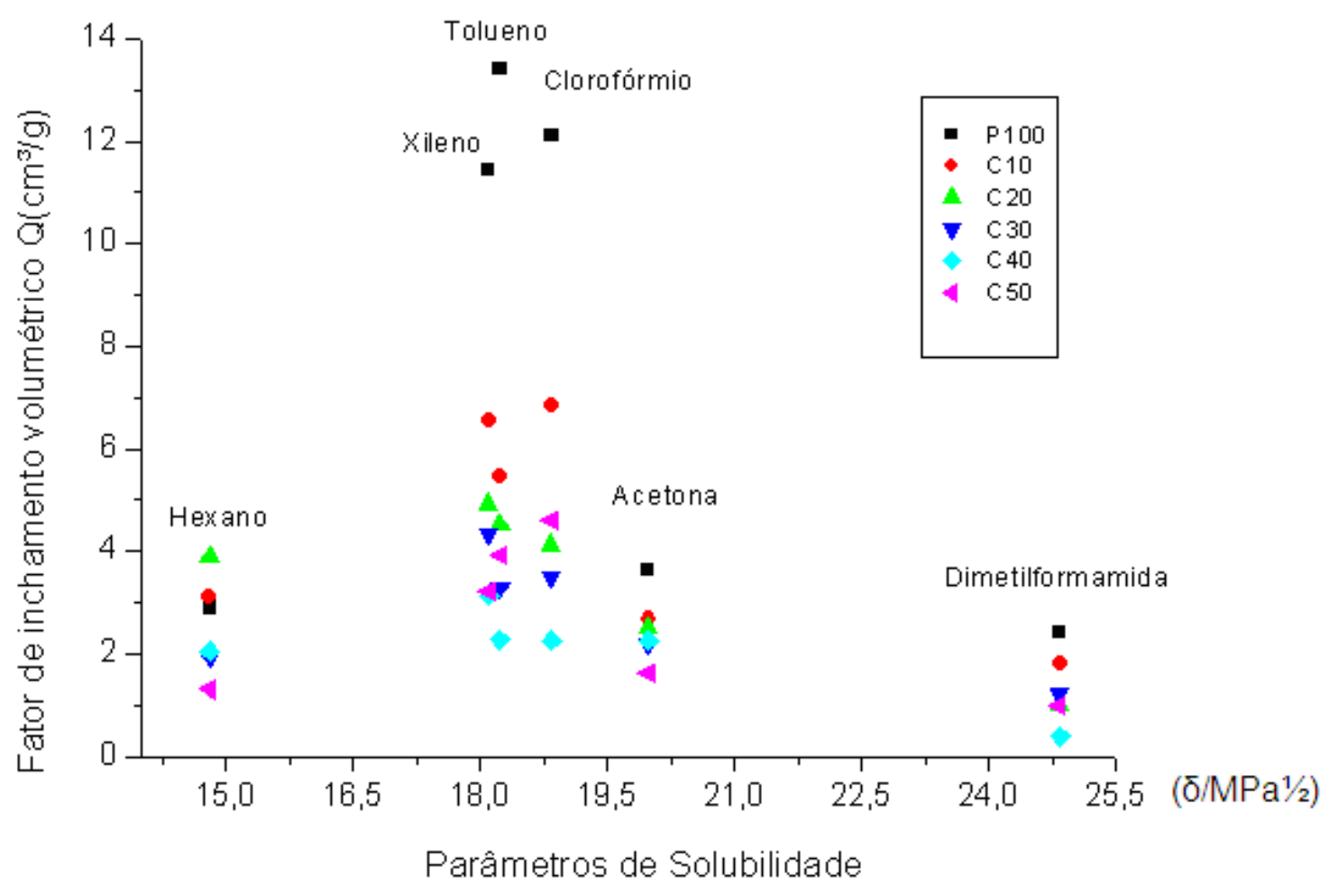

Figura 18 - Inchamento volumétrico em diferentes solventes após 72 horas. 
Nas Figuras 17 e 18 observa-se que existe um grau de inchamento percentual e volumétrico máximo para diferentes solventes, devido à miscibilidade termodinâmica entre o polímero e o solvente. Os gráficos de inchamento máximo, versus parâmetro de solubilidade [ס1] tornam possível a obtenção do valor de $\delta 2$, no ponto máximo, tendo sido determinado um valor de $18,65\left(\left(\delta / \mathrm{MPa}^{1} / 2\right)\right.$ para 0 polímero de poli(éter-siloxano).

A partir dos dados de inchamento no equilíbrio, a densidade de ligações cruzadas $(v)$ e o correspondente peso molecular médio entre os pontos de entrecruzamento ( $\overline{\mathrm{M}} \mathrm{c}$ ) puderam ser calculados, com a aplicação da Equação de Flory-Rehner. (Equação 2.9). Nas Tabelas 10 e 11 são apresentados os dados obtidos nos ensaios de inchamento, desde o volume reduzido ( $\mathrm{Vr}$ ) das amostras até a determinação de $\overline{\mathrm{M}}$ c, para os polímeros preparados com diferentes concentrações de carga.

Tabela 10 - Resultados calculados pela Equação de Flory-Rehner após 72 horas de inchamento.

\begin{tabular}{|c|c|c|c|c|c|c|c|}
\hline & Solvente & \multicolumn{5}{c|}{ Densidade de Ligações Cruzadas $(v)^{*}$} \\
\hline & $\begin{array}{c}\text { Parâmetro de } \\
\text { Sol.((ס/MPa } 1 / 2)\end{array}$ & P100 & C10 & C20 & C30 & C40 & C50 \\
\hline Xileno & 18,1000 & 0,0005 & 0,0245 & 0,0007 & 0,0008 & 0,0009 & 0,0009 \\
\hline Hexano & 14,8100 & 0,0278 & 0,0499 & 0,0191 & 0,0285 & 0,0342 & 0,0309 \\
\hline Acetona & 19,9800 & 0,0111 & 0,0300 & 0,0122 & 0,0128 & 0,0159 & 0,0149 \\
\hline Dimetilformamida & 24,8300 & 0,0472 & 0,0131 & 0,0682 & 0,0588 & 0,1200 & 0,0560 \\
\hline Tolueno & 18,2300 & 0,0001 & 0,0275 & 0,0002 & 0,0002 & 0,0005 & 0,0001 \\
\hline Clorofórmio & 18,8400 & 0,0008 & 0,0222 & 0,0018 & 0,0020 & 0,0037 & 0,0020 \\
\hline
\end{tabular}


Tabela 11 - Resultados calculados pela Equação de Flory-Rehner após 720 horas de inchamento.

\begin{tabular}{|c|c|c|c|c|c|c|c|}
\hline \multirow{2}{*}{ Solvente } & \multicolumn{5}{|c|}{ Densidade de Ligações Cruzadas $(v)^{*}$} \\
\hline & $\begin{array}{c}\text { Parâmetro de } \\
\text { Sol.((ס/MPa } 1 / 2)\end{array}$ & P100 & C10 & C20 & C30 & C40 & C50 \\
\hline Xileno & 18,1000 & 0,0003 & 0,0236 & 0,0004 & 0,0006 & 0,0006 & 0,0007 \\
\hline Hexano & 14,8100 & 0,0182 & 0,0329 & 0,0072 & 0,0183 & 0,0155 & 0,0144 \\
\hline Acetona & 19,9800 & 0,0079 & 0,0344 & 0,0078 & 0,0123 & 0,0072 & 0,0121 \\
\hline Dimetilformamida & 24,8300 & 0,0467 & 0,0112 & 0,0805 & 0,0547 & 0,0831 & 0,1020 \\
\hline Tolueno & 18,2300 & 0,0001 & 0,0274 & 0,0002 & 0,0002 & 0,0002 & 0,0010 \\
\hline Clorofórmio & 18,8400 & 0,0006 & 0,0255 & 0,0012 & 0,0016 & 0,0018 & 0,0023 \\
\hline
\end{tabular}

* $(\bar{M} c)=1 / u$ onde 0 peso molecular médio entre pontos de cruzamento é inversamente proporcional à densidade de ligações cruzadas.

Sabe-se que a interação entre polímero-solvente é diferente para cada amostra, devido as diferentes interações físicas entre os solventes e o polímero e os compósitos, ocasionado pela variação das densidades de ligações cruzadas. Os resultados dos ensaios representam um valor médio da contribuição de cada um das componentes espaciais, que constitui outra possibilidade para a separação das contribuições dos diferentes domínios.

\subsection{Microscopia Eletrônica de Varredura}

Na Figura 19 é apresentada a micrografia do particulado de titanato de bário sem nenhum prévio tratamento. Como esperado, observa-se que o particulado tem formato de esferas, mas o tamanho médio de partículas supera o que é divulgado pelo fabricante, sendo em torno de $5 \mu \mathrm{m}$, esse fato pode ser ocasionado à agregação das nanopartículas e à dispersão desuniforme do nanomaterial na matriz polimérica. 


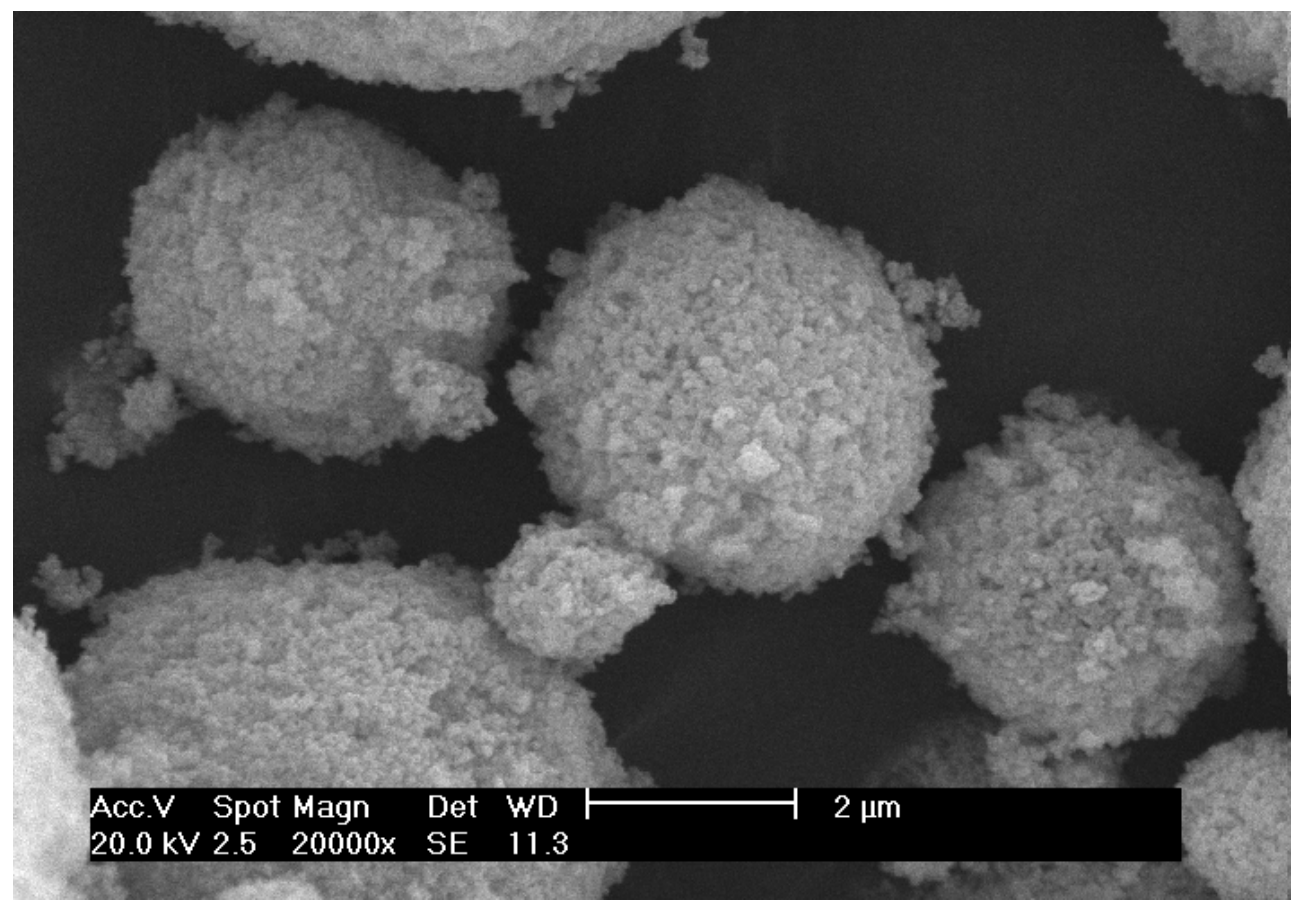

Figura 19 - Microscopia eletrônica de varredura da amostra de titanato de bário, aumento 20000 vezes.

As alterações significativas do tamanho do particulado têm como principais influências as forças de atração eletrostática, à medida que as dimensões dos corpos diminuem, alguns efeitos tornam-se mais importantes, nanoparticulados em escala nanométrica possuem efeito predominante de forças eletrostáticas, que é confirmada pela literatura ${ }^{22}$.

Como pode ser também observada por meio da micrografia da Figura 20, 0 particulado de titanato de bário é formado por aglomerados de partículas menores. A provável diminuição da área de superficie do nanoparticulado provoca uma diminuição significativa das propriedades, que estão diretamente ligadas a efeitos predominantes acima citados e dificultam a dispersão do particulado. 


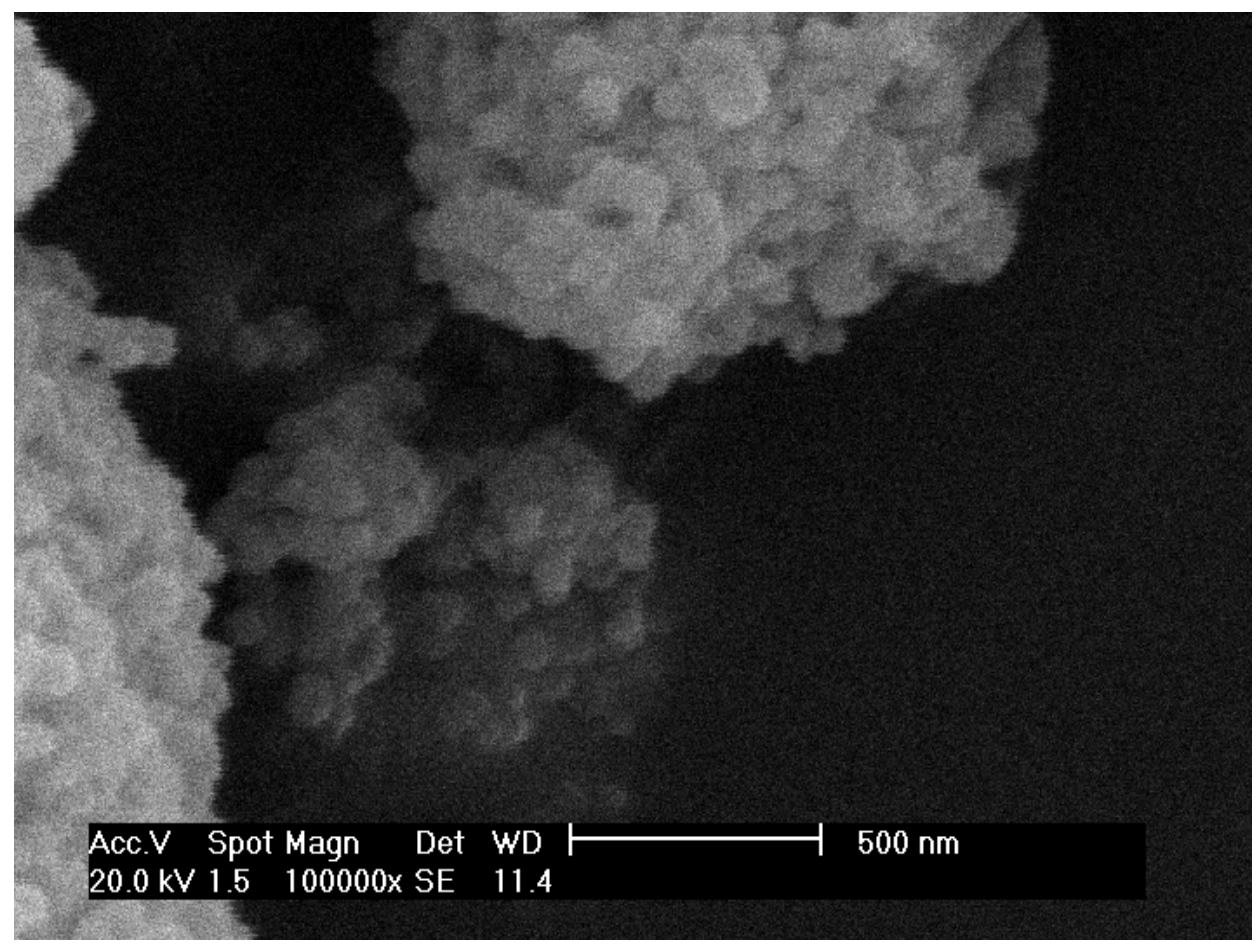

Figura 20 - Microscopia eletrônica de varredura da amostra de titanato de bário.

Na Figura 21, na amostra P100 do polímero puro pode ser observado um destacamento superficial do material com uma orientação preferencial, fenômeno esse promovido pelo cisalhamento criogênico do material apresentando, portanto uma fase única bem definida.

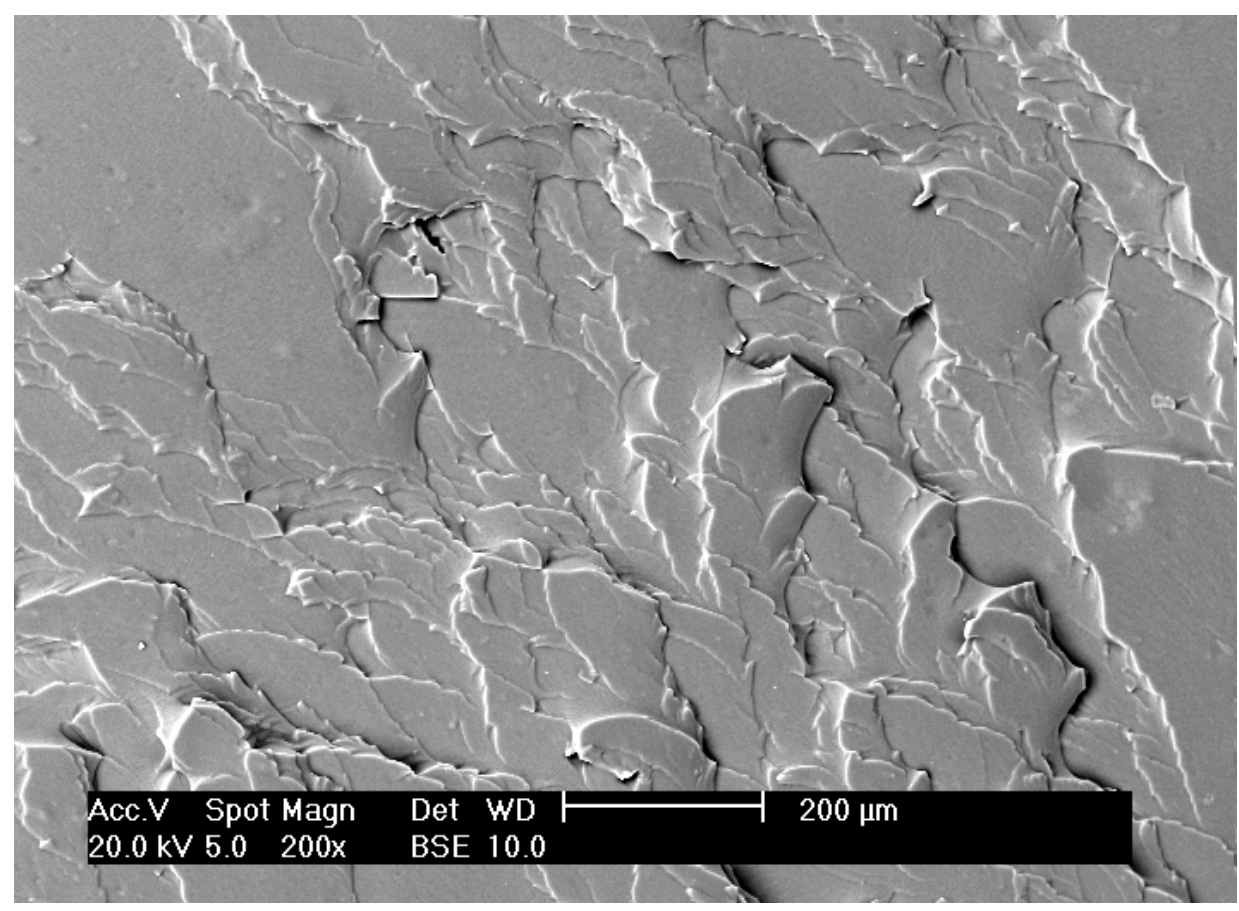

Figura 21 - Microscopia eletrônica de varredura da amostra P100. 
Por meio da micrografia das amostras C10, C20, C30, C40 e C50 podem ser observadas a dispersão do material particulado na matriz polimérica bem como a presença de fases distintas e respectiva interface entre elas. As Figuras 22 a 26 ilustram as micrografias e dispersão do particulado de titanato de bário para diferentes concentrações.

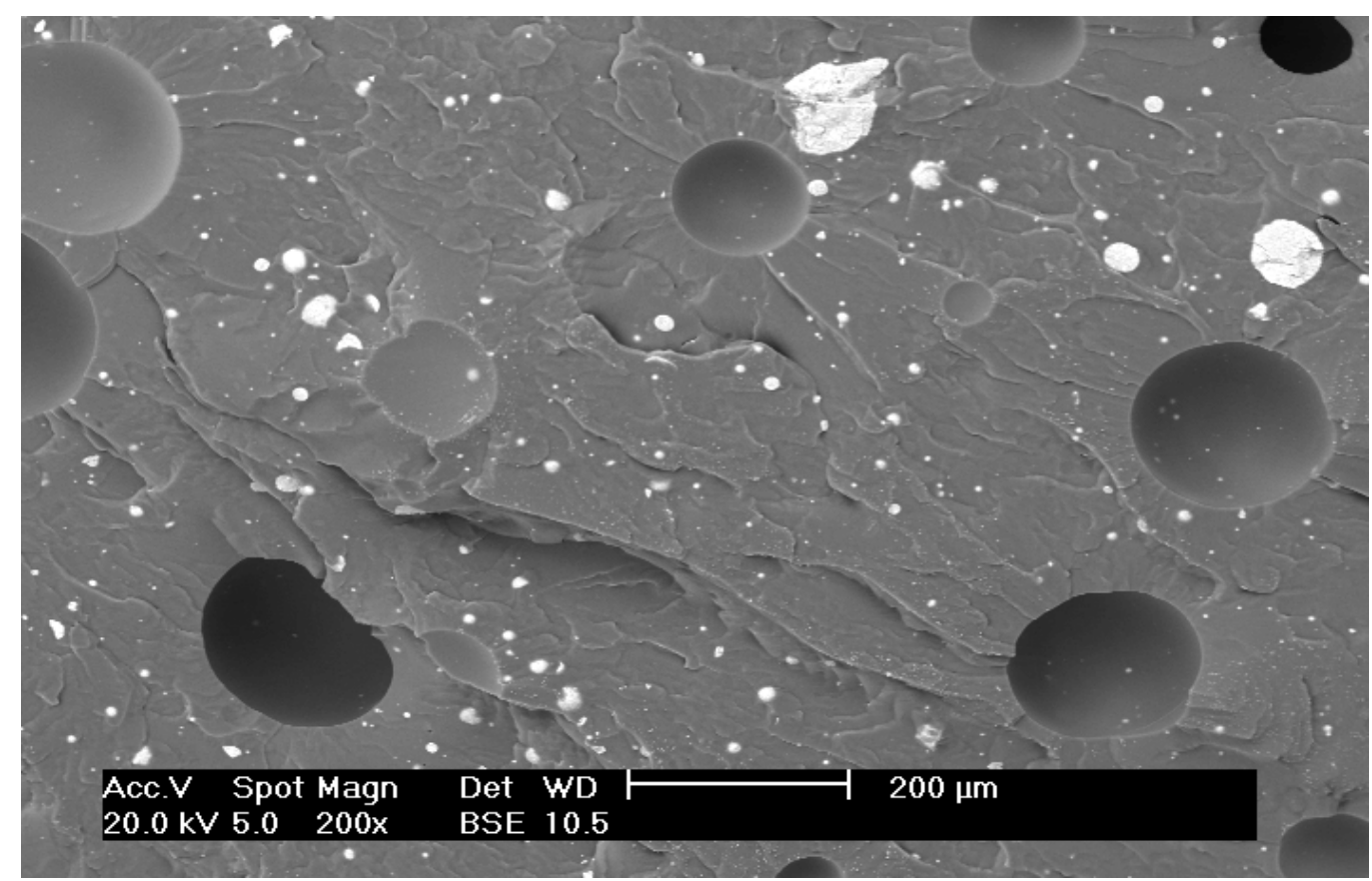

Figura 22 - Microscopia eletrônica de varredura da amostra C10.

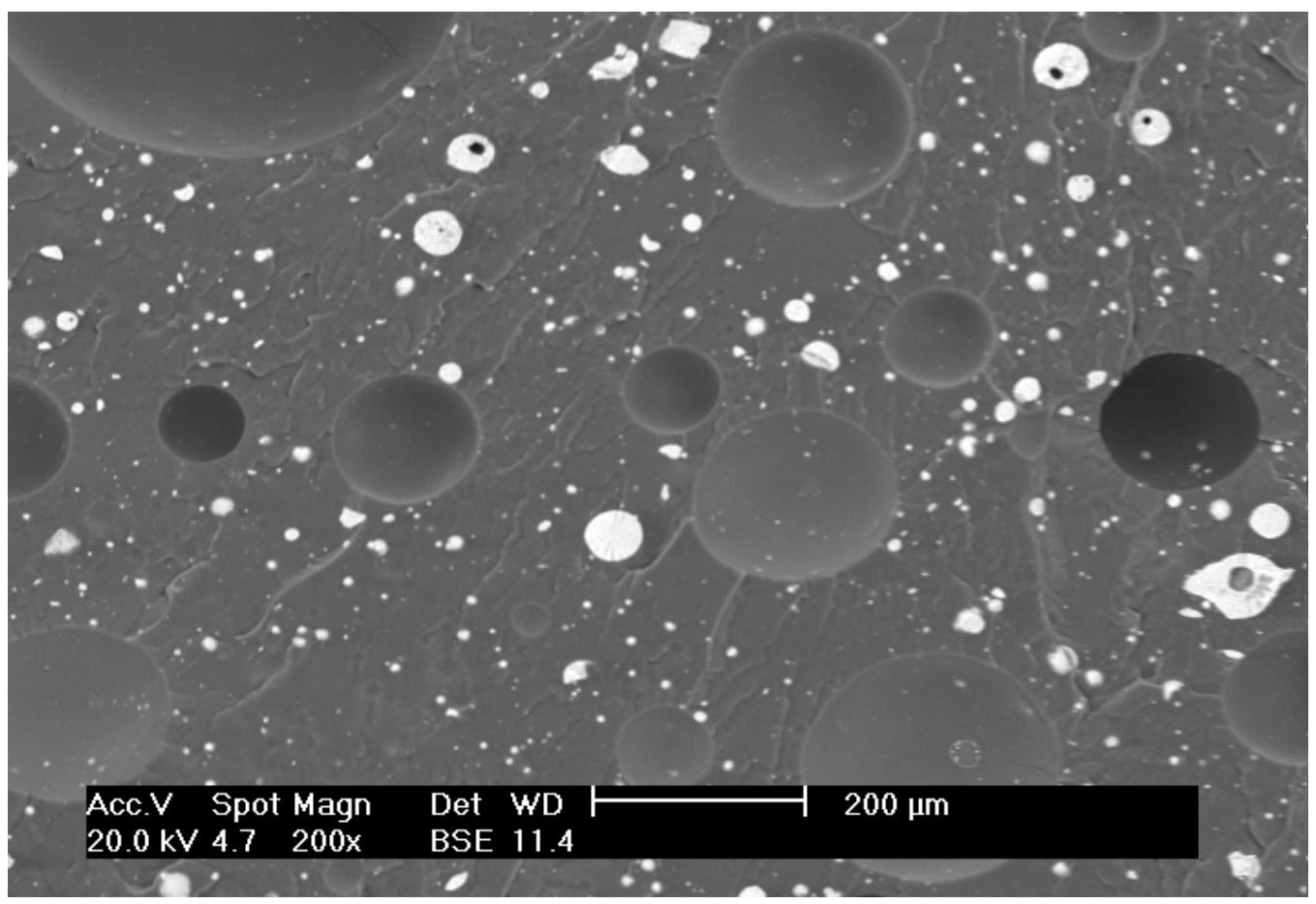

Figura 23 - Microscopia eletrônica de varredura da amostra C20. 


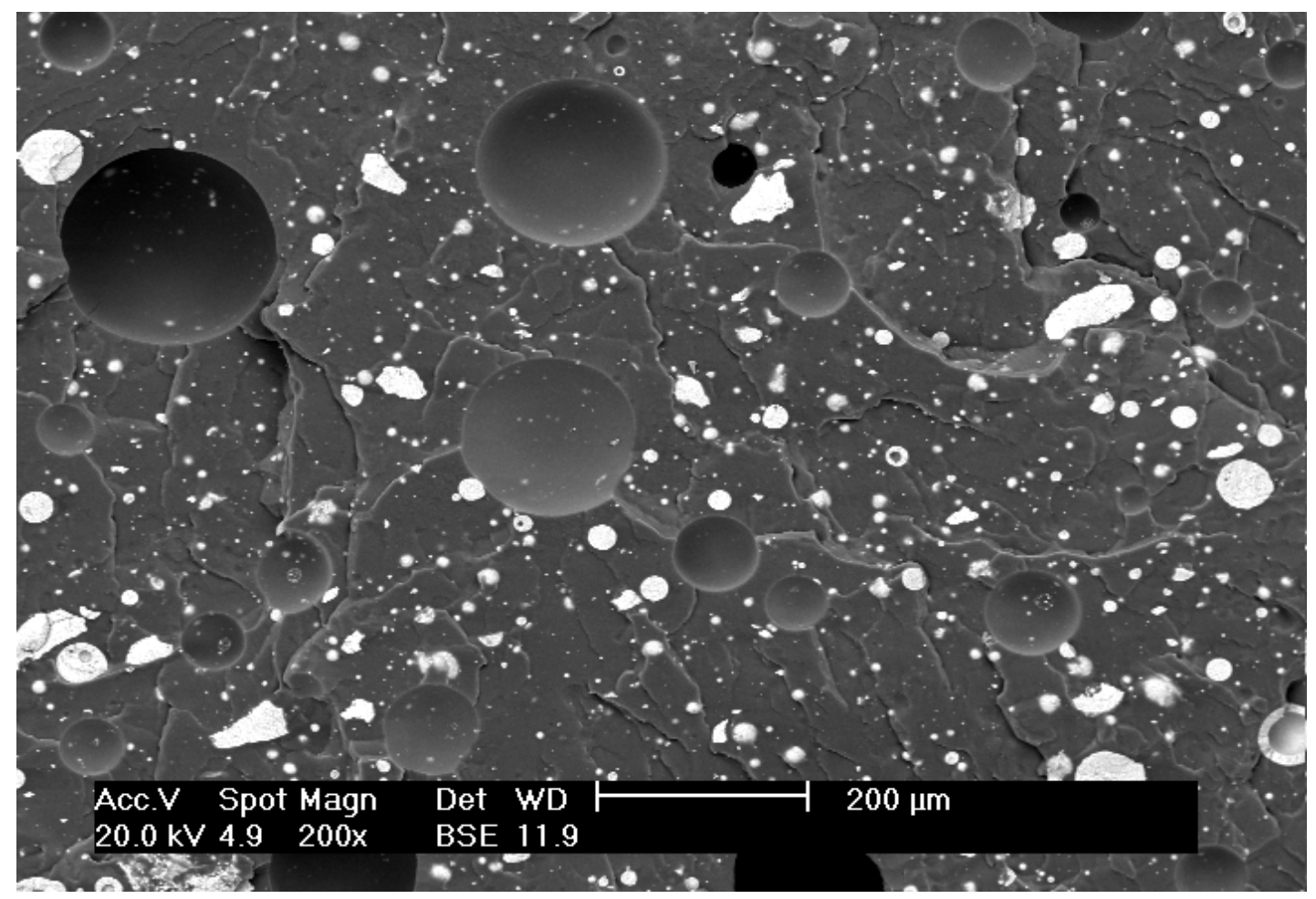

Figura 24 - Microscopia eletrônica de varredura da amostra C30.

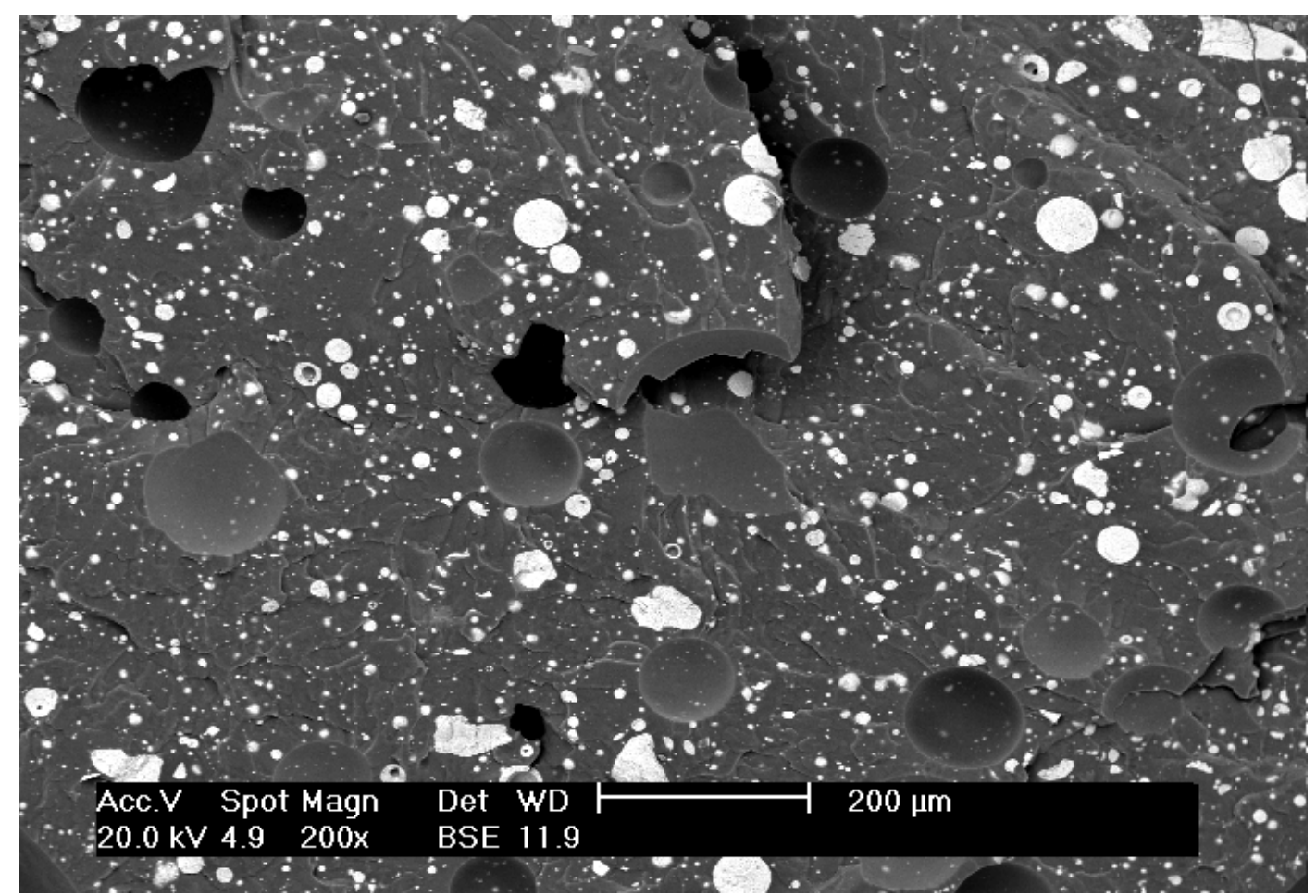

Figura 25 - Microscopia eletrônica de varredura da amostra C40. 


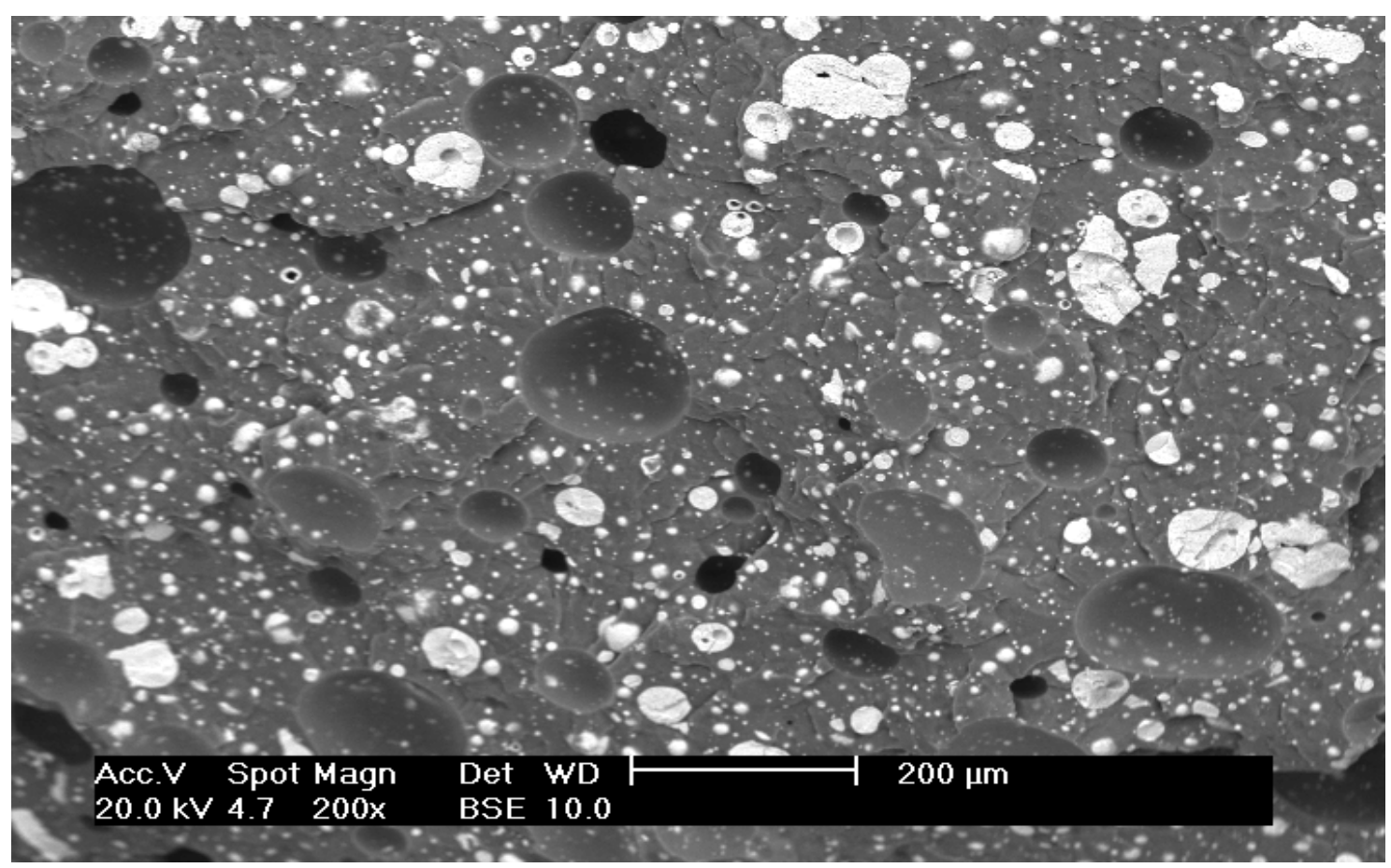

Figura 26 - Microscopia eletrônica de varredura da amostra C50.

Nestas imagens dos compósitos podem ser notadas a presença de bolhas e a ausência de "escamas" na superfície do compósito, esse fato pode ser explicado pelo comportamento dúctil da amostra de polímero puro e do comportamento frágil do material compósito na presença do sólido particulado na rede polimérica. As cadeias do polímero na presença do particulado são suscetíveis à reação de substituição, possibilitando a ruptura de ligações e, consequente, liberação de álcoois (subproduto da reação de reticulação), resultando na presença de bolhas no interior da matriz polimérica.

Na Figura 27, o compósito mostra alto grau de interação ou adesão entre as fases constituintes do compósito particulado-interface-matriz. 


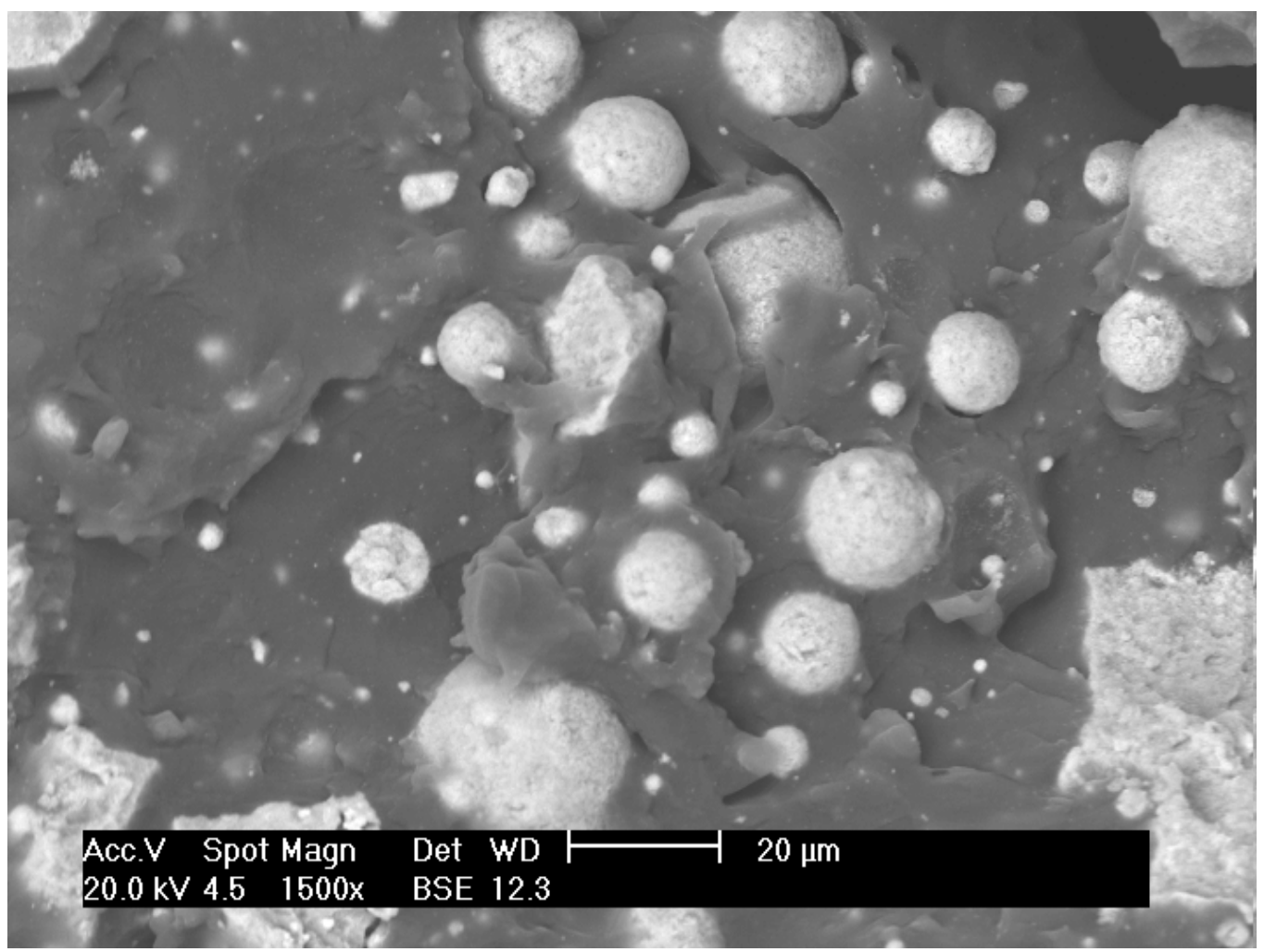

Figura 27 - Microscopia eletrônica de varredura da amostra C50, aumento 1500 vezes.

Por meio do equipamento de EDX (energy dispersive $x$-ray) acoplado ao microscópio eletrônico de varredura foi também possível fazer uma análise por espectroscopia por dispersão de energia de raio $\mathrm{x}$, com a finalidade de obter uma análise quantitativa e qualitativa dos materiais presentes nas amostras e a identificação dos particulados.

O uso em conjunto do EDX associado ao MEV foi de grande importância na caracterização dos compósitos, enquanto o MEV gerava nítidas imagens o EDX permitia imediata identificação das fases presentes; o limite de detecção foi da ordem de $1 \%$, mas pode variar de acordo as especificações utilizadas durante a análise, como o tempo de contagem, por exemplo. Tendo também como principal limitação o número atômico $(Z)$, pois apenas os elementos com número atômico superior a 4 são detectados e quantificados por essa técnica.

Para realização das análises por EDX foram utilizadas as mesmas amostras do MEV apresentadas anteriormente, com a finalidade de obter precisão nas medidas foram utilizadas também as mesmas áreas de varredura das imagens para 
todas as amostras. A análise da composição química e estequiométrica da amostras de titanato de bário é apresentada na Figura 28.

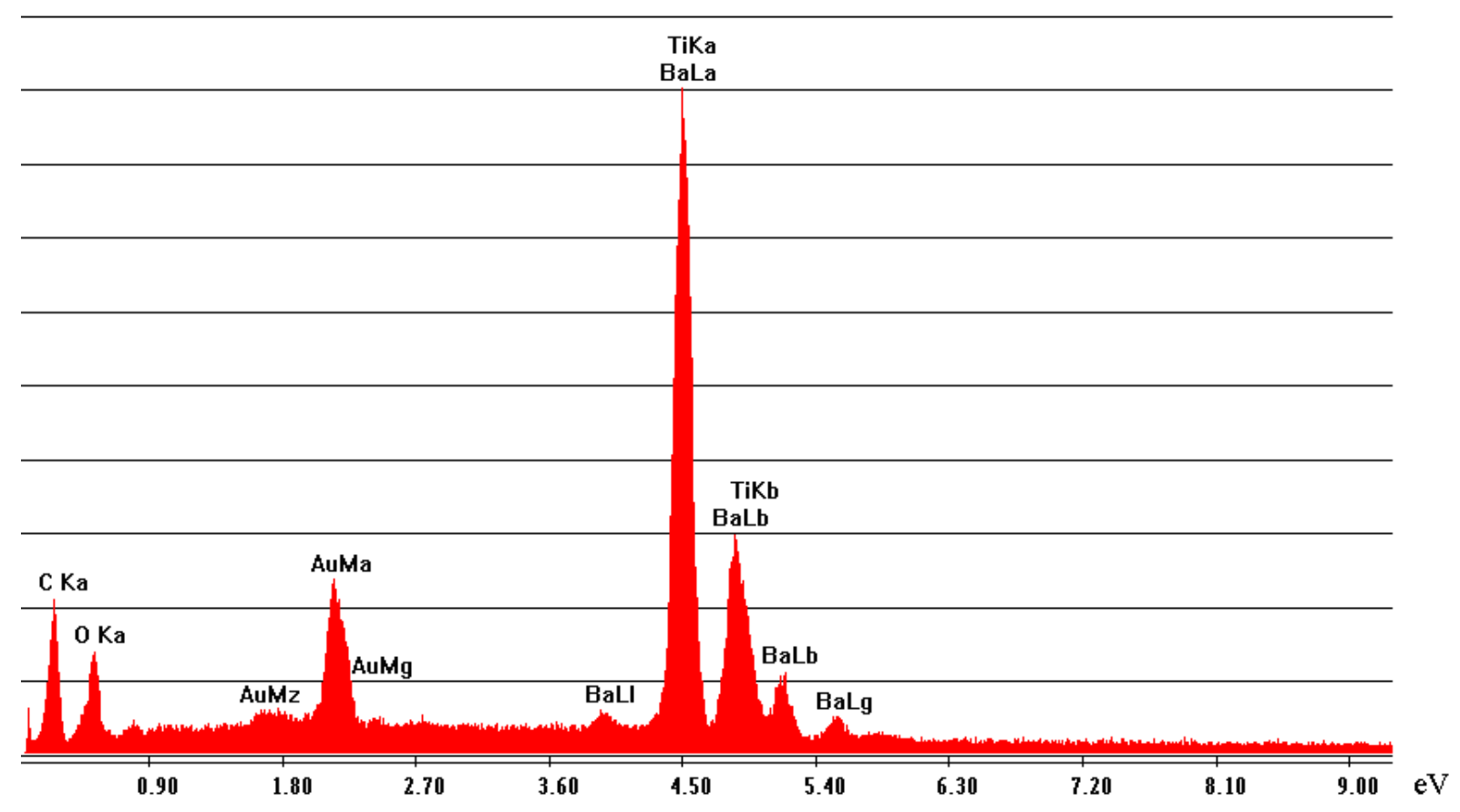

Figura 28 - EDX da amostra de titanato de bário.

A análise de EDX da amostra de titanato de bário apresentou picos de carbono e oxigênio presentes na fita adesiva condutora usada na fixação do particulado para analise. As Figuras 29 - 34 mostram o mapeamento elementar com a finalidade de determinar as concentrações presentes, detectar as impurezas e confirmar as espécies das misturas do nanocompósito. 


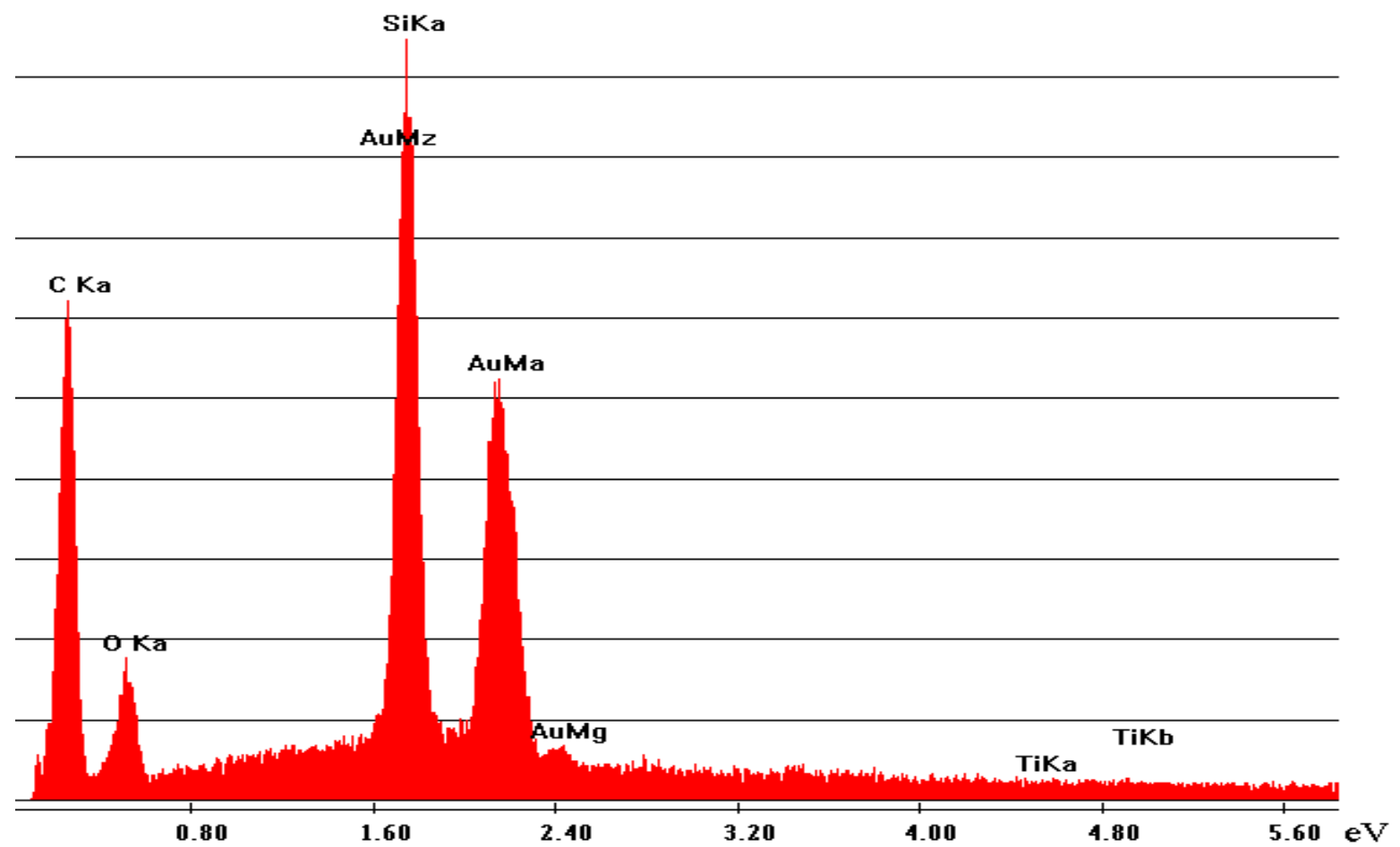

Figura 29 - EDX da amostra P100.

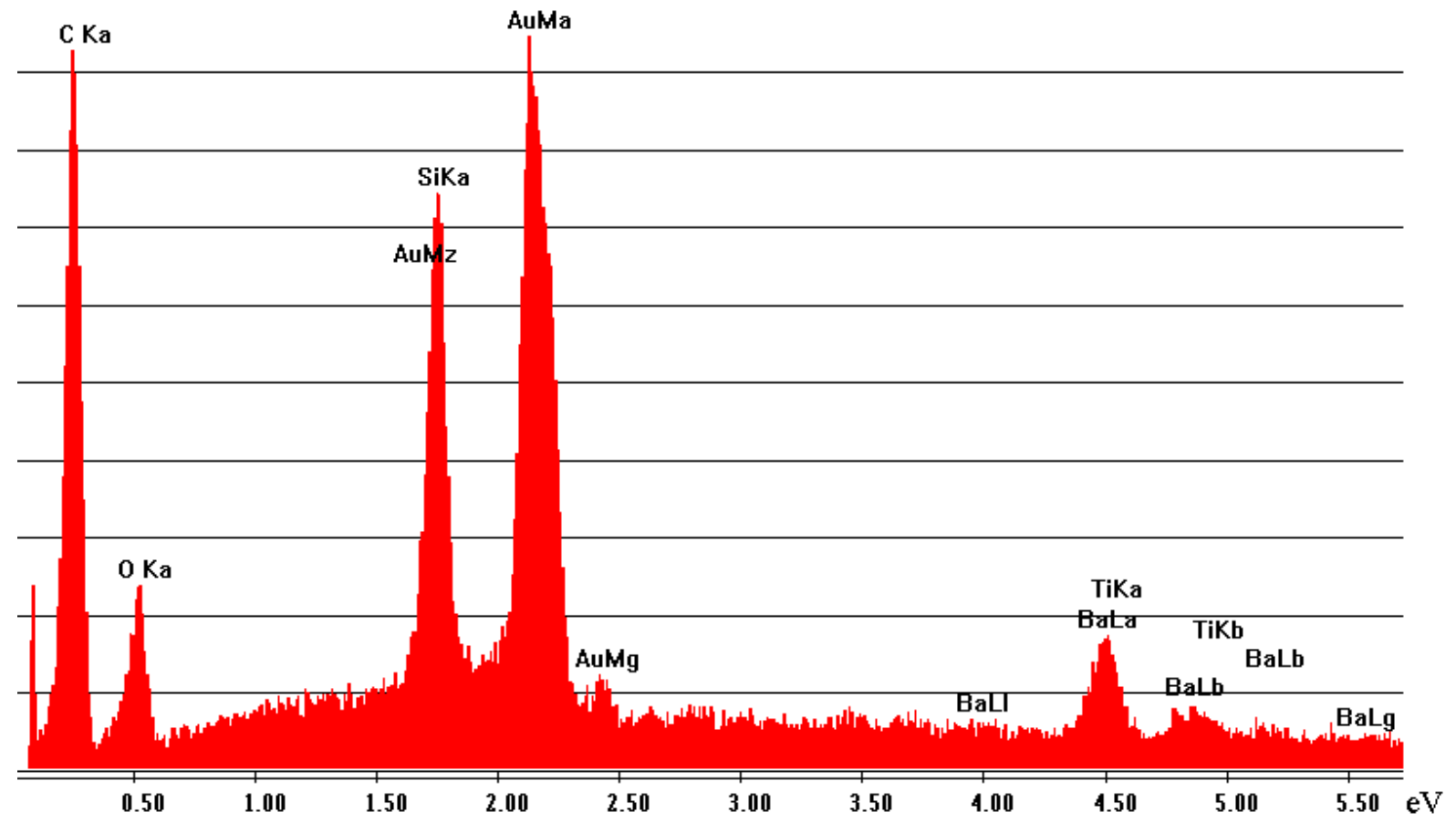

Figura 30 - EDX da amostra C10. 


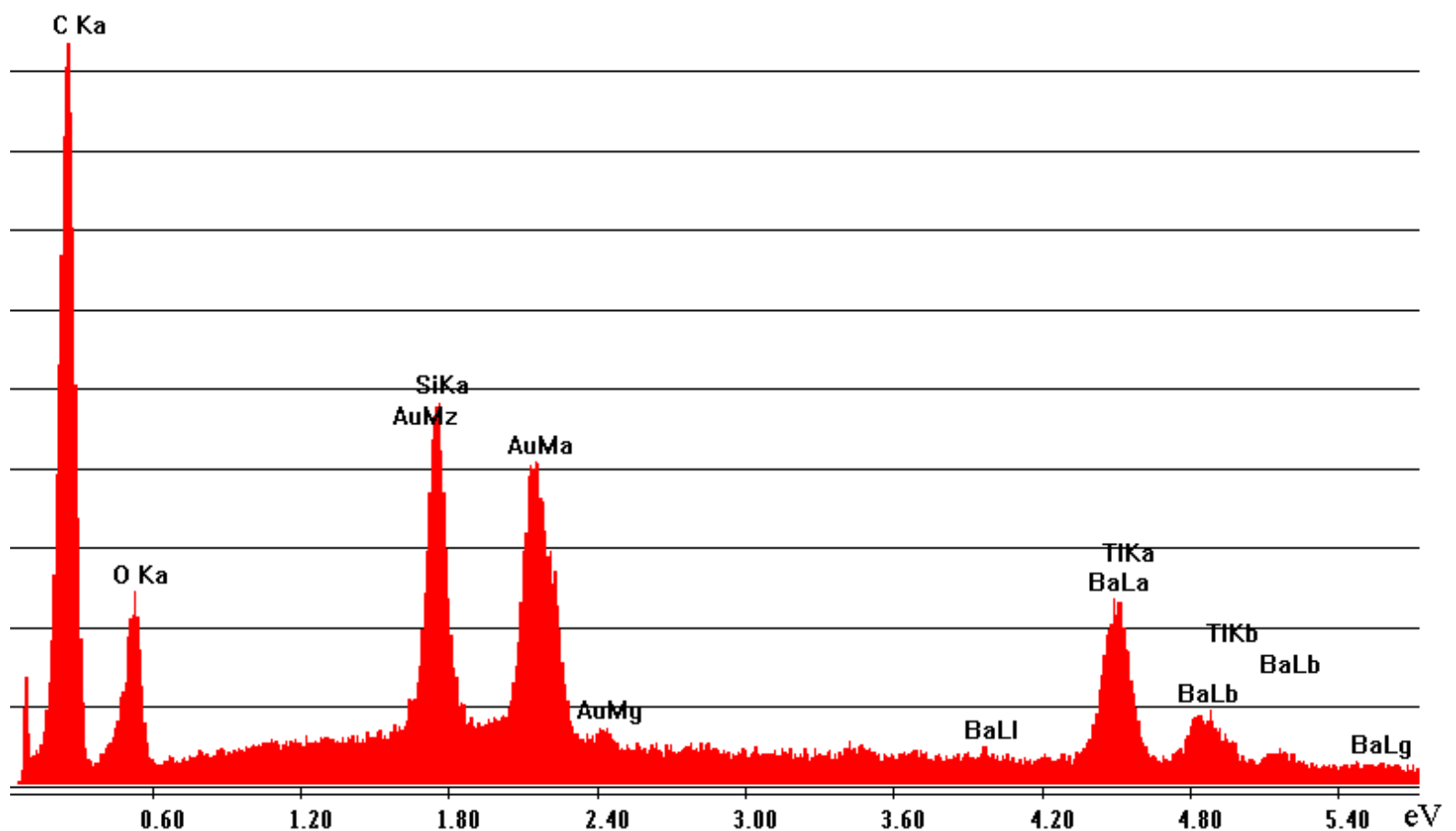

Figura 31 - EDX da amostra C20.

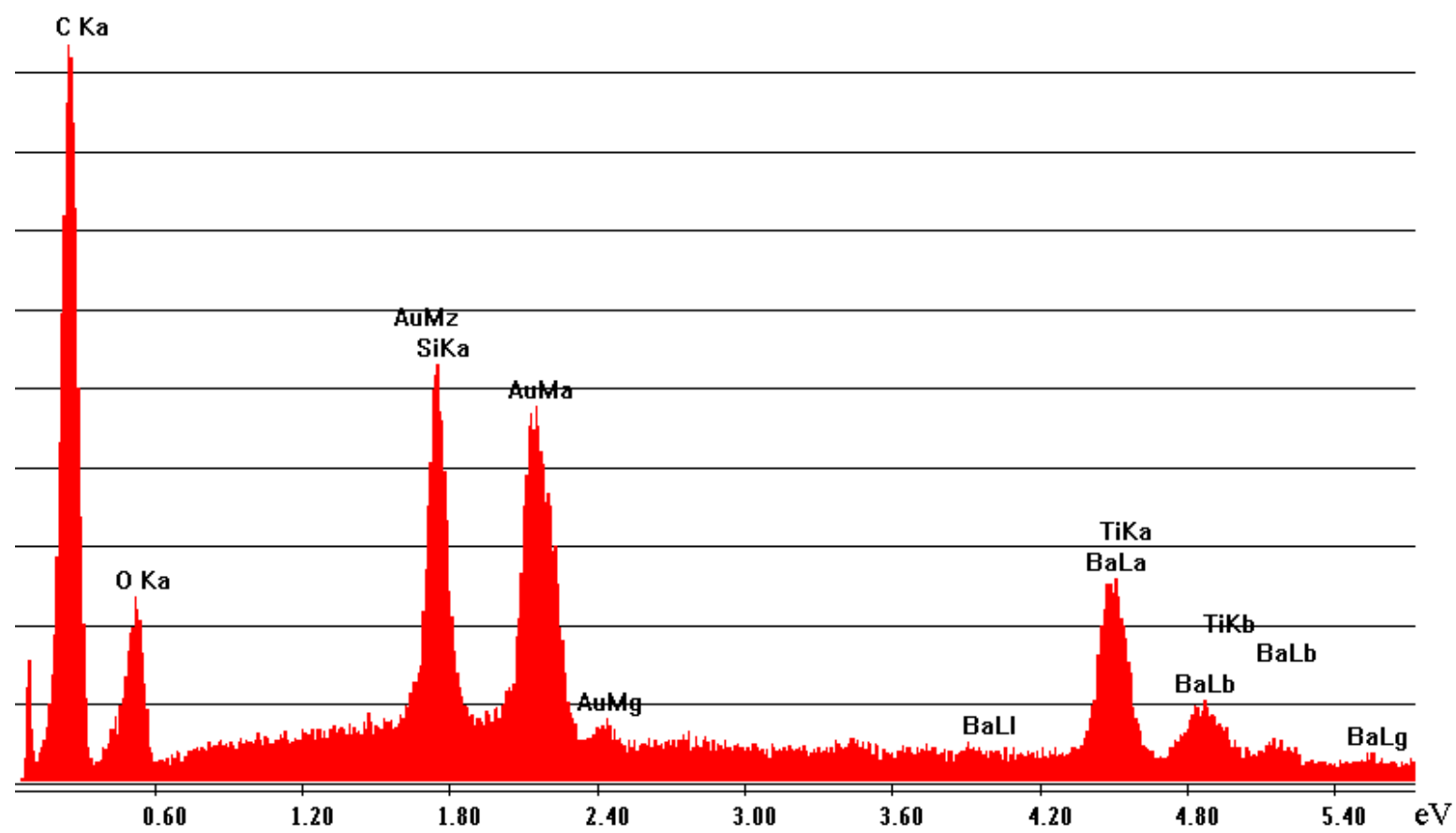

Figura 32 - EDX da amostra C30. 


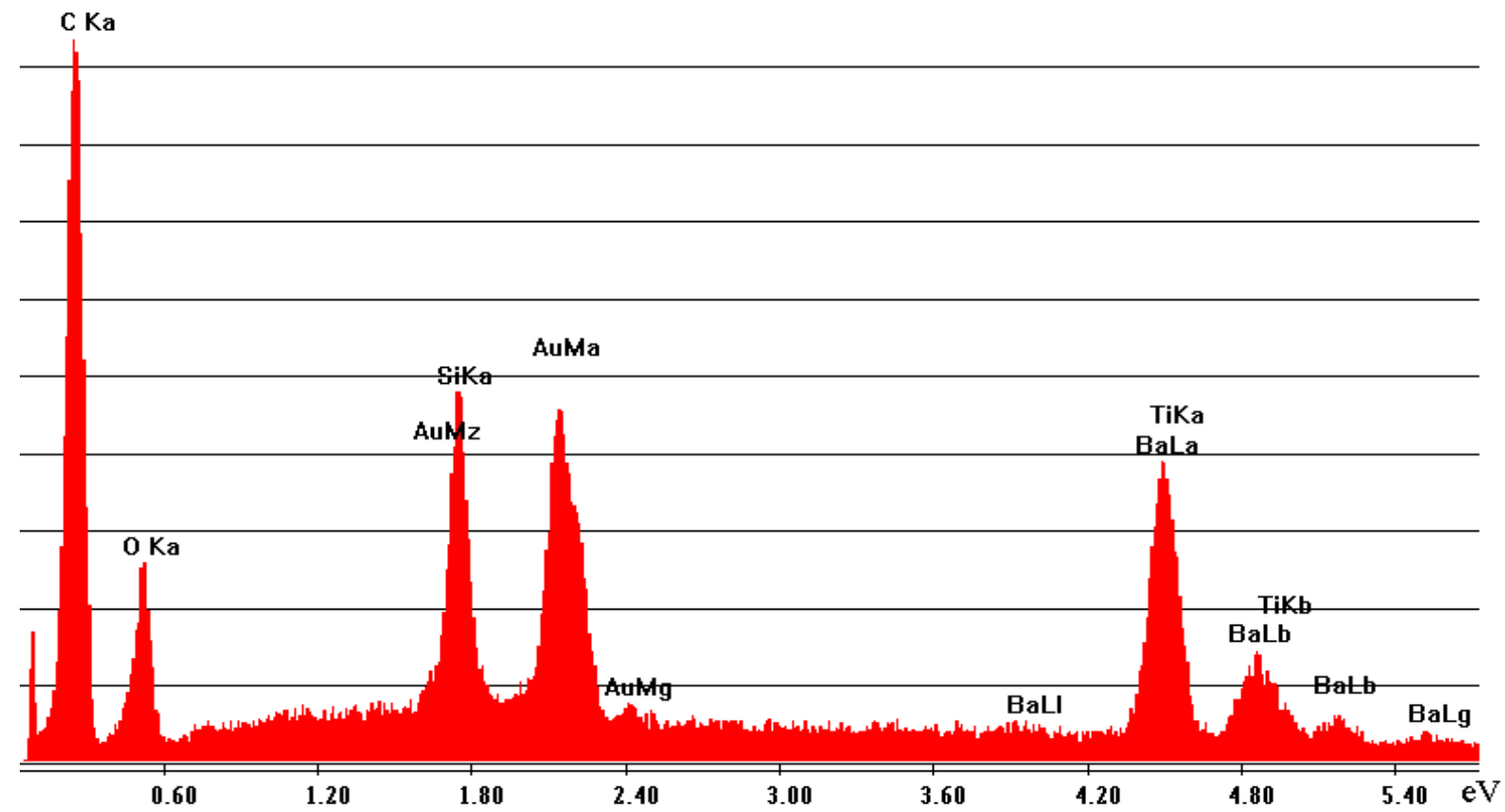

Figura 33 - EDX da amostra C40.

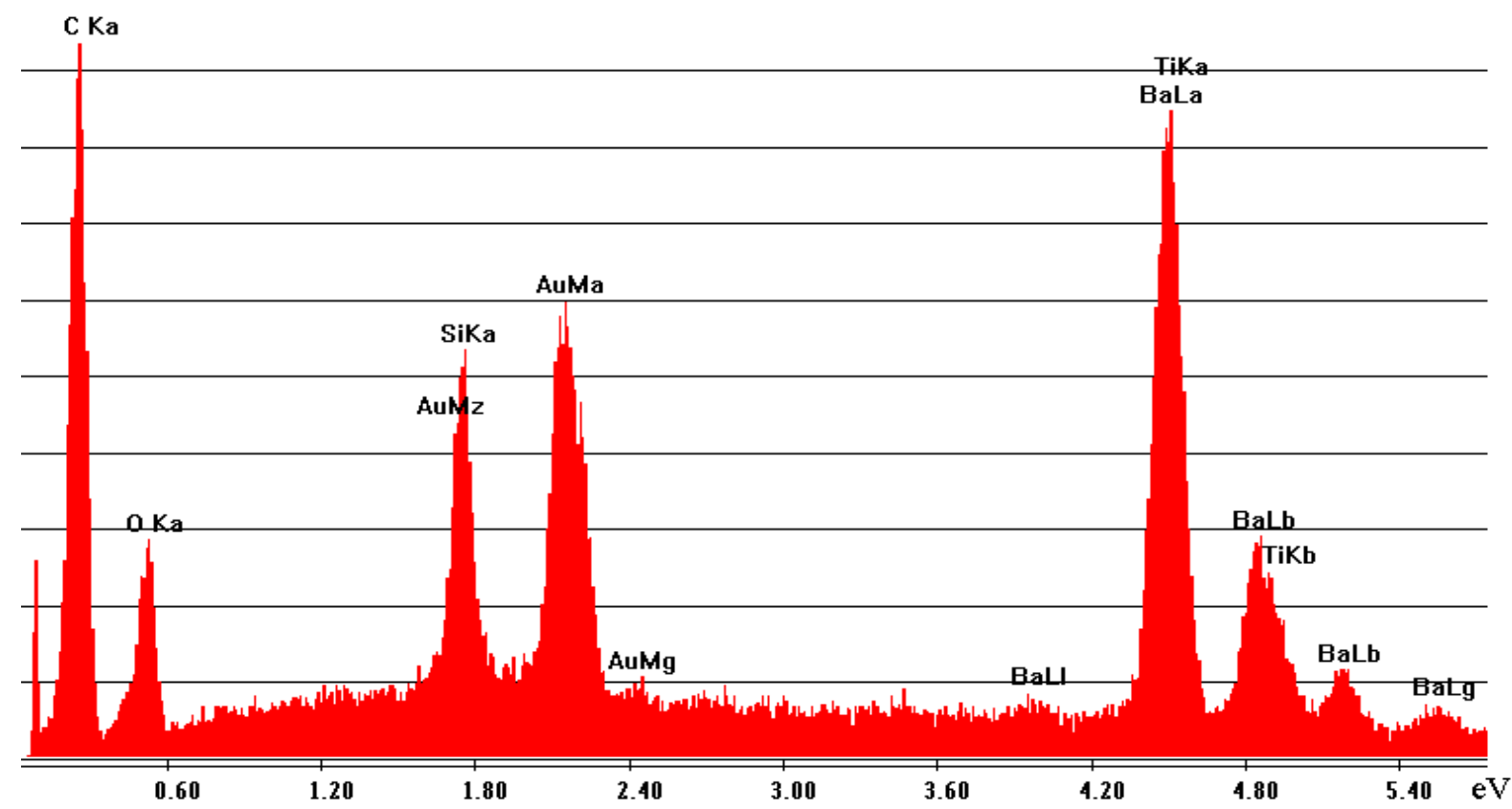

Figura 34 - EDX da amostra C50.

Por meio das análises de EDX foi possível identificar a natureza dos elementos constituintes agregados. Na Tabela 12 é apresentada a análise quantitativa e qualitativa dos polímeros e compósitos sem os picos de energia do elemento ouro presente no recobrimento. Os resultados comprovam não apenas os 
elementos presentes, mas também que as concentrações apresentam valores crescentes próximos dos adicionados.

Tabela 12 - Análise quantitativa e qualitativa do polímero e compósitos sem recobrimento de ouro.

\begin{tabular}{|c|c|c|c|c|c|c|c|}
\hline Elemento & \multicolumn{7}{|c|}{ Amostras } \\
\hline & $\mathrm{BaTiO}_{3}$ & $\mathrm{P} 100$ & $\mathrm{C} 10$ & $\mathrm{C} 20$ & $\mathrm{C} 30$ & $\mathrm{C} 40$ & $\mathrm{C} 50$ \\
\hline $\mathrm{C}$ & 0,78 & 73,22 & 68,29 & 63,42 & 44,32 & 56,82 & 40,43 \\
\hline $\mathrm{O}$ & 8,61 & 15,65 & 14,50 & 14,01 & 7,49 & 11,41 & 8,60 \\
\hline $\mathrm{Si}$ & 0,05 & 9,53 & 8,86 & 7,21 & 10,26 & 7,33 & 4,38 \\
\hline $\mathrm{Sn}$ & 0,15 & 1,31 & 1,44 & 1,21 & 2,10 & 0,73 & 0,85 \\
\hline $\mathrm{Ca}$ & 0,02 & 0,10 & 0,28 & 0,11 & 0,31 & 0,05 & 0,09 \\
\hline $\mathrm{Ba}$ & 62,19 & 0 & 5,51 & 10,85 & 27,82 & 19,23 & 34,77 \\
\hline $\mathrm{Ti}$ & 28,20 & 0,19 & 1,13 & 3,18 & 7,71 & 4,43 & 10,88 \\
\hline Total (\%) & 100 & 100 & 100 & 100 & 100 & 100 & 100 \\
\hline
\end{tabular}

$\mathrm{Na}$ Tabela 13 é apresentada a análise quantitativa e qualitativa dos polímeros e compósitos com a presença dos picos de energia do elemento ouro que foi adicionado no recobrimento.

Tabela 13 - Análise quantitativa e qualitativa da amostra do polímero e compósitos com recobrimento de ouro.

\begin{tabular}{|c|c|c|c|c|c|c|}
\hline Elemento & \multicolumn{7}{|c|}{ Amostra } \\
\hline & $\mathrm{P} 100$ & $\mathrm{C} 10$ & $\mathrm{C} 20$ & $\mathrm{C} 30$ & $\mathrm{C} 40$ & $\mathrm{C} 50$ \\
\hline $\mathrm{C}$ & 37,72 & 41,39 & 39,50 & 15,70 & 34,70 & 28,97 \\
\hline $\mathrm{O}$ & 4,90 & 5,92 & 5,90 & 1,89 & 4,99 & 4,81 \\
\hline $\mathrm{Si}$ & 3,24 & 3,74 & 3,02 & 2,31 & 3,04 & 2,21 \\
\hline $\mathrm{Sn}$ & 0,49 & 0,68 & 0,59 & 0,64 & 0,37 & 0,53 \\
\hline $\mathrm{Ca}$ & 0,04 & 0,13 & 0,05 & 0,09 & 0,02 & 0,05 \\
\hline $\mathrm{Ba}$ & 0 & 2,36 & 4,74 & 7,13 & 8,55 & 19,51 \\
\hline $\mathrm{Ti}$ & 0,07 & 0,51 & 1,38 & 1,97 & 1,97 & 6,11 \\
\hline $\mathrm{Au}$ & 53,54 & 45,27 & 44,83 & 70,26 & 46,36 & 37,81 \\
\hline Total (\%) & 100 & 100 & 100 & 100 & 100 & 100 \\
\hline
\end{tabular}


Os dados da Tabela 12 e 13 servem para comprovar as proporções presentes de cada elemento e verificar eventuais impurezas não detectadas nas amostras. Valores de concentração abaixo de $1 \%$ podem ser desconsiderados, devido estarem no limite de detecção do equipamento e por se tratar de uma técnica que mede uma contagem estatística da energia associada à transição eletrônica dos elementos presentes.

A caracterização por EDX é fundamental nesse estudo tanto para determinar as concentrações e elementos presentes, mas também para detectar impurezas e confirmar as espécies das misturas. Além de ter sido uma técnica não destrutiva e rápida para obtenção dos resultados.

\subsection{TGA}

A Figura 35 apresenta a curva de decomposição térmica da amostra P100, que caracteriza-se por um processo de múltiplas reações de perda de massa desde a temperatura ambiente até o patamar de $850^{\circ} \mathrm{C}$. 


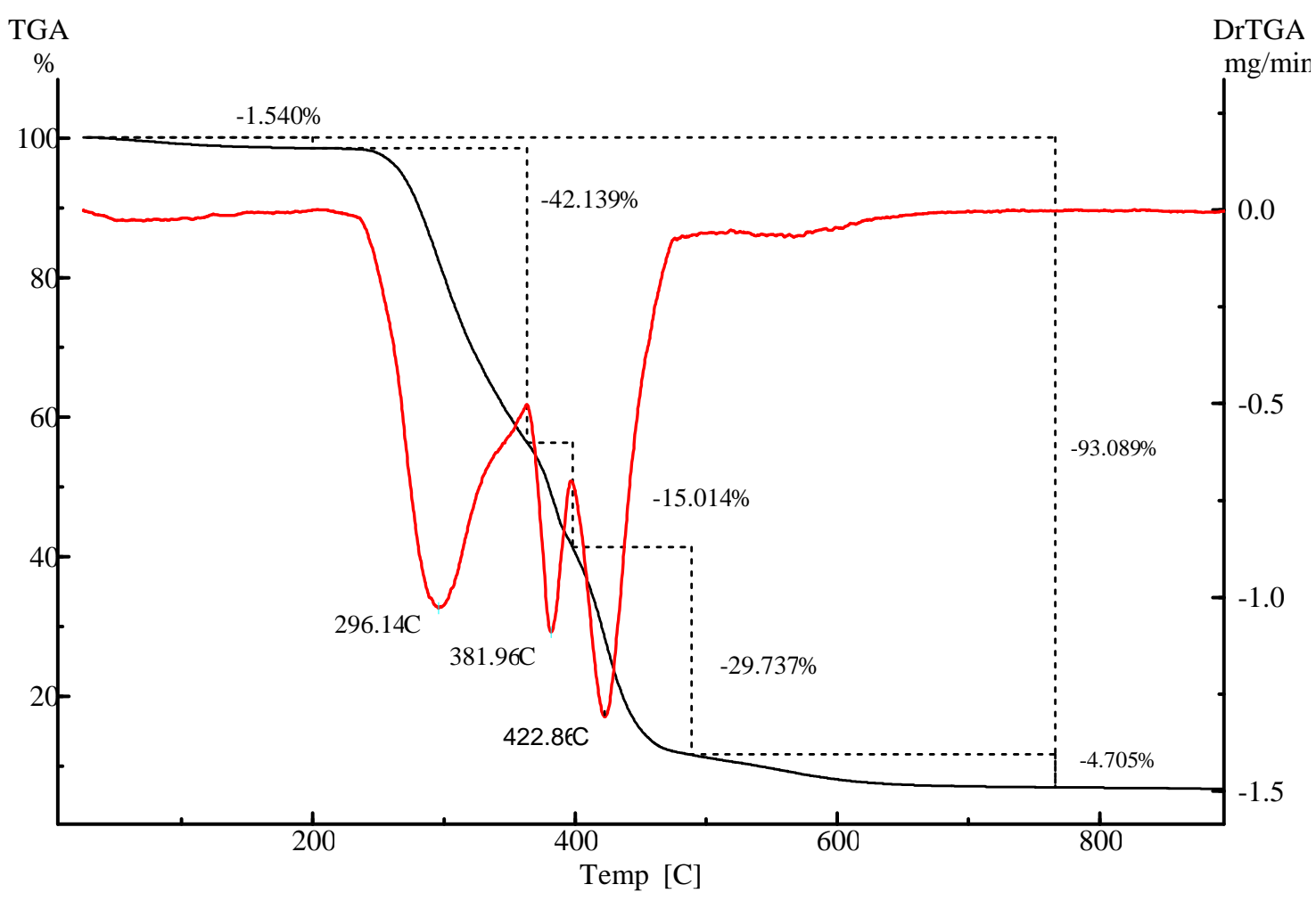

Figura 35 - Curvas de análise termogravimétrica de amostra P100.

A decomposição térmica da amostra de referência P100 ocorre em três estágios. No primeiro estágio, com o máximo em cerca de $296{ }^{\circ} \mathrm{C}$, inicia-se a degradação de grupos alquileno de cadeias laterais e a formação de produtos voláteis de baixa massa molar. No segundo estágio, com o máximo em $381^{\circ} \mathrm{C}$, inicia-se a cisão de ligações mais fortes da cadeia principal, entre elas grupos alquilenos fortemente ligados e ligações de grupos carbonilados. Finalmente, no terceiro estágio ocorre a quebra da cadeia principal e de ligações siloxano e, consequente, formação de compostos gasosos com oxigênio.

A curva de perda de massa da amostra de referencia P100 e dos compósitos são apresentadas na Figura 36, o perfil de degradação dos compósitos segue um único estágio de perda de massa, em uma estreita faixa de temperatura, entre $250 \mathrm{e}$ $300^{\circ} \mathrm{C}$. Foi observado também que com o aumento da concentração da carga de particulado ocorre a redução da temperatura de degradação, fato esse que reduz a estabilidade térmica do compósito provocada pela redução da reticulação e aumento 
da presença de defeitos na estrutura polimérica. Estes resultados sugerem que a incorporação de particulado na rede polimérica promove uma considerável alteração na mobilidade das cadeias, alterando o rearranjo estrutural provocado pelo aumento da temperatura do ensaio.

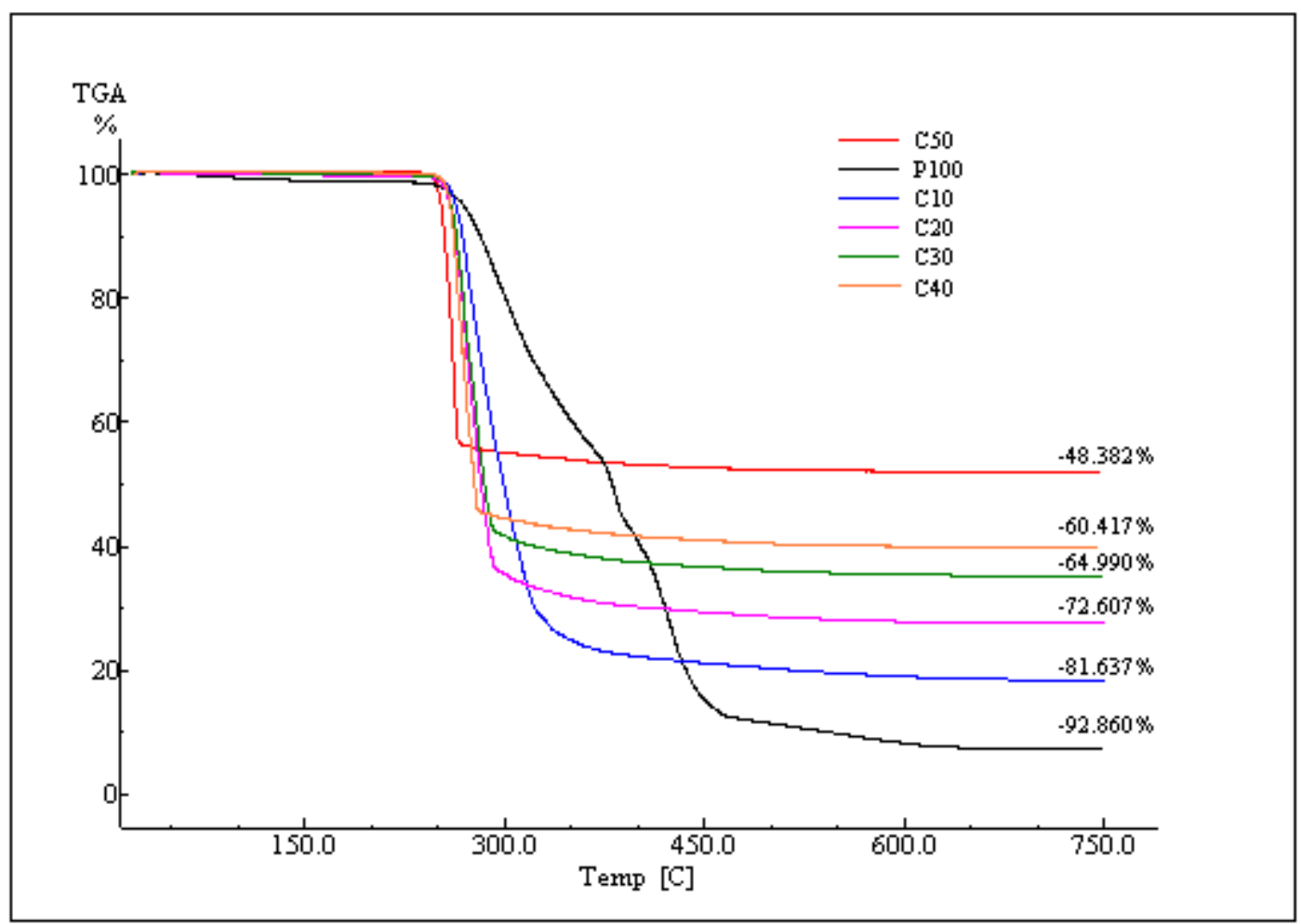

Figura 36 - Curvas de análise termogravimétrica de amostra P100 e compósitos.

Os picos de degradação das curvas termogravimétrica foram obtidos por meio da derivada (DTG). Observando a Figura 37 é possível notar os eventos de degradação que foram extraídos das curvas de TG. Verifica-se por meio das derivadas, as temperaturas em que a perda de massa é maior, além da área abaixo da curva de DTG, que é diretamente proporcional à perda de massa, e os respectivos picos de degradação das amostras. 


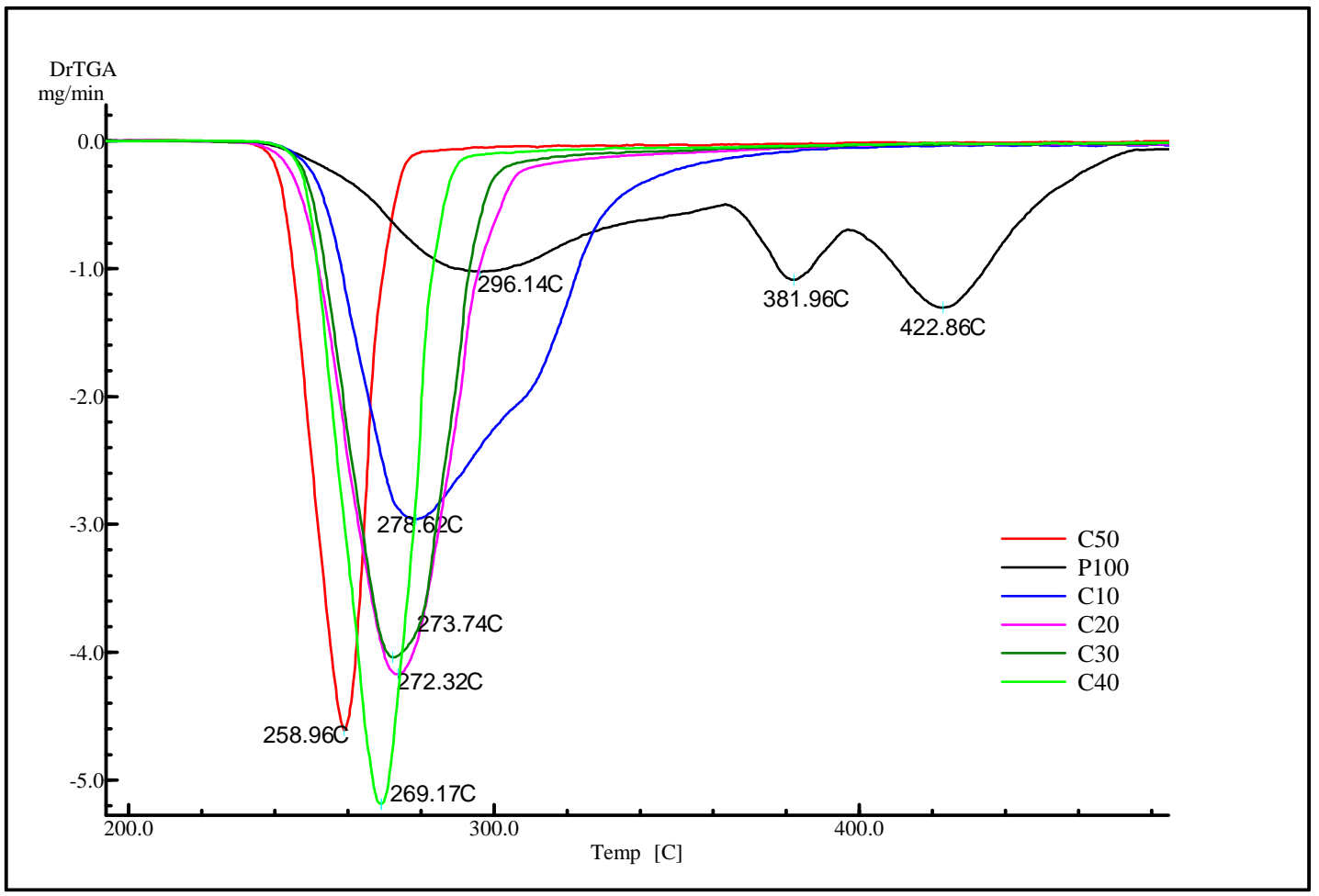

Figura 37 - Derivada da curva de análise termogravimétrica (DrTg).

$\mathrm{Na}$ Tabela 14 são apresentados alguns valores de perda de massa do polímero e seus compósitos para diferentes concentrações e patamares de temperatura.

Tabela 14 - Perda de massa para temperatura de 150, 350, 550 e $750{ }^{\circ} \mathrm{C}$.

\begin{tabular}{|c|c|c|c|c|c|c|c|}
\hline $\begin{array}{c}\text { Temperatura } \\
(\text { C) }\end{array}$ & \multicolumn{7}{|c|}{ Perda de Massa (\%) } \\
\hline Inicial & Final & P100 & C10 & C20 & C30 & C40 & C50 \\
\hline \multirow{4}{*}{25} & 150 & 1,129 & 0,119 & 0,217 & 0,032 & 0,191 & 0,247 \\
\cline { 2 - 8 } & 350 & 39,779 & 75,293 & 68,246 & 68,248 & 57,325 & 46,113 \\
\cline { 2 - 9 } & 550 & 90,278 & 80,602 & 71,924 & 64,44 & 59,923 & 47,924 \\
\cline { 2 - 8 } & 750 & 92,86 & 81,637 & 72,607 & 64,99 & 60,417 & 48,382 \\
\hline
\end{tabular}

A análise da Tabela 14 mostra que as perdas de massa para todas as amostras até a temperatura de $150{ }^{\circ} \mathrm{C}$ foram inferiores a $1,129 \%$, resultado da evaporação de fases liquidas absorvidas nas amostras. 


\subsection{DSC}

Na Figura 38 são apresentados os resultados das análises de calorimetria diferencial exploratória (DSC), onde foi medida a temperatura de transição vítrea $\left(T_{g}\right)$. Para isso foi usado o método do ponto médio, obtido como ponto de inflexão e como o ponto equidistante na interseção vertical entre as linhas tangentes traçadas antes e após a transição vítrea.

Os valores de temperatura de transição vítrea dos compósitos foram de aproximadamente $-68,34{ }^{\circ} \mathrm{C}$, esses valores não apresentaram modificações significativas com a alteração da concentração dos compósitos. Como a transição vítrea observada a baixas temperaturas está relacionada aos segmentos flexíveis formados pelo poliéter e à influência da reticulação sobre a sua mobilidade, era esperado que a temperatura de transição vítrea dos segmentos flexíveis não se alterasse significativamente, visto que o polímero utilizado foi idêntico para todos os compósitos e os compósitos obtidos continuaram elastoméricos, portanto, não apresentam alto grau de reticulação, como aquele observado em resinas termofixas. 


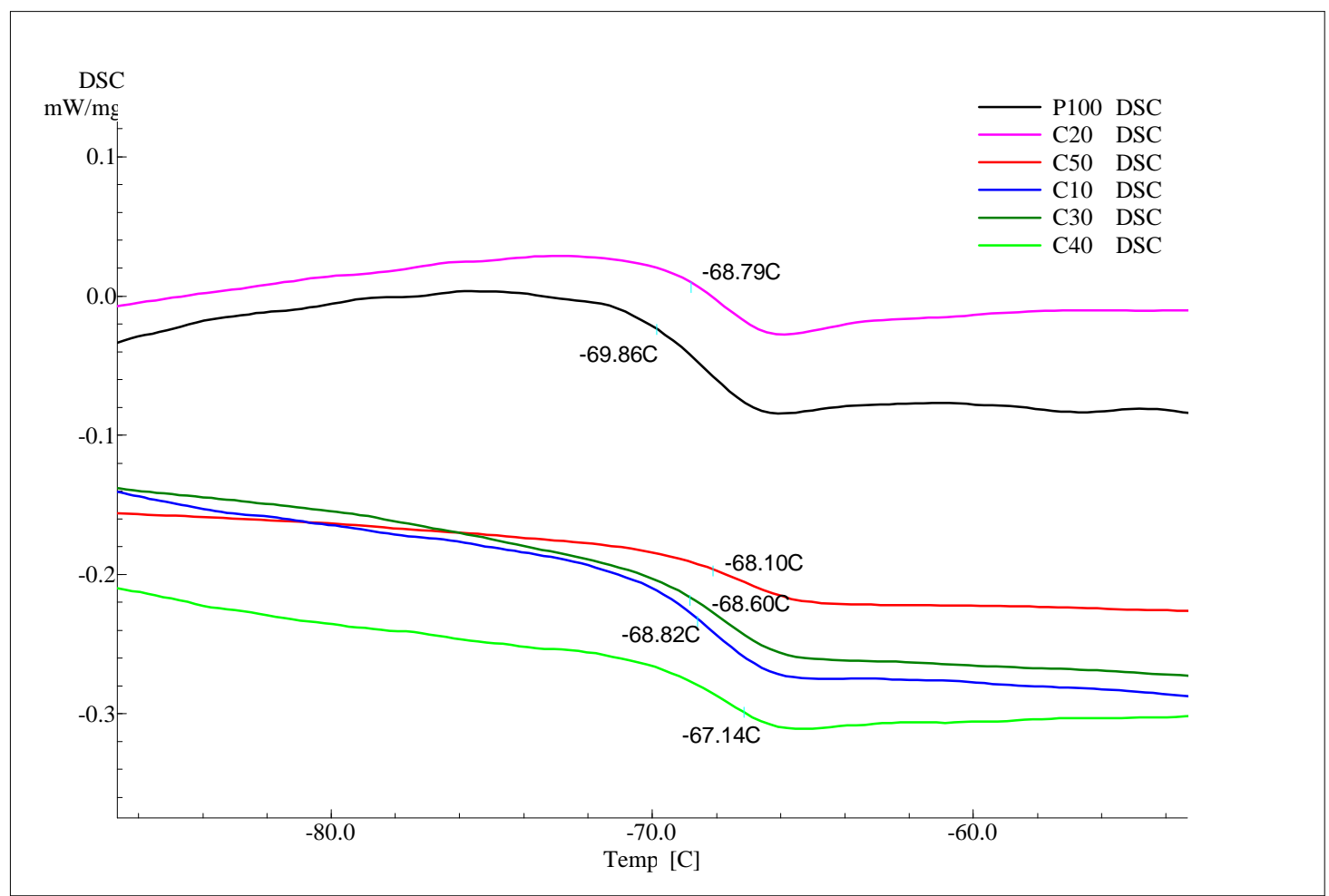

Figura 38 - Curvas DSC amostra P100 e de compósitos ( $\downarrow$ Endo).

As temperaturas de transição vítrea dos segmentos foram de fácil identificação, visto que esta variação de capacidade calorífica ficou facilmente identificada por meio da aplicação da primeira derivada. Porém, as formas desses picos não sofreram alterações de temperatura, provavelmente devido se tratar da mesma espécie de polímero e compósito formados durante a cura.

A pequena variação de temperatura observada pode ser atribuída a uma variação na fração de nanopartículas, cujos efeitos são conflitantes, por contribuir no afastamento das moléculas reduzindo a reticulação, portanto, aumentando a mobilidade molecular, e, simultaneamente, provocar o efeito oposto ao introduzir uma superfície onde ocorre a adesão das cadeias poliméricas.

A Figura 39 apresenta os resultados das análises DSC para a temperatura de 10 a 110 C. Os eventos térmicos observados nesta faixa de temperatura apresentam pequena variação energética, o que pode ser explicado por fenômenos de relaxação de tensão, devido à acomodação das cadeias em temperatura acima 
da $T_{g}$ e por se tratar de material elastomérico que possui grande mobilidade de cadeias.

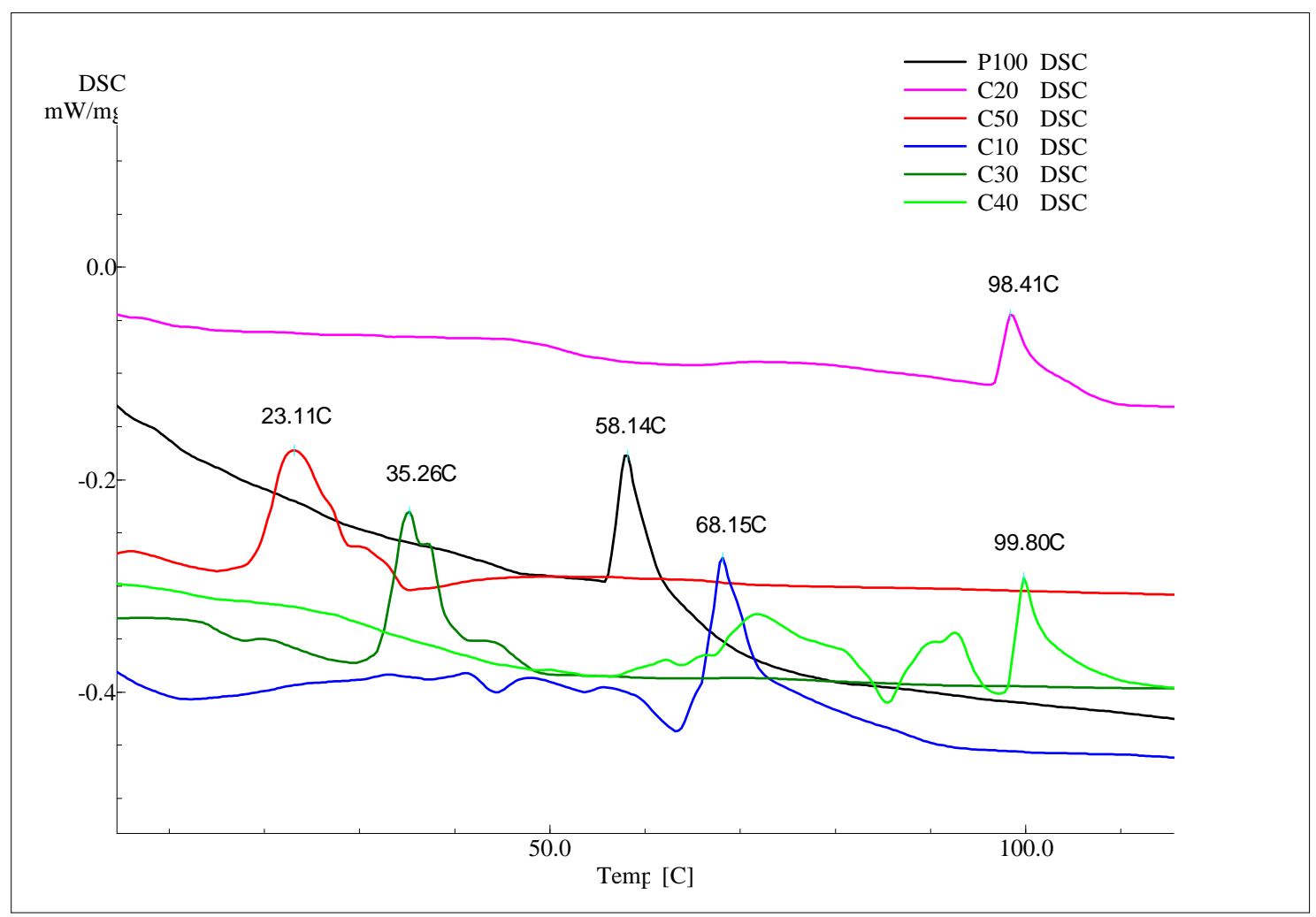

Figura 39 - Curvas DSC da amostra P100 e de compósitos ( $\downarrow$ Endo).

Na Tabela 15 é apresentada uma caracterização das amostras, obtidas a partir das análises de DSC das Figuras.

Tabela 15 - Análise das curvas de calorimetria diferencial exploratória.

\begin{tabular}{|c|c|c|c|}
\hline & & $\begin{array}{c}\text { Picos } \\
\text { Endotérmicos } \\
\text { Amostra }\end{array}$ & \\
\hline P100 & $-69,86$ & 58,14 & -0.07 \\
\hline C10 & $-68,60$ & 68,18 & -0.10 \\
\hline C20 & $-68,79$ & 98,41 & -0.11 \\
\hline C30 & $-68,82$ & 35,26 & -0.11 \\
\hline C40 & $-67,14$ & 99,80 & -0.10 \\
\hline C50 & -68.10 & 23,11 & -0.10 \\
\hline
\end{tabular}




\subsection{Caracterização Elétrica de Capacitância}

Os resultados obtidos de capacitância para o polímero puro e dos compósitos são apresentados na Figura 40. Entre os valores medidos e calculados de capacitância existe um erro de 8 \%, tal variação de valores pode ocorrer devido à variação de espessura entre as placas após introdução do polímero entre as placas paralelas.

A medida de resistividade elétrica apresentou valores próximos aos apresentados na literatura ${ }^{55}$ a temperatura ambiente, conforme apresentado na Figura 40. Com o aumento acentuado da carga adicionada observou-se um aumento considerável da rigidez dielétrica. A Figura 41 apresenta os gráficos de constante dielétrica em função da tensão aplicada a temperatura ambiente.

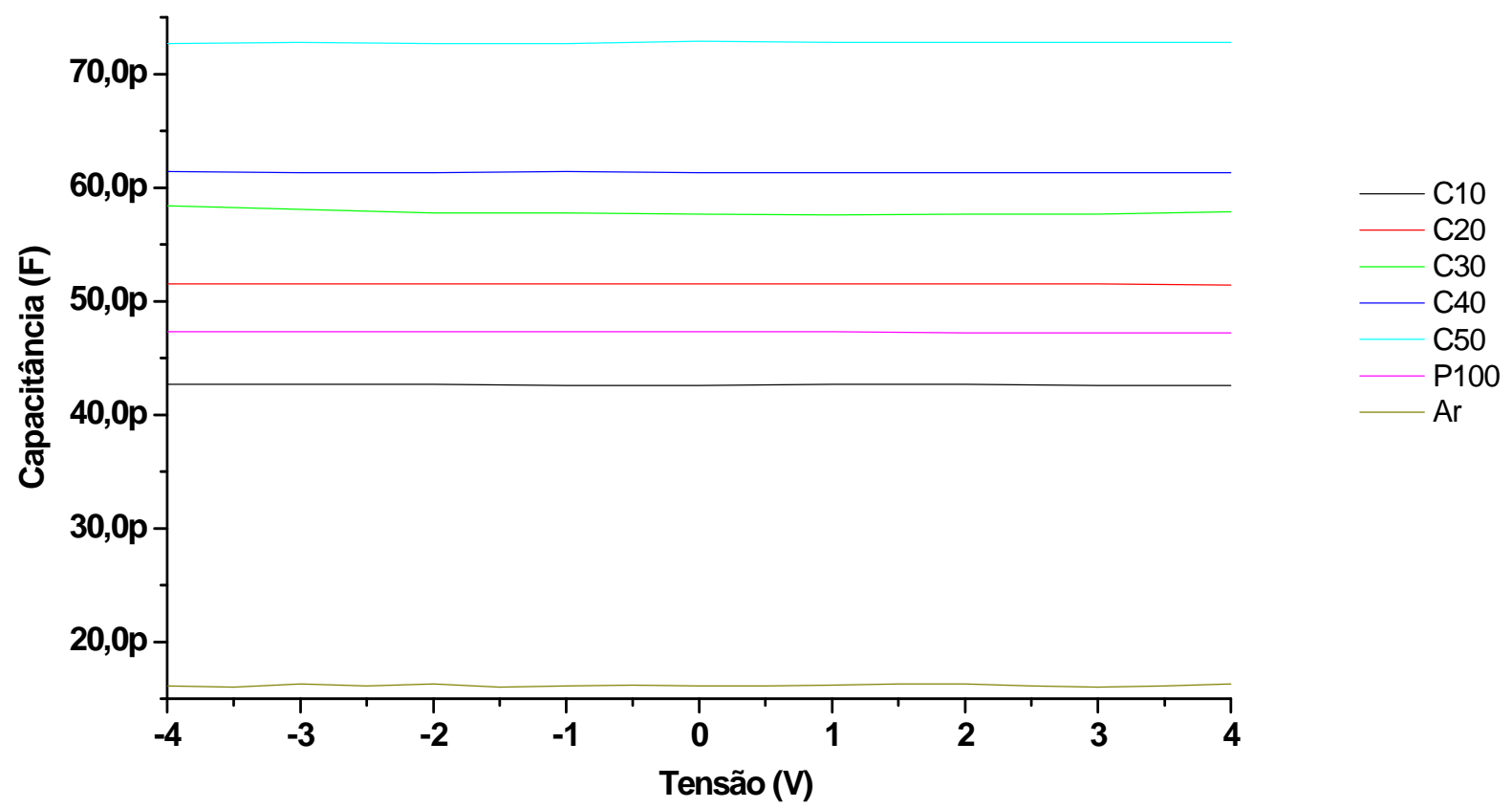

Figura 40 - Medida elétrica de capacitância versus tensão. 


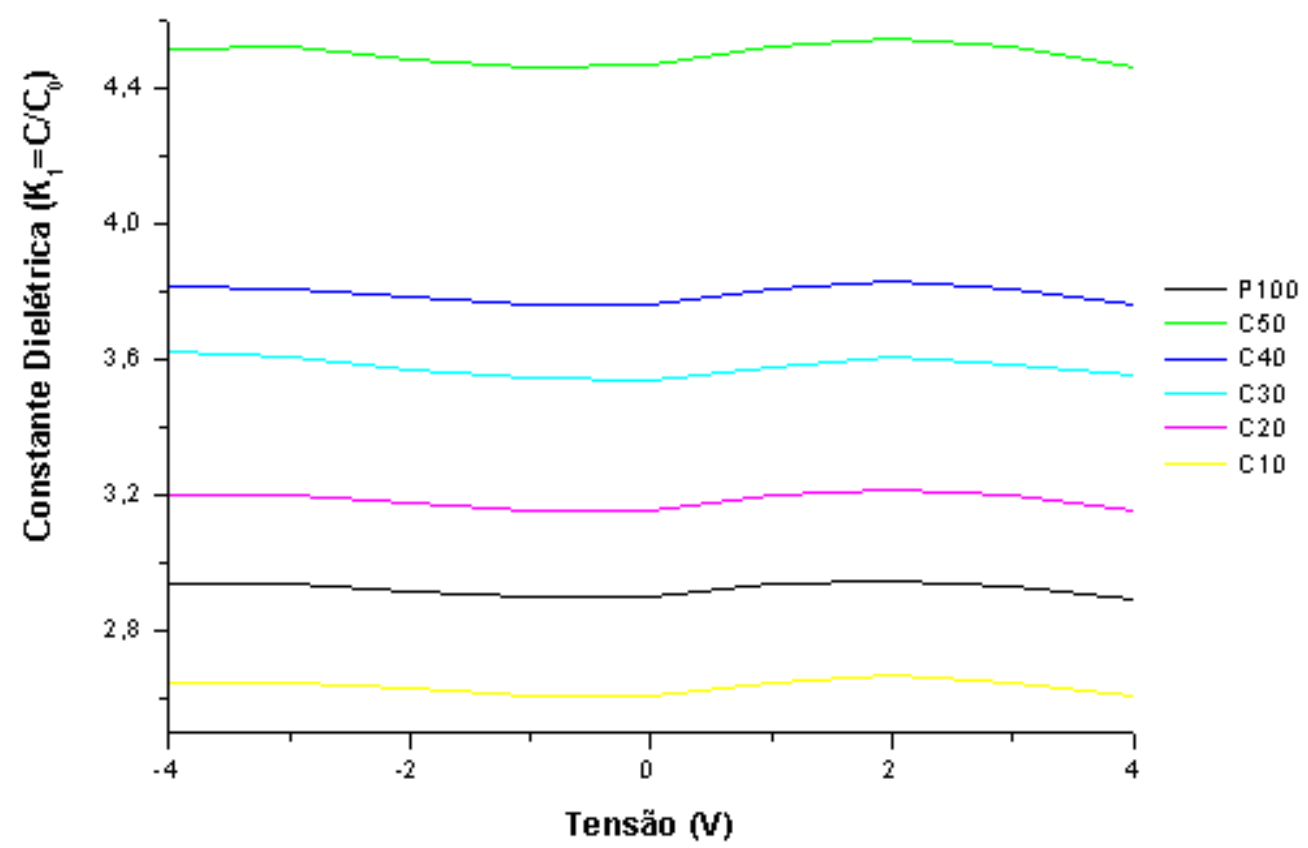

Figura 41 - Medida de Constante Dielétrica versus Tensão.

As Figuras 40 e 41 mostram as características dielétricas dos compósitos e do polímero puro. Pode se observar que uma maior concentração do titanato de bário ocasiona um aumento dos valores de constante dielétrica e das propriedades dielétricas do material. No entanto, os valores de constante dielétrica $(\mathrm{C} / \mathrm{Co})$ ainda são considerados baixos para essa classe de particulado adicionado. Os valores de resistividade elétrica são apresentados na Figura 42.

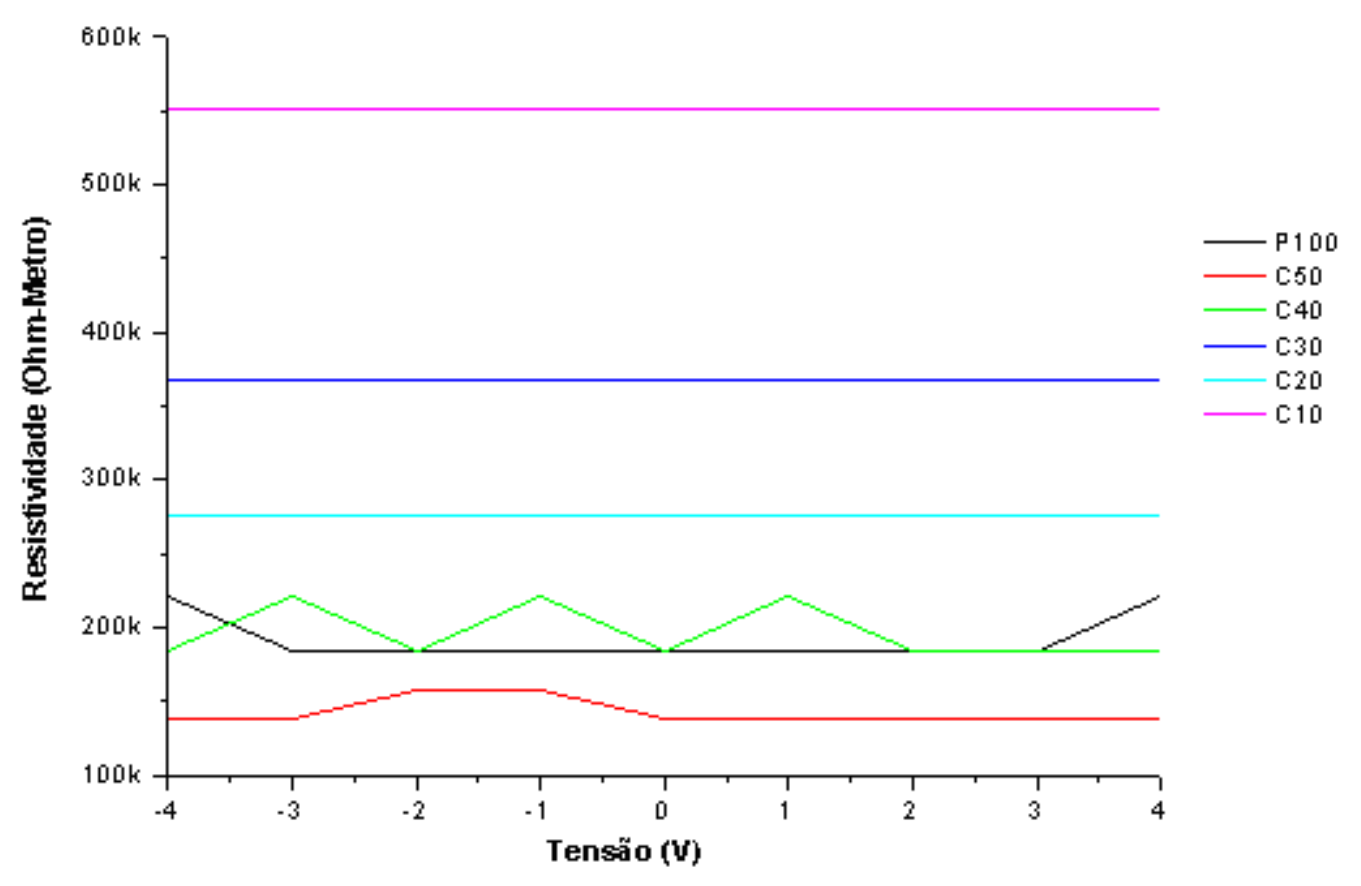

Figura 42 - Medidas de resistividade do polímero e seus compósitos. 
Os valores de resistividade elétrica apresentaram diferenciação entre as amostras com diferentes concentrações de nanoparticulado, conforme apresentado pela Figura 42, com queda acentuada da resistividade em função do aumento da carga adicionada. Fato esse que pode ocorrer devido ao aumento de imperfeições na ma0triz polimérica com a adição do sólido particulado, seja pela introdução de bolhas ou pela dispersão não-uniforme do titanato de bário.

O levantamento das características dielétricas mostrou-se efetivo para a caracterização das amostras P100 e dos compósitos, através da análise conjunta das duas propriedades investigadas: capacitância e constante dielétrica. As variações ou taxa de decréscimo da constante dielétrica em função das concentrações, comprovam as características dielétricas do titanato de bário e comportamento apolar da matriz polimérica.

\subsection{Ensaio mecânico de Tração}

Para avaliar as propriedades mecânicas do polímero e dos compósitos foram realizados ensaios de tração, com a finalidade de determinar a tensão máxima de ruptura, alongamento máximo e módulos de elasticidade. As curvas tensão versus deformação até o momento de ruptura obtidas nos ensaios estão representadas na Figura 43. 


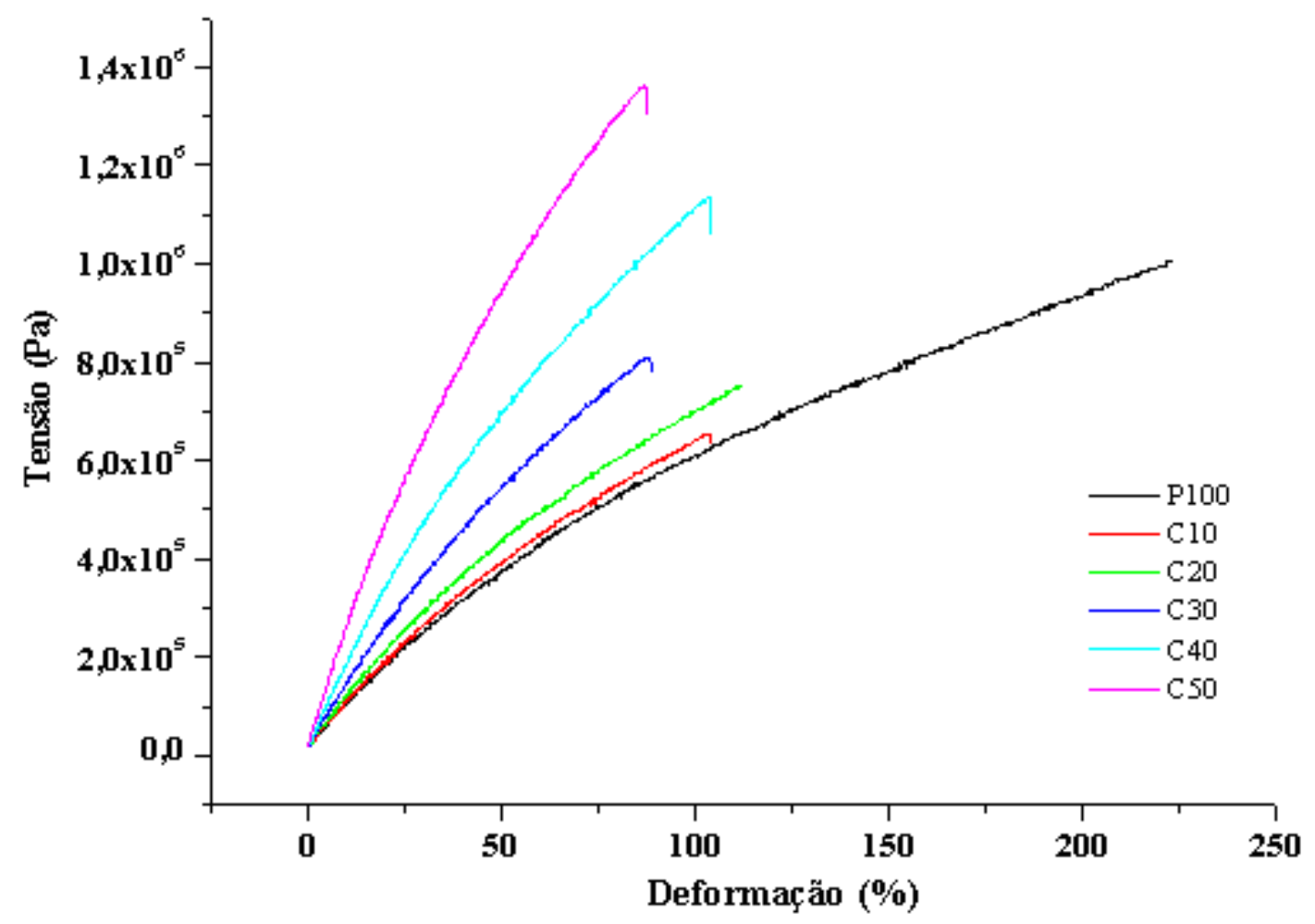

Figura 43 - Curva de ensaio mecânico de tração.

Analisando as curvas, pode-se notar que o comportamento elástico não foi alterado com a adição do particulado. Em contrapartida estas amostras tiveram uma significativa alteração nos seus valores de alongamento e carga máxima na ruptura.

Como pode ser também observado, as curvas de tensão-deformação indicam que os compósitos com concentração crescente de titanato de bário apresentam um aumento da tensão de ruptura e redução de deformação em relação à amostra de referência (P100). O alongamento total dos compósitos ficou em torno de $80 \%$ caracterizando comportamento dúctil e indicando que existe uma adesão interfacial entre o polímero e o particulado, fato esse comprovado por meio das imagens da microscopia eletrônica. A ruptura ocorre provavelmente devido à presença de imperfeições na amostra, tais como bolhas.

A partir dos pontos obtidos nas curvas de tensão - deformação (Tabela 16) foram calculados alguns parâmetros mecânicos, objetivando a comparação das propriedades mecânicas do polímero puro (P100) e seus compósitos. 
Tabela 16 - Propriedades do ensaio de tração.

\begin{tabular}{|c|c|c|c|c|c|}
\hline Amostra & $\begin{array}{c}\text { Carga } \\
\text { máxima na } \\
\text { ruptura (N) }\end{array}$ & $\begin{array}{c}\text { Alongamento } \\
\text { na ruptura } \\
(\%)\end{array}$ & $\begin{array}{c}\text { Limite de } \\
\text { resistência } \\
(\mathrm{MPa})\end{array}$ & $\begin{array}{c}\text { Limite de } \\
\text { escoamento } \\
(\mathrm{MPa})\end{array}$ & $\begin{array}{c}\text { Módulo de } \\
\text { Young } \\
\text { (alongamento } \\
50 \%)(\mathrm{Pa})\end{array}$ \\
\hline P100 & 9,0713 & 223,67 & 1,0079 & 0,6417 & $1,86 \cdot 10^{6}$ \\
\hline C10 & 6,7667 & 111,73 & 0,7519 & 0,5278 & $1,96 \cdot 10^{6}$ \\
\hline C20 & 5,8818 & 104,02 & 0,6538 & 0,6843 & $1,96 \cdot 10^{6}$ \\
\hline C30 & 7,2816 & 88,47 & 0,8091 & 0,5611 & $1,98 \cdot 10^{6}$ \\
\hline C40 & 10,1991 & 104,13 & 1,1332 & 0,7656 & $3,34 \cdot 10^{6}$ \\
\hline C50 & 12,2585 & 87,80 & 1,3621 & 0,9317 & $3,59 \cdot 10^{6}$ \\
\hline
\end{tabular}

A amostra P100, polímero puro segmentado, tem elevado número de ligações cruzadas. Os compósitos por outro lado, possuem número mais limitado de ligações cruzadas em sua estrutura macromolecular e apresentam, entretanto, adesão de trechos das cadeias sobre as partículas, o que leva a menor mobilidade destas no compósito em comparação com aquelas no estado puro. São dois efeitos contrários.

Nos casos de baixos teores de ligações cruzadas o módulo de elasticidade decresce. Enquanto, a fixação dos trechos da cadeia sobre os domínios rígidos enrijece o compósito. Seria esperado que a reticulação aumentasse o limite de resistência e diminuísse o alongamento do material, por meio dos ensaios mecânicos essa suposição foi confirmada para o polímero puro em sistema com alta reticulação, que apresentou um maior alongamento (maior ductilidade) comparado ao material compósito que apresentou comportamento menos dúctil. 


\section{CONCLUSÕES}

O presente trabalho teve como finalidade o estudo da obtenção e caracterização de nanocompósitos de titanato de bário na matriz polimérica de poli(éter-siloxano).

Por meio da adição controlada de titanato de bário a porcentagens em massa nas frações de $10,20,30,40$ e $50 \%$ foi possível observar o comportamento do compósito para diferentes concentrações. Os ensaios de inchamento apresentaram diferença de afinidade entre os solventes e o polímero no estado puro e os compósitos. Apesar do método de inchamento no equilíbrio ser universalmente adotado para a determinação do número de ligações de reticulação do polímero, é importante salientar que o método pressupõe que as interações intermoleculares sejam unicamente do tipo dispersivo, não levando em consideração interações dipolares ou pontes de hidrogênio, os resultados apresentados são um valor estimado que refletem a contribuição da somatória de cada um dos tipos de ligação presentes, através da aplicação da Equação de Flory-Rehner.

Por meio das análises de TGA podemos concluir que as amostras até a temperatura de $150{ }^{\circ} \mathrm{C}$ não tiveram perda de massa si gnificativa, os patamares de degradação total do polímero puro e dos compósitos ocorreram entre 250 e $400{ }^{\circ} \mathrm{C}$, sendo que para esse valor pode-se esperar que o mecanismo de degradação seja a cisão de cadeias principais e de ligações cruzadas. A degradação dos compósitos ocorreu a temperaturas inferiores, creditada à catálise na oxidação suprida pelo titanato de bário. A estabilidade térmica até $250^{\circ} \mathrm{C}$ é devida à presença de estrutura macromolecular composta por silício ligado por átomos de oxigênio que são excepcionalmente estáveis. A massa residual apresentou valores acima das proporções adicionadas, podendo esperar que essa variação tenha ocorrido devido à formação de sílica como resíduo da degradação do elastômero.

As análises DSC permitiram a determinação da temperatura de transição vítrea, visto que estas temperaturas ocorreram em valores esperados para elastômeros, de acordo com a literatura ${ }^{56}$. A análise mostrou também que entre as 
temperaturas de 23 - $99{ }^{\circ} \mathrm{C}$ existem pequenos picos exotérmicos que variaram em grande faixa de temperatura, atribuídos a processos de relaxação do material polimérico.

As micrografias dos nanocompósitos apresentaram perfis distintos de acordo com as diferentes concentrações de titanato de bário nos nanocompósitos. As micrografias revelaram a presença de bolhas e má dispersão do material particulado na matriz polimérica, fato esse que influência consideravelmente os valores de densidade. As análises de EDX confirmaram os elementos presentes nas amostras e foi ferramenta fundamental para identificação das fases presentes.

A caracterização elétrica de capacitância apresentou baixos valores tanto para o polímero puro quanto para os compósitos, esse resultado se deve à baixa constante de rigidez dielétrica do polímero empregado e à presença de estruturas apolares. Embora tenha sido observado um pequeno aumento da capacitância nos compósitos, entre 2,6-4,5, os valores estão muito abaixo daquele do apresentado pela literatura, entre $50-300$.

Através dos ensaios mecânicos, foram observadas curvas características de elastômero e valores de módulo de elasticidade típicos desta classe de polímero. Foi notado também que com o aumento da concentração do material particulado ocorre também um aumento da fragilidade do compósito, tanto que os valores de alongamento na ruptura tiveram uma grande variação, a presença do titanato de bário pode ter dificultado a reticulação do polímero provocando uma menor quantidade de entrelaçamento entre as cadeias poliméricas.

Nos últimos anos, uma enorme quantidade de estudos vem sendo feito no sentido de concretizar as novas idéias que surgem na área de compósitos. Mesmo assim, apesar dos avanços alcançados, ainda há muito a ser feito. O impacto da nanotecnologia é bastante penetrante em diversas áreas: medicina e saúde, aeronáutica e exploração espacial, energia, meio ambiente, tecnologia de computadores, biotecnologia e segurança. 


\section{BIBLIOGRAFIA}

1 PILATO, L. A.; MICHNO M, J. Advanced Composite Materials. Berlin, Springer Verlag, 1994. p. 9-10.

2 FARADAY, M. Experimental Relations of Gold (and other Metals) to light. Foreign Associate of the Acad. Sciences Paris, 1857. p.145.

3 SANCHEZ, C., JULIA, B., BELLEVILLE, P., POPALL, M. Applications of hybrid organic-inorganic nanocomposites. Journal of Materials Chemistry, v.15, p.3559-3592, 2005.

4 WALKER, B. M.; RADER, C. P. Handbook thermoplastic elastomers. New York, William Andrew Publishing, 2007. p. 5-10.

${ }^{5}$ BROWMICK, A. K.; Hall, M. M. BENAREY H. A. Rubber products manufacturing technology. New York, Marcel Dekker Inc, 1997. p. 315-332.

6 GEOFFREY, H., HANS, R. K., RODERIC, R. P. Quirk - Thermoplastic Elastomers. 3.ed. Munich, Geoffrey Holden, 2004. p. 31-33.

7 INTERNATIONAL RUBBER STUDY GROUP. Statistical Summary of World Rubber Situation 2007 and 2008.

8 URAYAMA, K., KAWAMURA, T., KOHJIYA, S., Structure-mechanical property correlations of model siloxane elastomers with controlled network topology. Polymer, v.50, p.347-356, 2008.

9 www.specialchem4polymers.com/tc/Silane-Crosslinking-Agents/index.aspx?id= mechanism, visitado em: 14/04/2009, Crosslinking Mechanism. 
10 DUSEK, K.; MACKNIGHT, W. J. Cross-Linking and Structure of Polymer Network. In: CROSS-LINKED POLYMER CHEMISTRY, PROPERTIES AND APPLICATIONS. Washigton DC, ACS, 1987. p. 2-6. (ACS Symposium Series 367).

11 URAYAMA, K., KAWAMURA, T., KOHJIYA, S., Structure-mechanical property correlations of model siloxane elastomers with controlled network topology. Polymer, v.50, p.347-356, 2008.

${ }^{12}$ BONART, R. Thermoplastic elastomers. Polymer, v.20, p.1389-1403, 1979.

13 http://www.adespec.com.br/fixtudo.html, visitado em 10/12/2009, Adesivos Especiais.

14 WAINER, E.; SALOMON, A.N. High dielectric constant ceramics. United States patent office 2,377,910. New York, 1943.

15 COURSEY R.; BRAND K. G.; Dielectric Constants of Some Titanates. Nature, v.157, p.297-298, 1946.

${ }^{16}$ WUL, B. M.; GOLDMAN, I. M., Dielectric Con-stants of. Titanates of. Metals of Second Group. Compt. Rend. Acad. Sci, v.46, p.141, 1945.

17 ROBERTS, S.; Dielectric and Piezoelectric Properties of Barium Titanate. Physical Review, v.71, n. 12, p.890, 1947.

18 MATTHIAS, B. HIPPEL, V. Structure, Eletrical and Optical Properties of Barium Titanate. Physical Review, v.73,n.3, p.268, 1947.

19 NJUGUNA, J. PIELICHOWSKI, K.; Polymer nanocomposites for Aerospace Applications: Properties. Advanced Engineering Materials, v.5, n.11, p.769-776, 2003. 
${ }^{21}$ RIETH, M. Nano-engineering in science and technology - An Introduction to the World of Nano-Design. London, Worls Scientific Publishing, 2003. p.1-3.

22 MOURITZ, A. P. GIBSON, A. G.; Fire Properties of Polymer Composite Materials. Netherlands, Springer, 2006. p.287.

$23 \mathrm{ROCO}, \mathrm{M}$. C. Societal implications of nanoscience and annotecnology, Netherlands, Kluwer Academic Publishers, 2001. p.5.

24 HUMMEL, R.E. Electronic Properties of Materials. 3.ed. Flórida, Springer Science, 2005. p.185-187.

25 CALLISTER, W. D. Ciências e Engenharia de Materiais: Uma Introdução. 7.ed. New York, John Wiley \& Sons Ltd., 2007. p.515-517.

26 PU, Y. Chen, W. CHEN, S. HANS, T. L.; Microstructure and dielectric properties of dysprosium-doped barium titanate ceramics. Cerâmica, v.51, p.214-218, 2005.

27 PADILHA, A. F. Materiais de Engenharia. Brazil, Hemus, 2007. p.273.

28 YANG, T. KOFINAS, P.; Dielectric properties of polymer nanoparticle composites. Polymer, v.48, p.791,798, 2007.

29 BOINARDA, P., BANKSA, W. M., PETHRICKB, R. A. Changes in the dielectric relaxations of water in epoxy resin as a function of the extent of water ingress in carbon fibre composites. Polymer, v.46, p. 2218-2229, 2005.

${ }^{30}$ BOERIO-GOATES, J. Chemical thermodynamics: principles and applications. 2. ed. London, Academic Press, 2000. p.113. 
${ }^{31}$ LINDER, B. Thermodynamics and introductory statistical mechanics. New Jersey, John Wiley and Sons, 2004. p.55.

32 WU, S. Polymer interface and adhesion. New York, CRC Press, 1982. p.3.

33 HILDEBRAND, J. H. The Solubility of Non-Electrolytes. New York; Reinhold, 1936.

34 HANSEN, C. M. Three Dimensional solubility Parameter - Key to paint component affinities II. Dyees, emulsifiers, Mutual solubility and compatibility, and Pigments. J. Paint Technol, v.39, p. 511, 1967.

35 GORDON, J.; GIAUQUE W. F. The entropy of ethyl chloride. Heat capacity fron 13 to $287 \mathrm{~K}$. Vapor pressure. Heats of fusion and vaporization. Journal Am. Chem. Soc, v.70, p.1506-1510, 1948.

${ }^{36}$ VASSALLO, D. A.; HARDEN, J. C. Precise Phase Transition Measurements of Organic Materials by Differential Thermal Analysis. Anal. Chem, v.34, p.132-135, 1962.

${ }^{37}$ FERMI, E. Thermodynamics. New York, Dover Pubns, 1937. p.11.

38 HANSEN, C.M. Aspects of solubility, surfaces and diffusion in polymers. Progress in Organic Coatings,v. 51, p.55-66,2004.

39 BARTON, A. F. M. CRC handbook of solubility parameters and other cohesion parameters. 2.ed. Flórida, CRC Press, 1991. p. 24.

40 FLORY, P. J.; Thermodynamics of high polymer solutions. J. Chem. Phys, v.10, p. 51-61,1942.

41 Lindvig, T. Michael, L. M. Georgios, M. K., A Flory-Huggins model based on the Hansen solubility parameters. Fluid Phase Equilibria, v.203, p. 247-260, 2002. 
${ }^{42}$ FORSMAN, W. C. Polymers in Solution, Teoretical Considerations and Newer Methods of Characterization. New York, Plenum Press, 1986. p.66.

${ }^{43}$ RIANDE, E. DIAZ-CALleJA, R. PROLONGO, M. MASEgOSA, R. SALOM, C.; Polymer viscoelasticity: stress and strain in practice. New York, Marcel Dekker Inc., 1999. p.79.

44 GRAESSLEY, W.W. Polymeric Liquids and Networks: Structure and Properties. New York, Garland Science, 2004. p. 490.

45 LiPATOV, Y. S.; LIPATOV, T.T.; AlEKSEEVA, T. Phase-separated interpenetrating polymer networks. Berlin Heidelberg, Springer-Verlag, 2007. p.58.

46 AMERICAN SOCIETY FOR TESTING AND MATERIALS - ASTM D 3800, Standard test method for density of high-modulus fibers. Philadelphia, 2004.

${ }^{47}$ HANSEN, C. M. Hansen solubility parameters: a user's handbook. Flórida, CRC Press, 2007. p.105.

48 AMERICAN SOCIETY FOR TESTING AND MATERIALS - ASTM D 1460 - 86, Standard Test Method for Rubber Property-Change in Length During Liquid Immersion. Philadelphia, 2005.

49 AMERICAN SOCIETY FOR TESTING AND MATERIALS - ASTM 6814-02, Standard Test Method for Determination of Percent Devulcanization of Crumb Rubber Based on Crosslink Density. Philadelphia, 2008.

50 AMERICAN SOCIETY FOR TESTING AND MATERIALS - ASTM D 3616 - 95, Standard Test Method for Rubber-Determination of Gel, Swelling Index, and Dilute Solution Viscosity. Philadelphia, 2004.

51 AMERICAN SOCIETY FOR TESTING AND MATERIALS - ASTM D $3418-08$, Standard Test Method for Transition Temperatures and Enthalpies of Fusion 
and Crystallization of Polymers by Differential Scanning Calorimetry. Philadelphia, 2008.

52 AMERICAN SOCIETY FOR TESTING AND MATERIALS - ASTM D 150 - 98, Standard test methods for AC - Loss Characteristics and Permittivity (dieletric constant) of Solid Electrical Insulation. West Conshohocken, PA, 1998.

53 AMERICAN SOCIETY FOR TESTING AND MATERIALS - ASTM D 257 - 93, Standard Test Methods for DC Resistance or Conductance of Insulating Materials. West Conshohocken, PA, 1993 (reaprovada em1998).

54 AMERICAN SOCIETY FOR TESTING AND MATERIALS - ASTM D $4762-08$, Standard Guide for Testing Polymer Matrix Composite Materials. Philadelphia, 2008.

55 ULABY, F. T. Eletromagnetismo para engenheiros. São Paulo, Bookman, 2007. p.104.

56 CHEREMISINOFF, N. P. Elastomer technology handbook. New York, CRC Press, 1989. p. 98. 